\title{
THE ADMINISTRATION OF ONLINE PROGRAMS IN STATEWIDE SYSTEMS: A CASE STUDY OF THE UNIVERSITY SYSTEM OF NEW HAMPSHIRE
}

\section{By}

Christopher Lynn LaBelle

\author{
A dissertation \\ submitted in partial fulfillment \\ of the requirements for the degree of \\ Doctor of Education in Educational Technology \\ Boise State University
}

December 2018 
(C) 2018

Christopher Lynn LaBelle ALL RIGHTS RESERVED 


\title{
BOISE STATE UNIVERSITY GRADUATE COLLEGE
}

\section{DEFENSE COMMITTEE AND FINAL READING APPROVALS}

\author{
of the dissertation submitted by
}

Christopher Lynn LaBelle

Dissertation Title: The Administration of Online Programs in Statewide Systems: A Case Study of the University System of New Hampshire

Date of Final Oral Examination: $\quad 26$ November 2018

The following individuals read and discussed the thesis submitted by student Christopher Lynn LaBelle, and they evaluated his presentation and response to questions during the final oral examination. They found that the student passed the final oral examination.

Patrick R. Lowenthal, Ph.D.

Kerry Lynn Rice, Ed.D.

Norm Friesen, Ph.D.
Chair, Supervisory Committee

Member, Supervisory Committee

Member, Supervisory Committee

The final reading approval of the thesis was granted by Patrick R. Lowenthal, Ph.D., Chair of the Supervisory Committee. The thesis was approved by the Graduate College. 


\section{DEDICATION}

I dedicate this dissertation to my wife, Melinda, and three children, Lucas, Ethan and Sophie. Even though this journey to complete a doctorate started almost 20 years ago, my wife, Melinda supported me every step of the way. 


\section{ACKNOWLEDGEMENTS}

First, I would like to thank God for providing me with the resources, support and strength to complete this dissertation. Completing this dissertation was the most difficult project I have ever completed and required focus, sacrifice and dedication; without God's day-to-day provisions, completing my doctorate would not have been possible.

Secondly, I would like to thank Dr. Patrick Lowenthal for the guidance and care he shows to his students. I was the beneficiary of his willingness to chair my committee and guide me through the dissertation process. Every step of the way, Dr. Lowenthal was patient, professional and committed to supporting my goals. I would also like to thank Dr. Friesen and Dr. Rice for serving on my committee and taking time out of their busy schedules to provide input about my methodology and research framework. Both Dr. Friesen and Dr. Rice offered invaluable input after reviewing my initial proposal and my dissertation draft.

Third, I would like to thank my study participants at USNH for providing thoughtful insight into the administration of online programs. Study participants from each USNH institution took time out of their busy schedules to help improve the quality

of data gathered for this study. Each participant also showed a willingness to think larger than their local responsibility by considering the possibilities of partnership.

Finally, I would like to thank my wife who supported me every step of the way over almost 20 years of starting and stopping my doctoral program. I share any benefit or honor conferred on me for the completion of this degree with my faithful, patient and 
kind wife. I also thank my oldest son, Lucas. His birth almost 20 years ago was the primary reason I left my first doctoral program at UCLA as I felt it necessary to enter the workforce, so I could provide a better life for him. In many ways, it feels fitting that I now complete this degree the same year that Lucas leaves our home to begin his own college journey. I hope that this milestone inspires Lucas to pursue his own intellectual journey with faith, courage and tenacity. I also thank my younger children, Ethan and Sophie, for showing me unconditional love and keeping our home filled with laughter even when I struggled to make time for my doctoral work. While it's been more than 30 years since I've lived with my parents, I would also like to thank my father, Gary LaBelle and my mother, Vickie LaBelle, for cheering me on.

Lastly, I would also like to thank my supervisor, Dean Ken LaValley, for supporting my desire to complete this program. Dean LaValley's support of my work made it possible for me to gain access to study participants and to feel that completing this program would be beneficial. 


\begin{abstract}
Enrollments in postsecondary online programs have grown over the years. As enrollments have grown, postsecondary institutions have experimented with different ways to administer their online programs. In many cases, institutions have shifted to a more centralized business model that consolidates the governance of their online programs under a single high-level institutional officer (Legon \& Garrett, 2017). However, even as more colleges and universities prioritize the administration of online programming and dedicate staffing and resources to administer those programs, there is very little research focused on the best way to administer online programs in four-year public statewide systems.
\end{abstract}

Given this gap in the literature, this study used an exploratory case study design to investigate how online programs are administered at four institutions in the University System of New Hampshire (USNH). Eighteen administrators from the University of New Hampshire, Keene State College, Granite State College, Plymouth State University and the USNH system office participated in a 20-question online survey. Survey questions were shaped by Rovai (2003) and Rovai and Downey’s (2010) factors of online program management. After survey data were analyzed using a constant comparison method, six survey respondents were invited to participate in a follow-up interview. As data from interviews were analyzed, several insights emerged about administering online programs in a statewide system. First, study participants had a difficult time finding a common vocabulary when talking about online programs and the potential benefits of system-level 
collaboration; second, administrators always prioritized their local program tasks before any consideration about collaboration could occur; and third, although there was not a strategic plan in place to help system institutions collaborate, all interview participants felt that such a plan would be valuable and several interview participants offered actionable suggestions for how to develop such a plan. 


\section{TABLE OF CONTENTS}

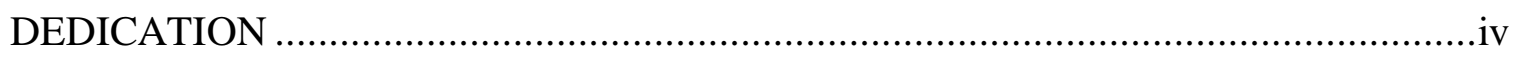

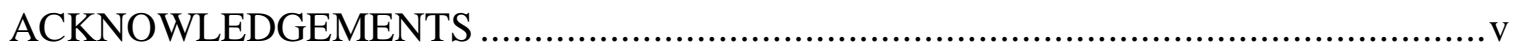

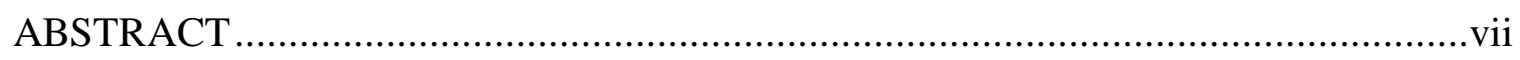

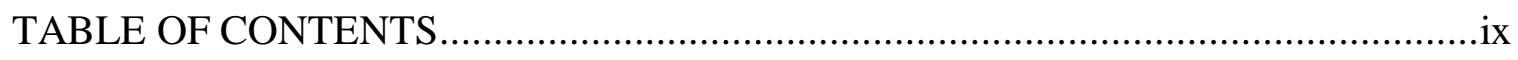

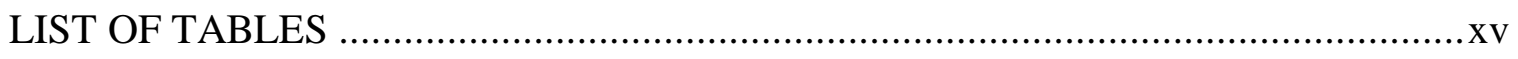

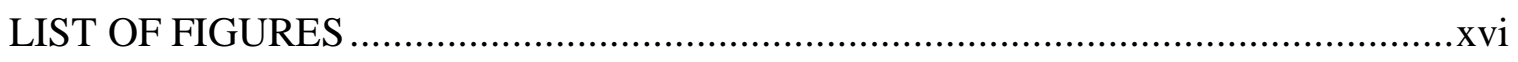

LIST OF ABBREVIATIONS ..........................................................................

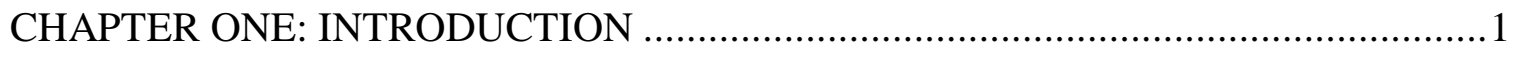

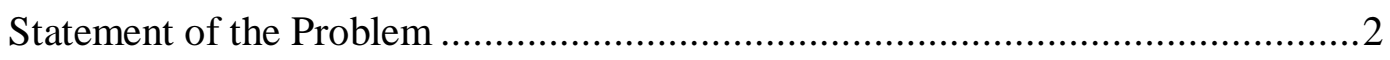

Reasons for Online Learning .............................................................

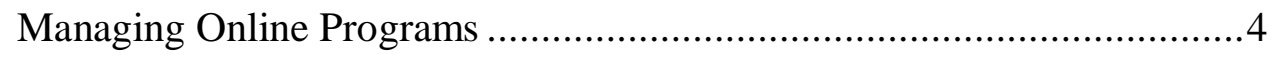

Challenges of Administering Online Programs .........................................6

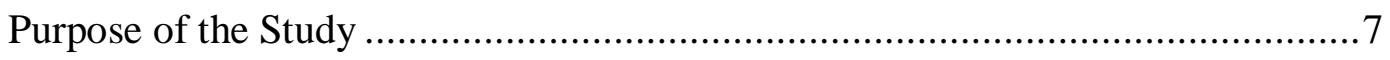

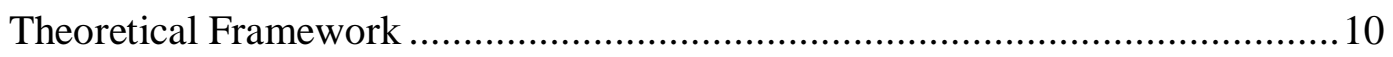

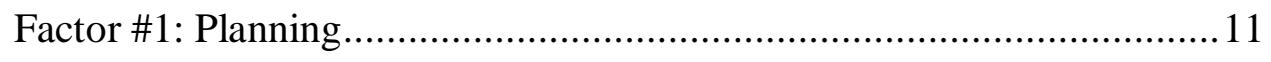

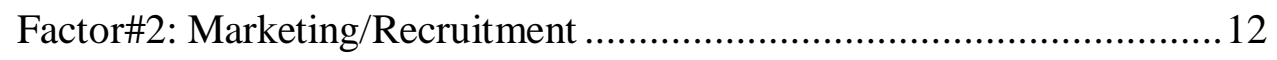

Factor \#3: Financial Management ......................................................... 12

Factor \#4: Quality Assurance ……………………………………….......13

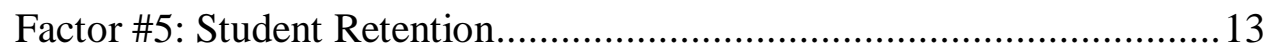




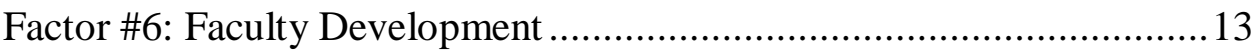

Factor \#7: Online Course Design and Pedagogy .................................. 14

Factor \#8: Subsidiarity Principle .................................................... 14

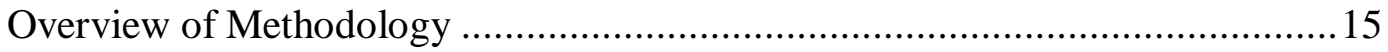

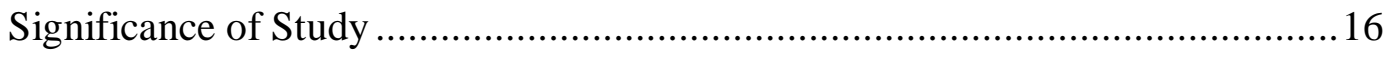

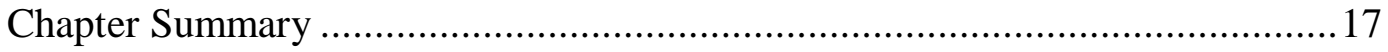

CHAPTER TWO: LITERATURE REVIEW ........................................................... 18

The Emergence of University Systems ...................................................... 18

Public Statewide Systems ..................................................................20

Statewide System Typologies ..................................................21

Goals of Statewide Systems .......................................................24

Advantages and Disadvantages of Statewide Systems ................................25

Resource Allocation to Support Innovation......................................22

Shared Services ............................................................... 28

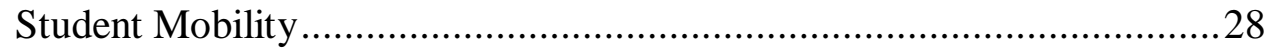

Community Colleges as Pathway to Success....................................28

Going Global............................................................................29

Cradle-to-Career Education .........................................................29

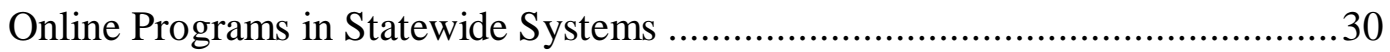

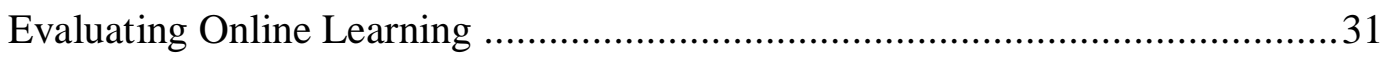

Early Attempts at Evaluating Online Learning .................................31

Online Program Evaluation Models ................................................ 32

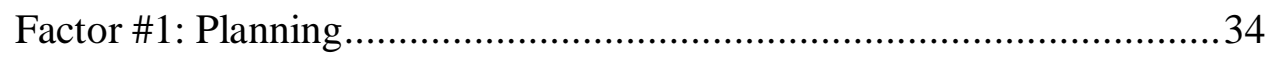




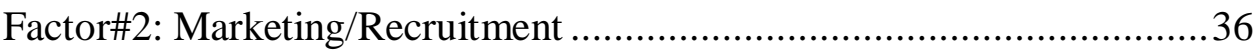

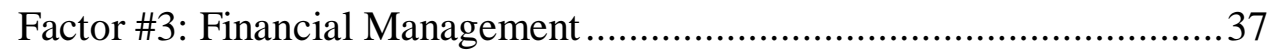

Factor \#4: Quality Assurance ....................................................................

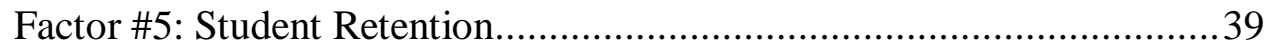

Factor \#6: Faculty Development .........................................................40

Factor \#7: Online Course Design and Pedagogy ......................................41

Subsidiarity Principle--The Missing Factor..................................................42

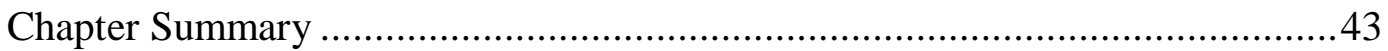

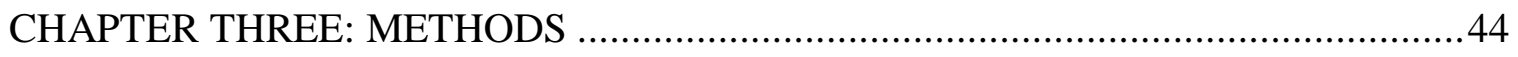

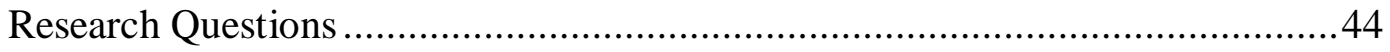

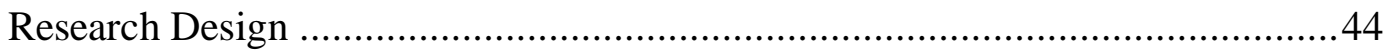

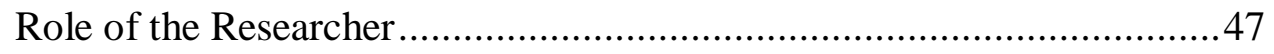

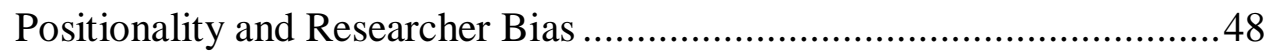

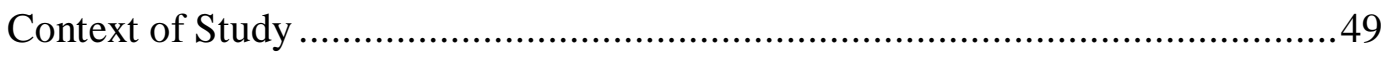

University of New Hampshire .........................................................51

Granite State College ........................................................................52

Plymouth State University ..................................................................53

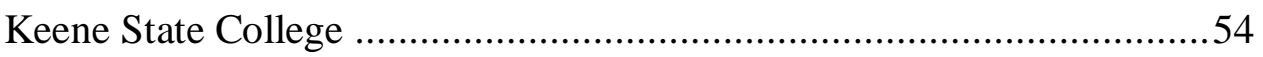

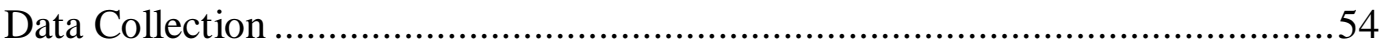

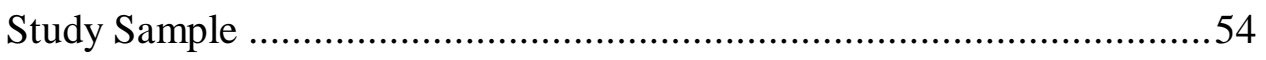

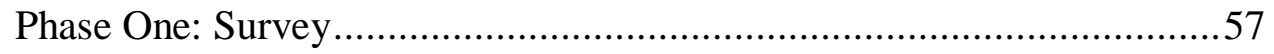

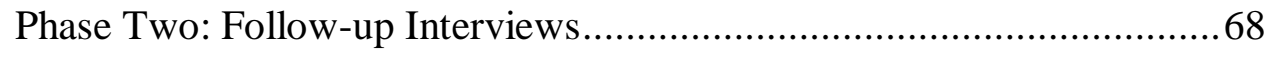

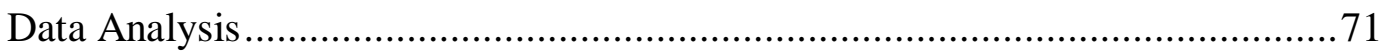


Phase One Data Analysis - Surveys ............................................... 72

Open Coding ............................................................................... 73

Identifying Categories ................................................................ 76

Phase Two Data Analysis - Semi-Structured Interviews.......................78

Interview Memos \& Field Notes ...................................................... 79

Coding of Qualitative Data ............................................................. 80

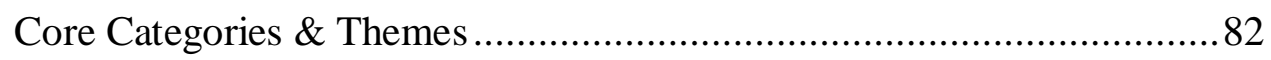

Reliability, Validation, Trustworthiness, and Credibility ............................. 82

Case Study Descriptions ....................................................... 83

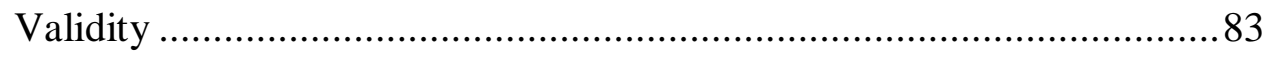

Member Checking …............................................................ 85

Triangulation ...................................................................... 86

Chapter Summary ......................................................................... 86

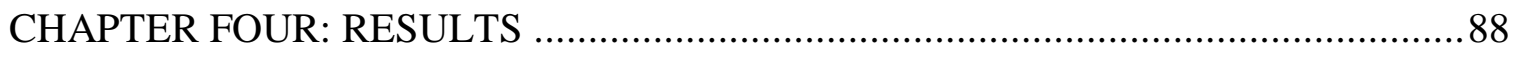

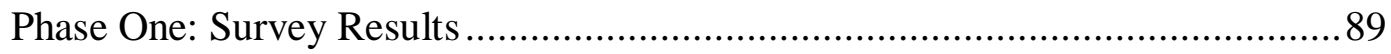

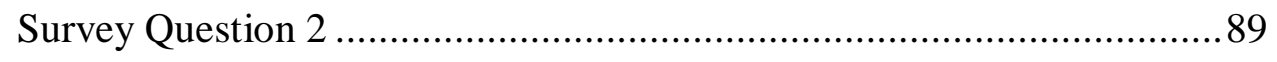

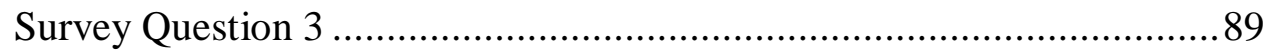

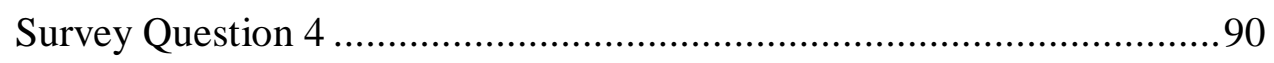

Survey Question 5 .....................................................................99

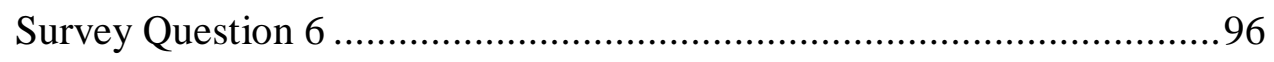

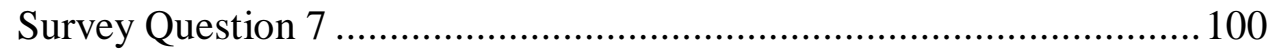

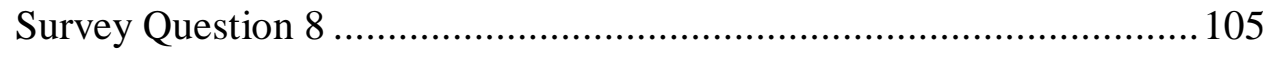

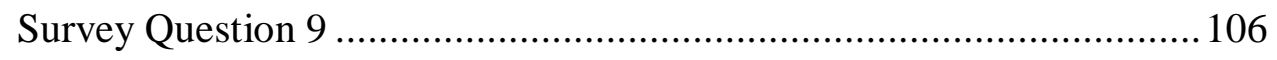




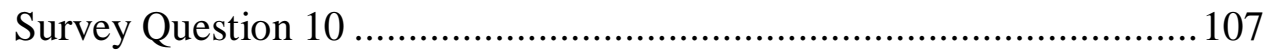

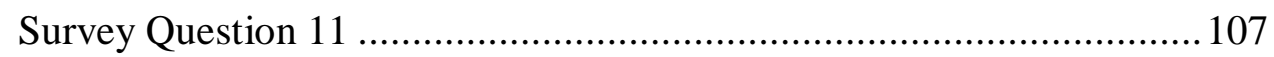

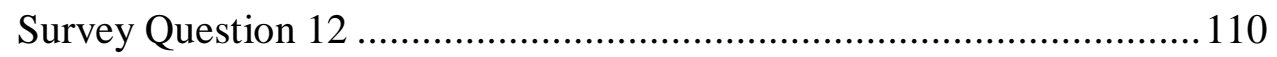

Survey Question $13 \ldots \ldots \ldots \ldots \ldots \ldots \ldots \ldots \ldots \ldots \ldots \ldots \ldots \ldots \ldots \ldots \ldots \ldots \ldots \ldots \ldots \ldots \ldots \ldots \ldots \ldots \ldots \ldots . . .111$

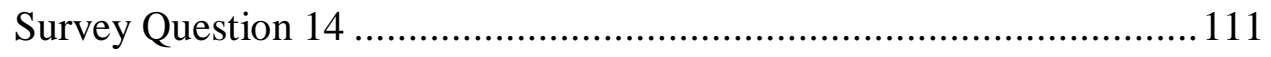

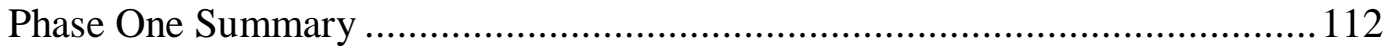

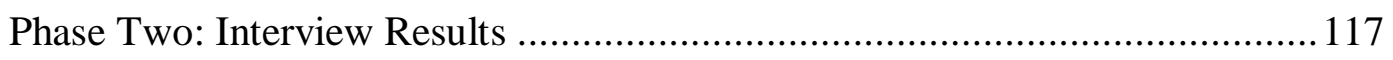

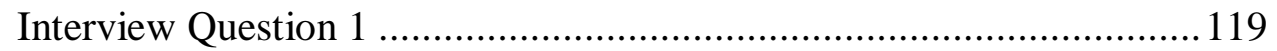

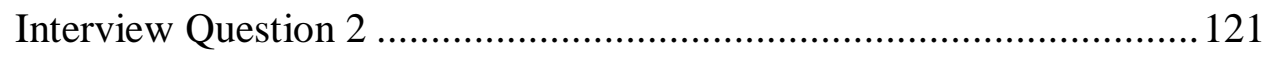

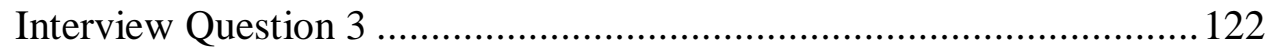

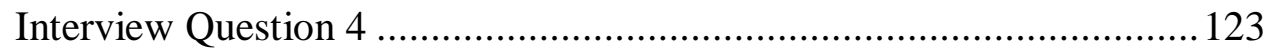

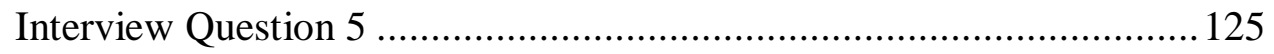

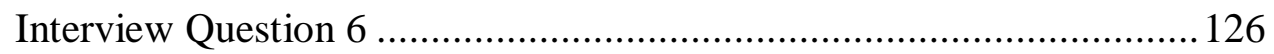

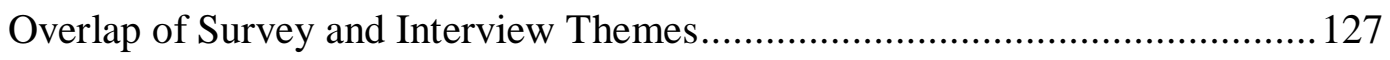

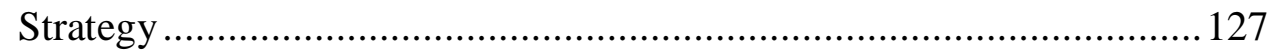

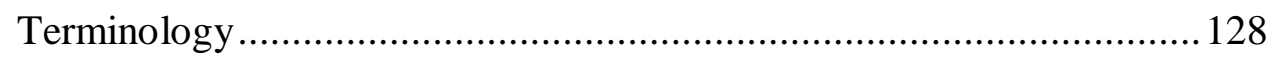

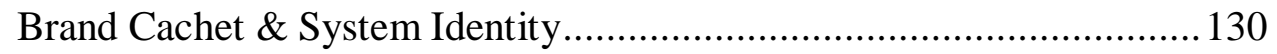

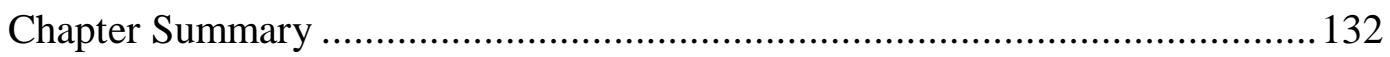

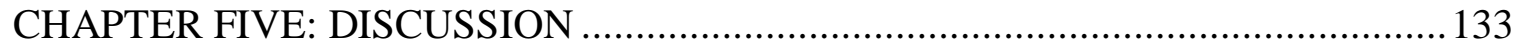

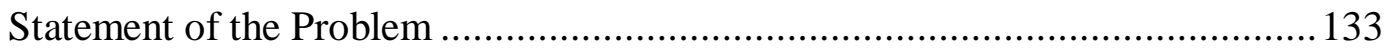

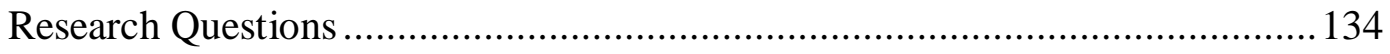

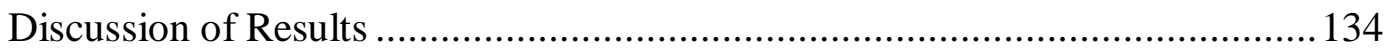

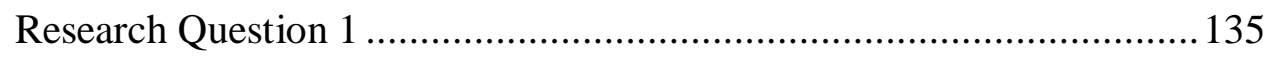


Research Question 2

Research Question 3 .....

Areas of Future Study

Affordability.

Implementation of Curricular Policy and Accreditation Requirements .. 148

Student Perception of Quality ..................................................... 148

Institutional Adaptation to Student Preferences................................. 149

Decisions that Codify How Work is Completed and by Whom ............. 150

Social Responsibility .......................................................... 150

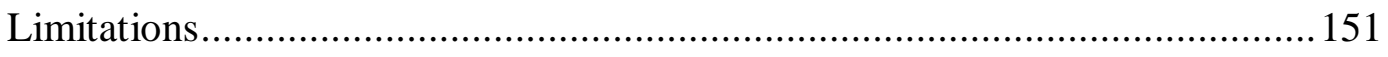

Local Versus Central ............................................................... 151

The Number of Study Participants ............................................... 152

Repeatability ........................................................................ 152

Generalizability and Transferability .......................................... 153

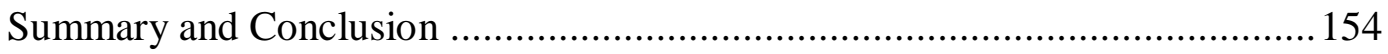

Finding 1. Common Vocabulary and Confusion about the System ........ 155

Finding 2. Local Priorities First ............................................... 156

Finding 3. Principles for Intra-System Collaboration ....................... 158

Chapter Summary ........................................................................ 160

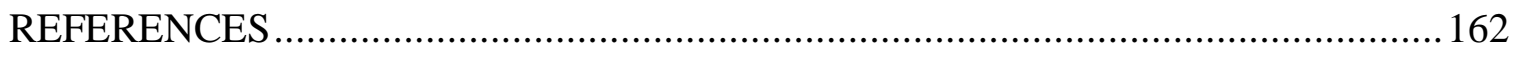

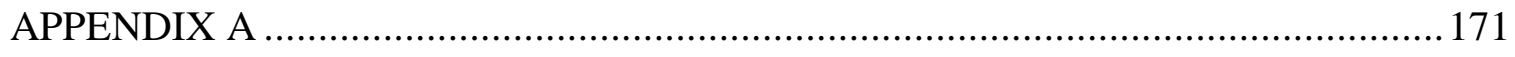

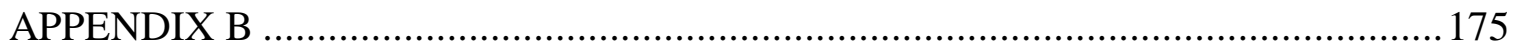

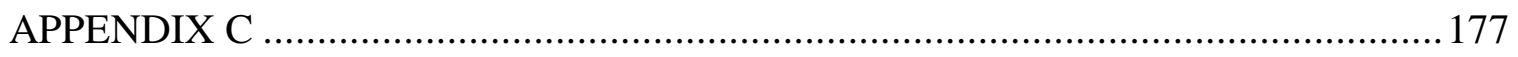




\section{LIST OF TABLES}

Table 1. A Typology of Multicampus Systems ……………………………....24

Table 2. The University System of New Hampshire Institutions (2016)................50

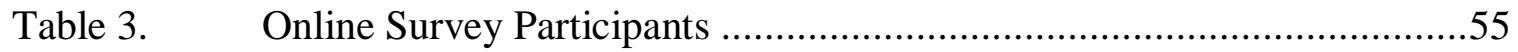

Table 4. Interview Participants ………………….........................................57

Table 5. Survey Question Alignment ...............................................................58

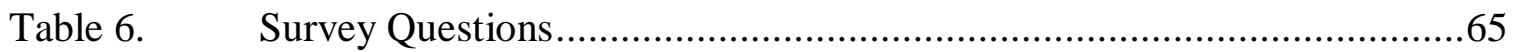

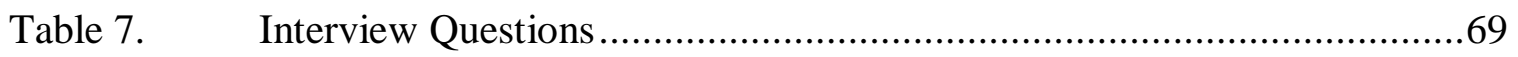

Table 8. Respondent Length of Employment .................................................90

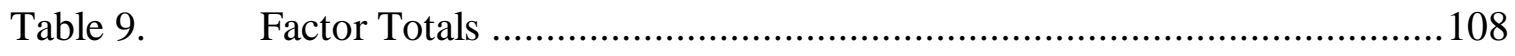

Table 10. Factor Priority …………...............................................................109

Table 11. Survey Themes, Definition \& Categories ............................................112

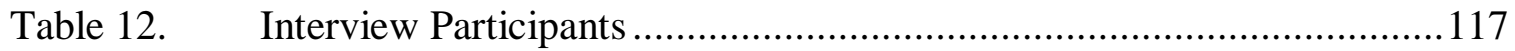

Table 13. Interview Themes, Definition \& Categories ........................................118

Table 14. Survey and Interview Theme Overlap .................................................131

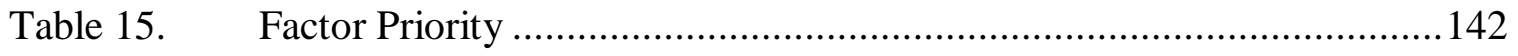




\section{LIST OF FIGURES}

Figure 1. Statewide System Online Program Evaluation Framework ...................11

Figure 2. Organization of Codes, Categories and Memos....................................68

Figure 3. Pre-coding with Bolded Text ........................................................ 73

$\begin{array}{lll}\text { Figure 4. } & \text { Glaser's Coding Process } & 74\end{array}$

Figure 5. Identifying Themes \& Theories (Glaser, 2017) .................................75

Figure 6. Glaser's Six C's Applied to Category Identification.............................76

Figure 7. Creating Memos and Open Coding ............................................... 80 


\section{LIST OF ABBREVIATIONS}

$\begin{array}{ll}\text { CSU } & \text { California State University (System) } \\ \text { CUNY } & \text { City of New York (System) } \\ \text { GSC } & \text { Granite State College } \\ \text { KSC } & \text { Keene State College } \\ \text { PSU } & \text { Plymouth State University } \\ \text { SUNY } & \text { State of New York (System) } \\ \text { UNH } & \text { University of New Hampshire } \\ \text { USNH } & \text { University System of New Hampshire }\end{array}$




\section{CHAPTER ONE: INTRODUCTION}

Nationwide, postsecondary enrollment has been flat or down since 2011 (National Student Clearinghouse Research Center, 2014). This trend has been attributed to a decreasing number of 18-24 year olds along with increased competition in the higher education market (Essary, 2014). Many institutions have sought out alternative sources of revenue to mitigate the negative impacts of these trends (Essary, 2014). For some universities, online programming has been a productive source of new revenue (Inglis, 2013; Laws, Howell, \& Lindsay, 2008; Moloney \& Oakley, 2010). Motivated in large part by revenue generation (Legon \& Garrett, 2017), by the fall of 2015, more than $75 \%$ of all postsecondary institutions in the United States offered online courses and more than $70 \%$ of chief academic leaders reported that online learning is critical to their long-term strategic planning (Allen \& Seaman, 2015). Within this same timeframe, at four-year postsecondary institutions, 1 in 14 students had no residential connection to their college or university and were pursuing their degree online (Ginder, Kelly-Reid, \& Mann, 2016). Understanding postsecondary students' needs and preferences is especially important in the Midwestern and Northeastern regions of the United States where birth rates and high school graduation rates are lower than the national average (Marcus, 2017). Some universities have attempted to overcome these challenging trends by recruiting online degree students from other states although it has become progressively 
more difficult to grow new online programs (Legon \& Garrett, 2018). In addition to geographical challenges, public postsecondary institutions in almost every state have lost much of their public funding over the last several decades (King, 2013; Legon \& Garrett, 2017). The convergence of these factors has only increased the priority many universities place on growing their online programs (Essary, 2014; Legon \& Garrett, 2017).

\section{Statement of the Problem}

Many researchers believe that efforts to introduce or expand online programs are motivated primarily by revenue generation (Berg, 2002; Legon \& Garrett, 2017; Rovai, 2009; Rovai \& Downey, 2010). Subsequently, a university's online programs should focus not only on academic priorities (Deepwell, 2007; Gómez-Rey, Barbera, \& Fernández-Navarro, 2016), but also on business principles that ensure online program resources are managed in a cost-effective and strategic manner (Miller \& Schiffman, 2006; Roby, Ashe, Singh, \& Clark, 2013). Business acumen is particularly important in today's higher education landscape since it has become progressively more difficult for new entrants in today's online degree market to succeed (Rovai \& Downey, 2010; Legon \& Garrett, 2017). Without competent program administration and the appropriate infrastructure, online programs often underperform or fail (Legon \& Garrett, 2017; Levy \& Beaulieu, 2003; Rovai \& Downey, 2010). In addition to administrative issues and insufficient infrastructure, Rovai and Downey (2010) identified several other reasons why online programs fail: marketing and recruitment, financial management, quality assurance, student retention, faculty development and online course design and pedagogy.

Researchers have found that effective online program administrators typically rely 
on business models that are different from those used to manage face-to-face programs (Chaney, Chaney, \& Eddy, 2010; Discenza, Howard, \& Schenk, 2002; Lowenthal \& White, 2014; Rovai, 2003; Rovai \& Downey, 2010). Additionally, online programs are typically managed with different policies, (Gaskell \& Hayton, 2015; Kenward, 2008; Levy \& Beaulieu, 2003; Maguire, 2007) organizational structures and staffing (Creswell, Roskens, \& Henry, 1985; Garrison \& Kanuka, 2008; Hanna, 2013). In order to find the appropriate approach to administer online programming, Berge (2007) suggests that institutions adapt their strategic planning and quality assurance practices to the unique needs of online students. While Rovai and Downey (2010) acknowledge that online programs differ from face-to-face programs in terms of how they should be administered, they also suggest that institutions should not abandon the traditional academic structures and policies that empower faculty to govern curricular decisions related to online programs.

\section{$\underline{\text { Reasons for Online Learning }}$}

While there are many reasons for the proliferation of postsecondary online programs, Berg (2002) identified four primary reasons institutions create or expand online programs: access, pedagogy, marketplace competition, and new revenue generation. Even though Berg offered these reasons more than 15 years ago, they are still relevant today. Berg (2002) focused on community colleges as opposed to four-year institutions and found that most community colleges were involved earlier with online programs than four-year institutions. He also discovered that community colleges prioritized improved access for students over revenue generation. Central to Berg's (2002) study was the assertion that to understand the differences between distance 
education programs, one must consider the different types of institutional structures that influence the policy and practice used to administer distance education programs. In terms of implementing online programs, Berg (2002) also found that top administrators were more than twice as likely as individual faculty to support the implementation of online programs.

Building on Berg's earlier work, Essary (2014) identified two primary factors driving the expansion of online programming at his university: the competitive advantage of online learning and the needs of nontraditional students for increased access to degree programs. Meyer and Wilson (2010) also point to the increased flexibility online programming affords students. While the initial concerns related to online programs were often tied to technology, innovation, and overcoming faculty resistance, the current priority of most institutions that manage online programs is on enrollment growth (i.e. revenue generation), student completion, and instructional quality (Legon \& Garrett, 2017). While an institution's reasons for offering online programs may differ, the need to understand the appropriate priorities and resources needed to effectively administer online programs is as relevant today as it was when online programs were first offered by community colleges and four-year colleges and universities.

\section{Managing Online Programs}

Since online programs can provide an alternative source of revenue to help mitigate the effects of reduced residential enrollment (Ernst \& Young, 2012; Inglis, 2013; Rovai \& Downey, 2010), online program administrators must be equipped to achieve both instructional and financial outcomes. This is even more important in the case of multicampus and public statewide systems, where challenges are often more complex and 
intertwined with organizational structure (King, 2013; Levy \& Beaulieu, 2003; Vines, 1998). Consequently, the opportunities and challenges afforded to stakeholders of large, multicampus online programs are amplified when an organization's size can be leveraged to lower operational costs, improve student access, and generate increased revenue (Discenza, Howard, \& Schenk, 2002; Maguire, 2007).

Typically, online programs rely on services, infrastructure, staffing, organizational structure and operations that are different from face-to-face programs (Rovai \& Downey, 2010). At many institutions, online programs were initially administered by an extension or continuing education office since these groups have traditionally been in charge of the university's outreach function. However, more recently, the role of administering online programs has often shifted to a single executive leader dedicated exclusively to managing online programs (Legon \& Garrett, 2017). This shift towards consolidating this function under an executive leader often occurs when a university recognizes the strategic value of online programming and then aligns their online programs more closely with the institution's core functions (Legon \& Garrett, 2017).

Because online programs frequently require dedicated staff, services, and infrastructure, several researchers who study online programs have developed program evaluation models that provide insight about how online programs should be administered. Shelton and Saltsman (2005) used seven factors to describe the unique operational characteristics of online programs: leadership and strategic planning, policy and operational issues, faculty issues, online student services, technology, courseware, and marketing. Similarly, Rovai and Downey (2010) drew on seven factors when 
studying successful outcomes of distance education programs: planning, marketing and recruitment, financial management, quality assurance, student retention, faculty development and online course design and pedagogy. While there are several areas of overlap when comparing these models, the criteria used in each model tend to differ based on whether the researcher is evaluating a specific characteristic of an online program or the entire program.

Chaney, Chaney and Eddy (2010) offer five criteria program planners should consider when managing online programs:

- Online programs are not superior to or inferior to traditional face-to-face instruction

- Successful online programs are driven by teaching and learning rather than technology

- Principles of marketing management apply to online program success

- Successful online programs meet the needs of multiple constituents (students, faculty, departments, professions, administrators, etc.)

- Online programs depend upon a supportive culture at all levels of the institution

Undoubtedly, the question of how best to manage an online program is still relevant today because emerging technologies and business practices continue to provide new opportunities for financial growth and enhancement of the student experience while the online learning landscape also continues to change (Legon \& Garrett, 2018).

\section{Challenges of Administering Online Programs}

Despite the growth of online learning, Rovai and Downey (2010) suggest that the 
"days of easy entry in the distance education market are long over" (p.143). As many colleges and universities have discovered, simply posting courses online does not guarantee success. While many institutions have generated increased online program revenue over time, others have not. Temple University's Virtual Temple, NYU online (Carlson \& Carnevale, 2001), US Open University (Krenelka, 2009), and the online University of Illinois venture (Rovai \& Downey, 2010) are just a few examples of failed online program initiatives. In the case of NYU online, NYU spent almost twenty-five million dollars while producing only seven courses (Carlson \& Carnevale, 2001). According to stakeholders familiar with the venture, the program failed due to a lack of faculty involvement and an inability to manage the program with the appropriate business and marketing models (Carlson \& Carnevale, 2001). Similarly, the University of Illinois spent $\$ 8.6$ million on its online program and had less than 130 students in only five degree programs after five years (Krenelka, 2009). This fell far short of the 9,000 students university administrators had hoped to enroll. The US Open University failed because of a lack of advocacy, improper business planning, lack of accreditation, market challenges, conflict with Open University's established curricula and a lack of advocacy from the parent institution (Krenelka, 2009). While there are many reasons each venture failed, Rovai and Downey (2010) attribute most failures to financial issues that were caused by one or more of the following factors: planning, marketing and recruitment, financial management, quality assurance, student retention, faculty development and online course design and pedagogy.

\section{Purpose of the Study}

As state-level funding for public institutions has dropped over the last several 
decades (King, 2013; Legon \& Garrett, 2017), institutions that previously had little need to change have implemented cost-cutting measures and sought out new means of increasing revenue while lowering expenses (King, 2013; Lane \& Johnstone, 2013). In light of this trend, some institutions have sought to mitigate the effects of reduced residential enrollment and state funding by expanding their online programs (Essary, 2014; Legon \& Garrett, 2017). Since the skills and resources needed to manage online programs are so different from face-to-face programs (Chaney, Chaney, \& Eddy, 2010; Rovai, 2003; Rovai \& Downey, 2010), it is important that the administrators of online programs are aware of these differences and are equipped to articulate them in the course of strategic planning, resource allocation and program management (Legon \& Garrett, 2017; Maguire, 2007; Rovai \& Downey, 2010).

Although there are numerous studies that describe how online programs should be administered, there are very few that focus on how online programs should be administered on a larger scale. Among studies that consider scale or program size as an important feature of analysis when administering online programs, Essary (2014) focused primarily on the financial benefits of scaling online programs and Vines documented the implementation of online degree programs in the California State System (1998). While this earlier research offers some insight as to how online programs should be administered in statewide systems, neither of these studies relied on a transferable research model. As online program administrators in statewide systems become better equipped to collaborate with other institutions in their system, they can improve the competitiveness of their online program by leveraging increased scale and collaboration (King, 2013). 
This study sought to understand how institutions affiliated with a statewide university system administer their online programs. Since each multicampus or public statewide system differs in significant ways (Creswell, Roskens, \& Henry, 1985; Lee \& Bowen, 1971), researchers have suggested that statewide or multicampus postsecondary systems be evaluated as discrete objects of analysis in terms of their structural and organizational characteristics (Creswell, Roskens, \& Henry, 1985; King, 2013; Lane \& Johnstone, 2013). Consequently, the following research questions, which consider how each system institution differs from the other, guided this study:

1. How are online programs administered by institutions affiliated with a public statewide system?

2. Based on the perspective of institutional administrators, what are the advantages and disadvantages of administering online programs in a public statewide system?

3. Do study participants prioritize some features or characteristics of their online program over others?

More than $75 \%$ of all postsecondary students are enrolled at an institution affiliated with a statewide system (the National Association of System Heads, n.d.). For many of these students, being able to complete some or all of their coursework influences their level of indebtedness and ability to graduate in a timely manner (Allen \& Seaman, 2015). Although most institutions understand the benefits of expanding their online programming, many institutions still lack a strategic plan to help stakeholders determine operational priorities and compete effectively against other institutions who offer similar programming (Legon \& Garrett, 2017). Aligning resources with the appropriate strategy is even more difficult in statewide systems where there are often competing agendas, 
mistrust across system institutions and a lack of agreement regarding roles and expectations (Maguire, 2007).

The aforementioned research questions and Rovai (2003) and Rovai and Downey’s (2010) factors of online program management were used to help create 20 survey questions. Eighteen administrators from UNH, PSU, KSC and GSC responded to these survey questions using Qualtrics, an online survey tool. After analyzing survey data, six survey participants were interviewed to explore themes identified in survey responses. Survey and interview questions were analyzed using a constant comparison approach, which helped the researcher identify themes and articulate several findings.

\section{Theoretical Framework}

This study used an exploratory case study framework to evaluate how online programs are administered within a single public statewide system. Rovai (2003) and Rovai and Downey's (2010) factors of online program analysis helped inform the creation of survey questions since these factors describe system-level aspects of online programs that lead to hoped-for outcomes (Rovai \& Downey, 2010). As stated by Moore and Kearsley, "Because distance education requires using a range of technical and human resources, it is always best delivered in a system, and understanding a distance education program is always best when a system approach is used" (p.9, 2012). In other words, instructional programming--face-to-face or online--cannot succeed unless there are systems, processes and tools in place to assess operational efficiency, student satisfaction, and instructor effectiveness (Rovai, 2003). Subsequently, Rovai (2003) and Rovai and Downey's (2010) factors of online program evaluation provide a robust lens to understand how online programs in a statewide system are administered and whether 
administrators consider some factors more important than others (see Figure 1). Each of these factors will be briefly described below and then addressed in more detail in Chapter 2.

Factor \#1: Planning

Factor \#2: Marketing / Recruitment

Factor \#3: Financial Management

Factor \#4: Quality Assurance

Factor \#5: Student Retention

Factor \#6: Faculty Development

Factor \#7: Online Course Design and Pedagogy

Factor \#8: Subsidiarity Principle

\section{Figure 1. Statewide System Online Program Evaluation Framework}

\section{Factor \#1: Planning}

Rovai and Downey (2010) suggest that the increased level of competition in higher education has elevated the need for effective strategic planning. Before an online program can be created or expanded, a strategic vision must be articulated by the appropriate stakeholders that "outlines the institution's aspirations in sufficient detail to inform planning and budgeting" (p.142). In addition to defining an effective strategic vision, institutions should seek out strategic partnerships and alliances that benefit both the student and the institutional stakeholders. In the case of online programs, partnerships often take the form of outsourcing certain functions such as enrollment management, student support, marketing or program development. To help ensure the ongoing success 
of an online program, Rovai and Downey (2010) suggest that strategic planning "helps ensure that all relevant opportunities and threats are identified and addressed in a systematic fashion" (p.142).

\section{Factor\#2: Marketing/Recruitment}

Effective marketing and recruitment refer to an institution's efforts to promote its online programs. A budget and dedicated marketing staff are essential resources needed to execute marketing strategies. Rovai and Downey (2010) suggest that a marketing budget is the most often overlooked aspect of entry into the online market and that without sufficient funding and dedicated marketing staff; an online program will struggle to succeed. Further, Rovai and Downey argue, "each school must align its marketing strategy with its strategic vision" (p.142, 2010). Subsequently, to ensure marketing efforts are successful, each institution must consider how its unique characteristics and strengths in the larger marketplace align with their marketing messaging. Examples of unique institutional characteristics include: geography, program price, and unique instructional strategies that help meet student needs.

\section{Factor \#3: Financial Management}

Institutions also need to manage their online program finances effectively so that sufficient revenue is generated to cover expenses. For some institutions, specific margins on revenue generated might be required to help ensure financial targets are achieved. Rovai and Downey (2010) suggest that institutions carefully consider the length of time it will take for new programs to become profitable since the time of entry to the market, the size of the target audience and the brand of the institution influence the potential scale and rate of growth for the online program initiative. In some cases, venture capital is 
required to create new program development and to help fund other online program strategic goals.

Factor \#4: Quality Assurance

Quality assurance is also a key component of successful online programs. Historically, colleges and universities have used accreditation as their primary means to validate quality assurance. Rovai and Downey (2010) suggest that a quality assurance strategy focus on faculty selection and qualifications, faculty professional development, and student support services. An effective quality assurance strategy must also be carried out on a regular basis to help satisfy program goals and student needs. As the level of competition increases to recruit students for online programs, so does the need to elevate the quality of the online programs (Rovai \& Downey, 2010).

Factor \#5: Student Retention

Institutions strive to retain as many students as they can. Since student retention rates are typically lower for students completing online classes than face-to-face classes (Brady, 2001; Wladis, Conway, \& Hachey, 2017), student retention is an especially important factor when managing online programs. Building on the work of Tinto (1987), Rovai and Downey (2010) focus on two different types of support needed to improve student retention: academic and social support. Social support refers to the need for meaningful peer- and student-to-teacher interactions. Academic support is provided by faculty and other support staff.

Factor \#6: Faculty Development

Teaching online differs from teaching face-to-face. Poorly prepared faculty can adversely influence online program quality (Rovai \& Downey, 2010). Thus, faculty 
development is an essential component of any successful online program. Faculty development programs often focus on instructional design, pedagogy, online tools, student support, media development and time management.

Ideally, faculty development programs allow faculty to engage in a range of different activities to advance their online teaching skills. Rovai and Downey (2010), though, found that (prior to 2010) effective faculty development programs were the exception rather than the norm.

Factor \#7: Online Course Design and Pedagogy

Online courses--both in terms of designing them and teaching them--differ from traditional face-to-face courses in many ways. For instance, an online course requires a significant amount of upfront design work that traditional courses do not. Thus, successful online programs focus on online course design and pedagogy by aligning course design with learning objectives and the optimal instructional approach to deliver course content. Consequently, it is important to develop a clear understanding of how to develop online programs in light of student needs and how online programs differ from face-to-face programs. Rovai and Downey (2010) suggest that the primary difference between online and face-to-face course design is that faculty teaching in online programs should spend more time designing their online courses compared to the design time needed for face-to-face classes.

Factor \#8: Subsidiarity Principle

Rovai (2003) and Rovai and Downey's (2010) models do not consider how managing online programs in large-scale contexts like statewide systems influences program outcomes. Thus, I have added an eighth factor called the subsidiarity principle 
(King, 2013) to help capture this additional variable of analysis, i.e. relation to a larger system. King (2013) believed that statewide systems are most successful when the principle of subsidiarity functions as the central organizing principle for system governance.

The subsidiarity principle states that administrative issues should be handled by the smallest, lowest or least-centralized competent authority. In the context of statewide university systems, King felt that the subsidiarity principle offered an effective foundation for governance: "The best level of governance for decisions to be made is where there is the most direct information about the body or bodies affected, with sufficient awareness of the various policies and organizational factors" (p. 4, 2013).

\section{Overview of Methodology}

This case study involves two phases of data collection and analysis to answer the research questions. During the first phase of the study, an online survey was used to collect data and identify initial codes and themes. The survey questions were shaped by the theoretical framework and research questions guiding this study. The survey construction and administration are discussed more in chapter three. The second phase of the study includes follow up semi-structured interviews and continued refinement of codes and themes. The questions for the interviews are shaped by categories identified in the survey data analysis and by the online program management factors described by Rovai (2003) and Rovai and Downey (2010). Additional information about the interviews are provided in chapter three. Additional details about the methodology used in this study is also provided in chapter three. 


\section{Significance of Study}

With more than $75 \%$ of all postsecondary students enrolled at an institution affiliated with a statewide system (the National Association of System Heads, n.d.), the benefits of improving the educational experience for this group of students are far ranging. When looking more closely at student preferences, one trend that continues to accelerate for all postsecondary students is an interest in taking some or all of their classes online (Allen \& Seaman, 2015). As the landscape of higher education has changed over the last decade, many institutions have found themselves ill equipped to compete in a more saturated and competitive online degree market (Krenelka, 2009; Legon \& Garrett, 2017). The potential opportunities and challenges of administering online programs are even more pronounced when these programs are administered in statewide systems (Legon \& Garrett, 2017; Maguire, 2007). To complicate matters, there is little research pointing to helpful strategies and principles of practice for administering online programs at institutions affiliated with statewide systems.

Identifying which factors contribute to the successful administration of online programs in statewide systems can help stakeholders determine whether some factors are more important than others. As stakeholders acquire a clearer understanding of which factors contribute to the operational effectiveness of their online programs, planning for an online program in a statewide system can become more effective based on an institution's strategic assets and the unique needs of the institution's target audience (Rovai \& Downey, 2010). Even though the results of this study cannot be generalized because of the unique characteristics of each institution's online program, institutions who administer online programs within statewide systems should find the results of this 
study helpful when they undertake strategic planning and take steps to improve the competitiveness of their online program.

\section{Chapter Summary}

Many public statewide colleges and universities are dealing with decreased yearover-year enrollment and are consequently looking to generate new sources of revenue while lowering operational costs (Essary, 2014). Among some public institutions, this trend has created increased interest in how online programs can be administered more effectively in a statewide system. This study will draw on earlier research conducted by King (2013), Rovai (2003), Rovai, and Downey (2010) to understand how online programs are being administered in the University of New Hampshire System and whether there are benefits that can be realized from increased collaboration among system institutions. In subsequent chapters, a literature review contextualizes the history of distance education against the unique characteristics of public postsecondary statewide systems. After describing the evolution of online programs in public statewide systems in chapter two, a more detailed description of this study's methodology is presented in chapter three. 


\section{CHAPTER TWO: LITERATURE REVIEW}

While the majority of postsecondary institutions offer online programs (Allen \& Seaman, 2015), not all online programs are successful (Carlson \& Carnevale, 2001; Krenelka, 2009). Even though there are some studies that have identified different characteristics of successful online programs, very little research to date has investigated how online programs are administered successfully in statewide systems. Thus, the purpose of this study is to investigate one four-year statewide system to address this gap in the literature. In the following chapter, I will review the relevant literature with a focus on how online program evaluation models are used to evaluate online programs.

\section{The Emergence of University Systems}

Fueled in part by the GI Bill, the number of students attending college and universities increased dramatically in the United States after World War II (Geiger, 2015). Veterans were given between $\$ 800$ and $\$ 1,400$ each year, which covered $50-80 \%$ of their total enrollment costs. This financial support boosted the number of veterans in higher education and spread the notion that higher education was available for the broader population and not just the elite.

Although America's first universities typically operated independently of each other, between 1944 and 1970, many public universities consolidated within statewide university systems. In these systems, governance was centralized under a chancellor, president, or board (King, 2013; McBain, 2009). In many cases, public universities 
formed statewide systems during this time to improve operational efficiencies, allow transfer of credit between member institutions, and to help coordinate advocacy around legislative issues that affected their member institutions (Geiger, 2015). For statewide systems in California, Florida, New York and many other states, this consolidation of institutions under a central governing entity was a period of tremendous growth for higher education, which resulted in a missional shift for many colleges and universities towards statewide initiatives.

Even though many postsecondary institutions benefited from centralizing operations under a statewide system, some postsecondary institutions began experiencing financial shortfalls by the early 1970s (Cahalan \& Perna, 2015; King, 2013; Legon \& Garrett, 2017). Public universities were particularly impacted during this period as many statewide systems lost significant financial support from their respective states (Cahalan \& Perna, 2015). As state funding for statewide systems decreased, tuition rates and student debt increased (Cahalan \& Perna, 2015). These financial challenges were often exacerbated by antiquated organizational structures that were ill equipped to manage the new cyclical ebb and flow of the highly diversified revenue sources that many institutions began to depend upon as state-level funding decreased (Legon \& Garrett, 2017).

In light of how challenging it can be to manage large-scale online programs in statewide systems, administrators who work in multicampus or statewide systems must understand the characteristics of their local institution and the relationship of their institution to their statewide system. For example, some institutions that are affiliated with a statewide system often have a unique charge to offer online programming. Additionally, all institutions affiliated with a statewide system have a specific geography 
and history--such as a culture of entrepreneurship--that can offer a competitive advantage when launching new online programs (Rovai \& Downey, 2010). As new approaches and technologies are implemented to achieve hoped-for outcomes, expenses can often be lowered by eliminating duplicate services or technologies (Ernst \& Young, 2012; Zimpher, 2013).

\section{Public Statewide Systems}

There are currently 46 postsecondary statewide systems in the United States (National Association of System Heads, n.d.). These statewide systems educate approximately three-quarters of the nation's students (National Association of System Heads, n.d.). In most states, like California, New York and New Hampshire, the leading research universities are members of statewide systems. Among these institutions, the State University of New York (SUNY) is the largest system with over 600,000 students. The SUNY system includes 64 campuses, over 90,000 faculty members, 8,000 degree and certificate programs and a budget that exceeds 10 billion dollars.

In addition to the SUNY system, New York also has the City University of New York (CUNY) system, which consists of institutions located exclusively in New York City. The CUNY system, which includes 24 colleges and graduate schools located across New York City's five boroughs, is separate from SUNY, the larger statewide system in New York. Unlike California, where community colleges are governed within their own discrete system, the SUNY system is inclusive of community colleges, institutions, and universities. To help administer online programs across the entire system, the SUNY system created a centralized unit in 1994 called Open SUNY. Because SUNY is made up of so many different institutions, Open SUNY is able to offer more than 470 online 
degrees from 64 different colleges and universities. Open SUNY claims that one major advantage it has over other programs is its reliance on a massive, system-wide online learning experience that prioritizes faculty support and individual student attention (SUNY, n.d.).

Unlike SUNY's integrated statewide system, California has three different and distinct statewide systems: the California Community Colleges System, the California State University System and the University of California System. The California State University (CSU) is comprised of 23 campuses and 8 off-campus centers enrolling almost 500,000 students. CSU employs over 24,000 faculty. The University of California System is considered to be a more prestigious and research-focused system and is made up of 10 campuses that are governed by a board. The University of California System enrolls approximately 250,000 students and employs over 21,000 faculty. Like New York's postsecondary systems, each of California's three separate systems rely on centralized governance, shared resources and some level of academic coordination between institutions. Like many statewide systems, each of the California statewide systems created their own system-wide online program. Statewide System Typologies

Statewide systems differ from state to state. The terms "multicampus" and "system institutions" are typically used interchangeably in the literature since both terms refer to institutions that have some form of shared or central governance and multiple campuses (Johnstone, 2013). Johnstone describes multicampus systems as, Groups of public institutions each with its own mission, academic and other programs, internal governing policies and procedures and chief executive officer, 
but governed by a single board with a system-wide chief executive officer, generally called chancellor or president--whichever term is not used for the campus heads. (p. 1,)

According to Johnstone, institutions often created these additional locations (e.g. branches or multiple sites) to help meet a demand for increased regional coverage. In most cases, such organizational structures were created before their state's more comprehensive statewide system evolved (Johnstone, 2013). Many multicampus institutions were created in large urban areas such as New York City where it was easier to spread a university out over different areas of a city to accommodate for space and parking constraints.

To help researchers and administrators study and compare multicampus institutions, academics have developed different typologies of postsecondary institutions. For instance, Creswell, Roskens and Henry (1985) suggested multicampus institutions be grouped along four different axes:

1. public or private;

2. governance by a statewide board or not governed by a statewide board;

3. the unique function of the institution in relation to other institutions in the system, and;

4. the administrative structure of the system office.

Gerth (2010) has argued that there are basically two types of statewide systems: segmented and comprehensive. Based on Gerth's classification, the California State University (CSU) system would be categorized as segmented since the institutions within the statewide system are divided into tiers based on their institutional mission and 
admissions criteria. The State University of New York System (SUNY) would be categorized as a comprehensive system since the system includes community colleges, state colleges, technical colleges, regional comprehensive university and research universities. Kenward (2008), on the other hand, grouped postsecondary institutions into three campus typologies: single campus, main campus with one or more satellite campus, and multicampuses.

Although these categorizations and the governing structures of multicampus postsecondary institutions vary widely between states and countries, for the purposes of this study, postsecondary statewide systems will also be referred to as "multicampus" institutions since both terms refer to institutions with multiple locations and some level of distributed governance (Creswell, Roskens, \& Henry, 1985). A heterogeneous multicampus system refers to institutions that fall under the same top-level governing organization but have different missions or institutional functions. For instance, a multicampus system that includes doctoral granting institutions and community colleges would be considered a public heterogeneous system. CUNY would be an example of a heterogeneous public system. A homogeneous system would include institutions that share the same mission or function. The University State System of Minnesota is an example of a public homogeneous system. See Table 1 for additional examples of system typologies described by Creswell, Roskens, \& Henry (1985). 
Table 1. A Typology of Multicampus Systems

\begin{tabular}{|l|l|l|l|l|}
\hline $\begin{array}{l}\text { Type of } \\
\text { Multicampus } \\
\text { Systems }\end{array}$ & $\begin{array}{l}\text { Public/ } \\
\text { Private }\end{array}$ & $\begin{array}{l}\text { Governance } \\
\text { (Jurisdiction) }\end{array}$ & $\begin{array}{l}\text { Function } \\
\text { within System }\end{array}$ & $\begin{array}{l}\text { Administrative } \\
\text { Structure }\end{array}$ \\
\hline $\begin{array}{l}\text { Private } \\
\text { Syracuse University, } \\
\text { Long Island } \\
\begin{array}{l}\text { University, Claremont } \\
\text { University) }\end{array}\end{array}$ & Private & $\begin{array}{l}\text { Less than } \\
\text { statewide }\end{array}$ & $\begin{array}{l}\text { Homogeneous } \\
\text { (either junior } \\
\text { or senior) }\end{array}$ & $\begin{array}{l}\text { Separate central } \\
\text { office (Long } \\
\text { Island } \\
\text { University) and } \\
\text { flagship } \\
\text { institution } \\
\text { (Claremont) }\end{array}$ \\
\hline $\begin{array}{l}\text { Statewide Public } \\
\text { Hawaii, Georgia, } \\
\text { Nevada, New } \\
\text { Hampshire }\end{array}$ & Public & Statewide & $\begin{array}{l}\text { Homogeneous } \\
\text { and } \\
\text { heterogeneous }\end{array}$ & $\begin{array}{l}\text { Separate central } \\
\text { office and no } \\
\text { flagship } \\
\text { institution }\end{array}$ \\
\hline $\begin{array}{l}\text { Heterogeneous public } \\
\text { multicampus } \\
\text { CUNY, Southern } \\
\text { Arkansas }\end{array}$ & Public & $\begin{array}{l}\text { Less than } \\
\text { statewide }\end{array}$ & $\begin{array}{l}\text { Heterogeneous } \\
\text { and not } \\
\text { homogeneous }\end{array}$ & $\begin{array}{l}\text { Separate central } \\
\text { office (SUNY) } \\
\text { and flagship } \\
\text { institution } \\
\text { (Texas A\&M) }\end{array}$ \\
\hline $\begin{array}{l}\text { Homogeneous public } \\
\text { multicampus } \\
\text { System of Minnesota, } \\
\text { University of Illinois, } \\
\text { University of Texas }\end{array}$ & Public & $\begin{array}{l}\text { Less than } \\
\text { statewide }\end{array}$ & $\begin{array}{l}\text { Homogeneous } \\
\text { (Texas A\&M) } \\
\text { and not } \\
\text { heterogeneous }\end{array}$ & $\begin{array}{l}\text { Separate central } \\
\text { office } \\
\text { (University of } \\
\text { Missouri) and } \\
\text { less frequent } \\
\text { flagship } \\
\text { (University of } \\
\text { Arkansas) }\end{array}$ \\
\hline
\end{tabular}

(Adapted from Creswell, Roskens, \& Henry, 1985)

Goals of Statewide Systems

Although postsecondary institutions can be categorized using different characteristics (Poulin \& Straut, 2015), one of the more salient characteristics of an institution associated with a larger system is its primary goal or function within the system (Creswell, Roskens, \& Henry, 1985; King, 2013). In some cases, a public college 
or university may assume a niche role in their state system in terms of mode, audience, geography or areas of content expertise (Gaskell \& Hatyon, 2015). For instance, Colorado State Global College, a member of the Colorado State University System, was created to focus solely on online programs (Colorado State University Global Campus, n.d.). In the University System of New Hampshire, Granite State College was initially the primary provider of online programs whereas the University of New Hampshire, the system's flagship university, is focused primarily on research and residential undergraduate education (University of New Hampshire, n.d.).

The ultimate goal of statewide higher education systems is to improve collaboration (Zimpher, 2013). Lane and Johnstone (2013) argue that better collaboration between system institutions will improve 1) the strength of individual institutions in the system; 2) access, costs and productivity of system institutions; and 3) the alignment of system institutions with state and community needs.

\section{Advantages and Disadvantages of Statewide Systems}

While there are advantages to being affiliated with a system (e.g., potential reduction in back-office expenses, collaboration with other system institutions), there are also disadvantages. Disadvantages are possible when system institutions cede too much operational control to central authority, compete with other system institutions, lose connection with regional workforce needs or struggle to manage more complex systems that member institutions are required to use as part of systemwide requirements (Lane \& Johnstone, 2013; Vines, 1998). Lane and Johnstone (2013) suggest the Great Recession in 2008 spurred many institutions to reconsider how they might lower operational expenses and compete more effectively with for-profit online institutions such as 
University of Phoenix and Capella University. While Johnstone (2013) believes that there are many benefits of affiliating campuses or institutions under a single statewide system, he also points out eight problems that can exist between individual member institutions and their systems. According to Johnstone (2013), these potential problems are:

1. Determination and alteration of institutional missions

2. The approval of campus requests to add or dissolve academic programs

3. Undergraduate admission numbers

4. A change in the standards for admission

5. The setting of tuition fees

6. The disposition of tuition dollars

7. Senior college acceptance of community college associate degree graduates

8. Senior college acceptance of community college associate degree credits Central to each of Johnstone's (2013) problems is the issue of governance and self-determination. For example, centralizing requests to add or dissolve academic programs has limited value if these decisions do not ultimately serve the needs of the individual institutions and the students they serve. Other issues, like the allocation of funds and credit transfer are decisions that are typically made locally.

In every statewide system, roles and responsibilities vary (King, 2013). Typically, administrators at the system level are responsible for allocating state-level capital and operational funds, auditing campus expenditures, approving academic programs, and overseeing campus compliance with state and federal rules and regulations (King, 2013). System leadership typically establishes legislative priorities, hires and reviews campus presidents or chancellors, and establishes rules regarding governance, personnel, 
academic and student issues, and intellectual property (King, 2013). A smaller number of systems allow system-level leadership to conduct collective bargaining and manage grants, benefits, and retirement systems. Eighteen states have a single, statewide system; nineteen have multiple systems, distinguished by geography or institutional type (King, 2013). There are also substantial differences in the degree of autonomy granted to component campuses, with some possessing separate governing boards (Gaskell \& Hayton, 2015; King, 2013).

Lee and Bowen's (1971) seminal book focused on the many different dimensions of administering multicampus institutions. These included public statewide systems and focused on nine of 11 US-based systems that fit their definition of multicampus institutions. Since Lee and Bowen (1971) focused on categorizing institutions based on their form of governance, they excluded some systems such as community colleges. In this early research, there was a strong focus on the financial benefits of organizing institutions under a form of shared governance that would allow for increased collaboration and reducing expenses (Lee \& Bowen, 1971).

Zimpher (2013), the former SUNY Chancellor, coined the term "systemness" to describe the numerous benefits of system affiliation: Zimpher identified eight benefits of system affiliation, which will be described briefly below.

\section{$\underline{\text { Resource Allocation to Support Innovation }}$}

This category refers to funds that are earmarked to support innovation. In the case of SUNY, the process of resource allocation involved cost reduction, more frequent evaluation of program outcomes and a commitment to reallocate funding to higher priority programs. 


\section{$\underline{\text { Shared Services }}$}

Institutions that share services consolidate resources and remove duplication of service functions to lower expenses. For instance, IT services, enrollment management systems, HR functions and technical resources are areas where statewide systems can identify overlap and then centralize the service. As expenses are lowered, funds can be directed to more important academic programs that support students directly. At SUNY, smaller institutions were able to leverage procurement contracts secured by larger system institutions to lower costs.

\section{$\underline{\text { Student Mobility }}$}

Because students often transfer to other statewide institutions before completing their degree, it is important to facilitate this process by ensuring credits earned at one system institution are accepted at another institution in the same system. As part of a commitment to this goal, SUNY became the only state to allow any SUNY community college student to transfer their associate's degree to a four-year SUNY institution and start their four-year degree as a junior.

\section{$\underline{\text { Strategic Enrollment Management }}$}

Strategic enrollment management helps ensure that students are encouraged to enroll in programs that are considered high-priority workforce areas. In some states or cities, certain occupations may be needed to help boost the economy. Strategic enrollment at a nearby institution can help meet these regional workforce needs.

\section{Community Colleges as Pathway to Success}

Tighter integration between the two-year community colleges and four-year colleges or universities is often improved when statewide systems find ways to simplify 
the transfer of credits between institutions. When students can build pathways between system institutions to simplify transfers, student retention within the system is improved. $\underline{\text { Research and Innovation }}$

As epicenters of the knowledge economy, statewide systems are able to capitalize on their size and relationships across multiple system institutions to build new research centers, lead collaborative projects and start new business incubators. Because large-scale grants often depend on the depth and reach of collaboration between research and industry, leveraging networks and resources across a large statewide system can provide a helpful competitive advantage over smaller institutions.

\section{Going Global}

In many cases, research universities depend on meaningful relationships with international researchers and international students who can support faculty with research projects. Additionally, many institutions depend heavily on higher tuition rates paid by international students and benefit from the improved diversity international students offer a campus.

\section{Cradle-to-Career Education}

Zimpher (2013) contends, "Education must embrace its capacity--or more accurately, its outright responsibility--to reach beyond college campuses in the opposite direction" (p. 39). In an effort to meet societal needs beyond the campus, institutions must seek out partnerships with civic organizations, businesses, schools, cities and other groups that impact residents' quality of life.

As mentioned by Zimpher (2013), the reasons for organizing multiple campuses or institutions under a system are varied but are most often due to the efficiencies gained 
by improving collaboration between system institutions. King (2013) refers to similar advantages when discussing the benefits of statewide systems: budget, infrastructure, operational coordination, governance and political expediency.

\section{Online Programs in Statewide Systems}

As institutions began offering fully online programs during the 1990s, researchers found that these programs needed to be administered differently than face-to-face residential programs (Essary, 2014; Legon \& Garrett, 2017; Rovai, 2003; Rovai \& Downey, 2010). However, very little research has been conducted on the administration of online programs in four-year statewide systems (Maguire, 2007; Vines, 1998), which has made it more difficult to identify best practices and to draw on lessons learned from earlier efforts to administer online programs in this context.

In one study, Maguire (2007) focused on how policy is created and administered in four-year statewide systems. She relied on the Multiple Streams model--a policy development model that helps explain how issues obtain agenda status and become policies (Kingdon, 2011)--to explain how policies in statewide systems are created. Using this model, Maguire sought to understand how faculty at three public, four-year institutions that were affiliated with a public statewide system viewed the creation of distance education policy. According to Maguire, students and faculty should be involved in the development of distance education policy as early in the process as possible. Because the process of developing policy depends upon a deep understanding of an institution's culture or context, Maguire encouraged online program stakeholders to consider the role of campus culture, structural and historical context, and politics.

In another study focused on online programming within a statewide system, Vines 
(1998) examined how the California State University System (CSUS) administered its online programs. According to Vines (1998), managing online programs in a multicampus environment increases the complexity of issues and affects the impact of various quality factors that must be considered in the design and implementation of these programs. Subsequently, Vines (1998) asserts that the "impact and interactions of distance education quality actors differs when designing large-scale versus smaller-scale distances learning programs" (p. 137, 1998).

Unfortunately, Vine's study lacked a viable methodology and replicable approach. Although Vines sought to understand how the complexity of administering online programs in multicampus or statewide systems was impacted by the scale of statewide systems, her findings were unqualified and lacked supporting detail.

\section{Evaluating Online Learning}

As online programs have grown, administrators, researchers, online educators, accreditors, and policy makers have investigated different ways to evaluate and ultimately improve online programs. In the remaining section of this chapter, I will describe how this work has evolved over time and conclude with the theoretical framework that will guide this study.

\section{Early Attempts at Evaluating Online Learning}

Online learning is a contemporary form of distance education. Distance education dates back over a 100-year period and has roots in correspondence courses first offered in England. For the purpose of this study, I will use the term "online programs" synonymously with "distance education" despite some of the nuanced differences between each term. Distance education, and more specifically online learning, has always 
attracted critics; mostly people who questioned whether learning at a distance was as good as face-to-face instruction.

Rumble $(1999,2001)$ was one of the first researchers to develop a framework for evaluating the cost benefit of online learning. His framework focused almost exclusively on the financial characteristics of distance education programs. Although Rumble (2012) later minimized the differences between online and face-to-face learning, he categorized institutions offering online programming into two distinct groups: those offering only face-to-face or online programs--single-mode--or those offering both--dual-mode. As colleges and universities began to use more sophisticated online technologies to serve a wider and more geographically dispersed audience, researchers began to identify significant differences between face-to-face and online programming. Central to these studies is the belief that the organizational structure of the institution offering online programming influences the cost and quality of online programs (Berge, 2007; Miller \& Schiffman, 2006).

Over time, researchers studying the characteristics of online programming expanded their program evaluation models beyond financial and learner characteristics by incorporating new categories of program differentiation: strategic planning, marketing and recruitment, student retention, faculty development, online course design, and pedagogy (Moloney \& Oakley, 2010; Rovai, 2003; Rovai \& Downey, 2010; Shelton \& Saltsman, 2005).

\section{Online Program Evaluation Models}

Rovai (2003) developed one of the first robust online program evaluation models, which was later refined by Rovai and Downey (2010). Rovai drew on the work of 
Stufflebeam (1971) to frame his model. Stufflebeam (1971) identified four high-level dimensions of analysis for program evaluation: context, input, process, and product; otherwise known as the CIPP approach. The CIPP approach is based on the view that the most important purpose of evaluation is not to prove but to improve. Each dimension of analysis seeks to understand a different aspect of a program-related process or phenomenon.

- Context: What needs to be done?

- Input: How should it be done?

- Process: Is it being done?

- Product: Is it succeeding?

Rovai (2003), like Stufflebeam (1971), felt that a dynamic, systems model was the appropriate model for analyzing online programs. A systems approach was particularly appropriate by the time Rovai and Downey (2010) described various factors of online program evaluation since online programs were becoming more complex over time with autonomous functional components in areas such as program development, marketing, technical infrastructure and strategic planning.

Ultimately, Rovai (2003) believed that using a systems approach to evaluate programs allows researchers to make judgements about whether distance education programs are successful: "Consequently, it is important to evaluate distance education programs by how they work as a whole rather than by evaluating individual components without regard to the overall program effectiveness" (p.113). To help ensure continued alignment with hoped-for program outcomes, Rovai (2003) suggested that periodic program evaluation is important to help programs avoid disorganization and 
discontinuation. Building on this earlier work, Rovai and Downey (2010) identified seven factors for online program evaluation, which I briefly describe in the following paragraphs.

\section{Factor \#1: Planning}

Rovai and Downey (2010) suggest that the increased level of competition in higher education elevates the need for effective strategic planning. Before the core operations of an online program can be created or expanded, a strategic vision must be articulated by the appropriate stakeholders that “outlines the institution's aspirations in sufficient detail to inform planning and budgeting” (p.142). In addition to defining an effective strategic vision, institutions should seek out strategic partnerships and alliances that benefit both the student and the institutional stakeholders. In the case of online programs, partnerships often take the form of outsourcing certain functions such as enrollment management, student support marketing or program development. To help sustain an online program and the appropriate coordination among stakeholders, Rovai and Downey (2010) argued that "strategic planning helps ensure that all relevant opportunities and threats are identified and addressed in a systematic fashion" (p. 142).

Four-year public institutions, according to Legon and Garrett (2017), are the most difficult type of university to study in relation to their administrative structures since "four-year public institutions have the widest internal variation or inconsistency in policy." (p.5). Policy and strategic planning, though, are essential components of statewide system planning (Maguire, 2007). King, Nugent, Eich, Mlinek and Russell (2000), define distance education policy as "a written course of action adopted to facilitate program development and delivery in distance education" (p.3). Online program 
policy facilitates growth in program development, student support and helps determine the level of autonomy program leaders are allowed to exercise (Gaskell \& Hayton, 2015; Maguire, 2007). Levy and Beaulieu (2003) found that many community colleges lacked strategic planning around areas such as online program procedures, governance and resources. While Rovai and Downey (2010) did not focus extensively on policy, their model does focus on strategic planning. According to Rovai and Downey (2010), a strategic plan outlines "the institution's aspirations in sufficient detail to inform planning and budgeting" (p.142).

Another important aspect of planning is defining a growth strategy. Moloney and Oakley (2010) described the characteristics of online programs that have scaled successfully and provided a list of ten organizational characteristics that facilitate effective growth:

1. institutional support,

2. specialization of resources for the online program,

3. appropriate financial models,

4. a focus on degree completion,

5. pedagogy,

6. marketing,

7. support for faculty,

8. support for students,

9. internal support for adding more faculty, and

10. a commitment to outreach. 
Laws, Howell and Lindsay (2008) also offer ten factors that contribute to or hinder the growth of an online program:

1. interaction,

2. learning levels,

3. student class standing,

4. faculty tenure or continuing status,

5. completion rates,

6. cohort versus non cohort settings,

7. degree- versus non-degree-seeking programs,

8. market type,

9. tuition costs,

10. and profitability.

\section{Factor\#2: Marketing/Recruitment}

Effective marketing and recruitment refer to an institution's efforts to promote its online programs with a target audience. Essential to this process is an appropriate marketing budget and dedicated marketing staff who can manage marketing tools and execute marketing campaigns. Rovai and Downey suggest a marketing budget is the most often overlooked aspect of entry into the online market and that without sufficient funding and dedicated staff, an online program will struggle to succeed. According to Rovai and Downey (2010), "Each school must align its marketing strategy with its strategic vision" (p.142). To help ensure a successful marketing effort, each institution must consider its unique characteristics and strengths in the larger marketplace. Rovai 
and Downey also urge institutions to align their branding with their specific geography, price, and strategic focus in relation to student needs. For example, in the University of New Hampshire System, Granite State College's (GSC) target audience is primarily working adults who are transfer students from other institutions. In light of the unique needs of this particular audience, the branding on the GSC homepage includes reference to institutional strengths that align with these needs: degree completion, affordability and intentional design of course content for working adults.

\section{Factor \#3: Financial Management}

Financial management refers to an institution's need to effectively manage their online program finances, so that they are able to generate sufficient revenue to cover expenses while achieving any other financial targets. Rovai and Downey (2010) also suggest that institutions must carefully consider the length of time it will take for new programs to become profitable. Since there is no standard formula that details the path to profitability, each institution must consider different factors that influence the financial success of online programs. In most cases, one of the more important requirements for new online programs is sufficient capital to fund the program's staff, infrastructure and marketing expenses. Once revenue for an online program is generated, re-investment becomes a priority to sustain the online program.

Another important consideration when assessing an online program's financial status is understanding current market conditions. When assessing market conditions, the goal is to understand what type of external forces lead to the success or failure of online programs. Essary (2014) suggests that his own university's online programs were impacted by the pricing of competitors, changing student demographics and decreased 
state funding. While Rovai and Downey (2010) do not discuss funding issues, their model does prioritize, "cost leadership strategies based on achieving a lower cost position than the competition, e.g. low-cost tuition and tuition discounting" (p.143).

\section{Factor \#4: Quality Assurance}

Quality assurance refers to an institution's efforts to ensure its programs are of high quality. Historically, colleges and universities have used accreditation as their primary means for quality assurance, but Rovai and Downey (2010) suggest that a quality assurance strategy should also focus on faculty selection and qualifications, faculty professional development, and student support services. An effective quality assurance strategy must also be carried out on a regular basis to help satisfy program goals and student needs. As the level of competition increases to recruit students for online programs, so does the need to elevate the quality of the online programs (Rovai \& Downey, 2010).

Some organizations have used quality assurance as a means to understand how to successfully design online courses and manage online programs. The Quality Matters $(\mathrm{QM})$ rubric in one commonly used method. Quality Matters consists of eight general standards and 43 specific review standards, which are coupled with a peer review of a course that focuses primarily on course design. Another common framework is the Online Learning Consortium's (OLC) Five Pillars of Quality Online Education (Lorenzo \& Moore, 2002). The OLC developed the Quality Scorecard for the Administration of Online Programs to assess the effectiveness of online program administration. This tool helps administrators determine strengths and weaknesses of online programs, and then improve areas that have been identified as deficient by the evaluation tool. The OLC 
evaluation rubric is also used to help identify elements of quality that can be referenced during the accreditation process.

Gómez-Rey, Barbera and Fernández-Navarro (2016) developed their own framework to evaluate the quality of online programming, based in part on the Online Learning Consortium's (OLC) quality scorecard and the Quality Matters rubric. GómezRey, Barbera and Fernández-Navarro’s model includes 11 categories: learning support, social presence, instruction, learning platform, instructor interaction, learner interaction, learning content, course design, learner satisfaction, knowledge acquisition, and ability to transfer. Gómez-Rey, Barbera and Fernández-Navarro (2016) found that while teachers perceive collaborative learning variables as crucial, learners are more concerned with their own learning benefits. Similar to Rovai and Downey’s (2010) online program evaluation model, quality assurance models such as these are focused on learner needs, instructor preparation, curriculum quality and learning technologies.

\section{Factor \#5: Student Retention}

Student retention describes how many students complete a given program. Retention rates among online learners are lower than those for face-to-face classes (Brady, 2001; Wladis, Conway, \& Hachey, 2017). Thus, student retention--that is, students completing the courses and programs that they begin--is a key component for sustaining an online program and measuring the quality of program outcomes. Building on the work of Tinto (1987), Rovai and Downey (2010) focus on two different types of support needed to improve student retention: academic and social support. Social support refers to the need for meaningful peer and student-to-teacher interactions. Academic support is provided by faculty and other support staff. 
Boston, Ice and Gibson (2011) sought to develop a model to predict student retention in the context of online learning. To do so, they analyzed the enrollment and academic achievement data of 20,569 students at the American Public University System (APUS) to identify which factors influence retention in online courses. After analyzing student data, they found that one of the most important variables that could be correlated to retention was the amount of transfer credit possessed by a student. Their findings also indicated that a significant number of students disenrolled after two courses. The authors suggested that this was because many students enrolling in online programs are still exploring their options during the first several courses and need additional social engagement during this period to support future engagement with online classes (Boston, Ice, \& Gibson, 2011).

Factor \#6: Faculty Development

While "faculty development" can refer to a wide variety of activities, in the context of Rovai and Downey's factors, faculty development focuses on the ongoing training faculty need to effectively teach online courses. Poorly prepared faculty can adversely influence online program quality (Rovai \& Downey, 2010). Thus, it is important for online programs to prioritize faculty development. Faculty development programs often include a focus on instructional design, pedagogy, online tools, student support, media development and time management (Cook \& Steinert, 2013). Ideally, faculty development programs encourage faculty to engage in a range of different activities to advance their online teaching skills. According to Rovai and Downey (2010), effective faculty development programs are the exception rather than the norm.

Another important aspect of faculty development is leadership; both in terms of 
developing faculty to be more effective leaders and in terms of an online program receiving support from a committed leader who has the best interests of the institution, faculty and students in mind (Garrison \& Kanuka, 2008; Johnstone, 2005). Several studies seeking to understand important characteristics of successful online programs have identified leadership as an important factor (Garrison \& Kanuka, 2008; Johnstone, 2005) Garrison and Kanuka (2008) state, "Successful leadership of complex organizations in times of change requires more than a charismatic leader and fundraiser" (p.21). Johnstone (2005) asserts that the most important function of a governing board or central leader is the appointment of executive leaders. Leaders who successfully grow online programs or any new institution-wide initiative possess vision and the ability to mobilize other key stakeholders. Additionally, effective leaders must be fully engaged in the process of transformation from beginning to end. They must also be held accountable for the initiative outcomes. Legon and Garrett also document the need for a capable senior administrator who can manage online programs (2017).

Factor \#7: Online Course Design and Pedagogy

Online courses--both in terms of designing them and teaching them--differ from traditional face-to-face courses in many ways (Gaskell \& Hayton, 2015). For instance, an online course requires a significant amount of upfront design work that traditional courses do not. Thus, successful online programs focus on improving online course design and pedagogy by aligning course design with learning objectives and the optimal instructional approach to deliver course content. Because of this difference between how online and face-to-face courses are designed and taught, it is important that online program administrators include the appropriate budget and other resources to ensure 
online programs are designed to achieve the appropriate instructional outcomes.

Consequently, it is important to develop a clear understanding of how to develop online courses in light of student needs and how online programs differ from onsite, residential programs. Rovai and Downey (2010) provide additional requirements and suggest that the primary difference between online and onsite course design is that online faculty should spend less time teaching and more time designing their online programs. Subsidiarity Principle--The Missing Factor

As useful as Rovai and Downey's (2010) seven factors are for evaluating online programs, I posit that they are missing one important factor called the subsidiarity principle. In the context of government, subsidiarity refers to a preference for governance at the most local level consistent with achieving government's stated purposes. While this concept has been used in literature about political governance, King (2013) suggests that the subsidiarity principle should be used to help organize governance structures in postsecondary statewide systems. When describing the ideal form of governance in statewide systems, King (2013) states,

The best level of governance for decisions to be made is where there is the most direct information about the body or bodies affected, with sufficient awareness of the various relevant policies and organizational factors. The logic of subsidiarity is most compelling for complex, multi-tiered organizations and for organizations where the most valuable human resources for carrying out the mission are on the front line, e.g. the faculty. Public universities are manifestations of both these criteria. (p.4,)

Bermann describes the role of subsidiarity in the European and American political system and offers several benefits of shaping governance using this principle: selfdetermination and accountability, political liberty, flexibility, preservation of identities, diversity, respect for internal divisions of component states (pp.340-344, 1994). Since 
this study used a case study approach with constant comparison to analyze date, identifying existing patterns or themes from prior studies--such as subsidiarity--will help narrow the focus of this study and align the research framework with the observed context.

\section{Chapter Summary}

Administrators who work in multicampus institutions must understand how to administer their online programs based on their institution's unique characteristics and other important factors mentioned in this chapter. As administrators learn to manage their online program systems and resources, they typically improve their organization's overall competitiveness in relation to positive outcomes such as student recruitment and retention. When managed with the appropriate mix of business acumen and academic experience, a successful distance education program can help secure an institution's future by generating new revenue and improving access for traditional, nontraditional and underserved students. Because of decreasing residential enrollment and changing student preferences, there is often a level of urgency for institutions who are affiliated with statewide systems to grow their online programming in ways that leverage local partnerships and draw on other successful models. While it might be tempting to adapt a model of management for online programming that is used for face-to-face programs, prior research suggests that successful online programs should be administered using differentiated process, infrastructure, pedagogy, leadership and staff. In the next chapter, I will provide a more detailed explanation of my methodology. 


\section{CHAPTER THREE: METHODS}

The literature focused on how to administer online programs continues to grow; however, there is still very little research focused on how online programs are administered in large-scale, statewide systems. The purpose of this study was to investigate how online programs are administered at institutions affiliated with the University System of New Hampshire. To that end, this chapter explains the methodology that was used to conduct this study. Details about the research design, participant selection, and data collection are described followed by an explanation of the data analysis and verification procedures used to conduct this study.

\section{Research Questions}

The following research questions guided this study:

1. How are online programs administered by institutions affiliated with a public statewide system?

2. Based on the perspective of institutional administrators, what are the advantages and disadvantages of administering online programs in a public statewide system?

3. Do study participants prioritize some features or characteristics of their online program over others?

\section{Research Design}

A single-case exploratory case study (Stake, 2006, 2010) was conducted focused on the four institutions that make up the University System of New Hampshire: The 
University of New Hampshire, Keene State College, Granite State College and Plymouth State University (each institution will be described in more detail in the following section).

This case study followed Yin's (2003) four-stage case study methodology: design the case study, conduct the case study, analyze the case study evidence and develop conclusions, articulate recommendations and implications. Yin's second stage, "conducting the case study," consisted of three phases: prepare for data collection, distribute the questionnaire, and conduct interviews. Each of these phases are described in this chapter. The survey's validity was enhanced by using a constant comparison method to develop "thick data" that helped improve transferability to other contexts and by using purposive sampling and member checking (Guba, 1981).

Yin (2003) identifies six primary sources of evidence during the data collection phase: documentation, archival records, interviews, direct observation, participant observation and physical artifacts. Relying on Yin's assertion that internal validity can be strengthened when using multiple sources of data and different methods (i.e. triangulation), this study sought to integrate data gathered from surveys, interviews, institutional websites when generating themes and reaching conclusions. Accordingly, during data collection, Yin (2003) recommends using multiple sources of data, creating a case study database, and maintaining a chain of evidence. In relation to this study, I gathered data from surveys and interviews and archived my data in an organized and secure manner, using secure, cloud-based storage. To maintain a chain of evidence, I documented how data were gathered, when and where data were collected and how and where data were secured. 
This study relied on an exploratory case study framework to help bound or delimit the unit of analysis (Yin, 2003) and to provide structure when completing data analysis. An exploratory case study was chosen as opposed to other types of case studies because there was very little existing research available about statewide systems to help structure this study using a critical instance or cumulative case study approach. Additionally, it was clear from earlier research that when studying online programs in any context, it is often difficult to find a common vocabulary and widely accepted operational conventions that could be used to define a more detailed research agenda that would facilitate the correlation of program characteristics or outcomes with causes. Furthermore, using an exploratory case study was most appropriate since exploratory case studies are often used when the study's research context is not clearly specified, and the researcher lacks clearly articulated hypotheses. This more open-ended type of case study provides the researcher with more flexibility in how data collection and data analysis are conducted (Mills, Durepos, \& Wiebe, 2010) and is complementary to a Grounded Theory approach to data analysis.

In this study, Yin's four stages (2003) were followed: design the case study, conduct the case study, analyze the case study evidence and develop conclusions, articulate recommendations and implications. Since there was so little prior research focused on the topic of online program management in statewide systems, a Grounded Theory approach was used to accommodate a more flexible and iterative means to identify categories and emerging findings. Because a Grounded Theory approach allows the researcher to gather and analyze simultaneously, using a Grounded Theory approach strengthened the relevance of interview questions since those questions were shaped by 
categories that emerged during the analysis of survey data. Additionally, the Grounded Theory approach allows the researcher to exercise decisions related to theoretical sampling as the study is in progress. In the case of this study, although there were highlevel criteria in place to help determine the selection of interview participants, a final decision about who would be asked to participate in the interview was made later in the study as more data were gathered and more informed opinions about who would provide the most helpful data were formed.

At a lower-level of analysis, a constant comparison method was used to explore the study's research questions and to reduce data gathered during surveys and interviews into concepts or categories that were used to articulate findings about the relationship between concepts (Glaser, 1998). Consequently, researchers typically assess the validity of a Grounded Theory study by judging the fit, relevance, workability, and modifiability of Grounded Theory study findings in relation to the data set (Glaser \& Strauss 1967, Glaser 1978, Glaser 1998).

Role of the Researcher

I currently work at the University of New Hampshire as the Director of Professional Development \& Training. I have worked in higher education as an instructional designer and a director of continuing education for almost 10 years. Prior to working in higher education, I was an e-learning development and technical trainer at both Siemens and Netflix. At both Netflix and Siemens, I frequently taught others in face-to-face and online contexts. In total, I have 20 years of experience teaching others how to use technology and designing online courses. While working at Oregon State University and the University of New Hampshire, each institution was affiliated with a 
statewide system; although the Oregon University System was disbanded in June 2015. Although I was familiar with other institutions in each statewide system, collaboration between system institutions was infrequent.

Positionality and Researcher Bias

After designing and teaching online courses for more than 20 years, I have developed biases about online pedagogy and the management of online programs in the context of private industry and higher education. Merriam, Johnson-Bailey, Lee, Kee, and Muhamad (2001) suggest that a richer understanding of a phenomenon can be gained by incorporating both insider and outsider positions. However, the same authors assert that one's positionality can change even during the same conversation. This fluidity is due to the fact that not only is the surrounding culture complex and changing, but so is the researcher's identity (Merriam, Johnson-Bailey, Lee, Kee, \& Muhamad, 2011). In my situation, I was an insider in respect to the USNH system and more specifically to UNH. On the other hand, I was an outsider when speaking to administrators at other institutions and also an outsider when interviewing high-level administrators such as presidents and provosts.

I also brought numerous biases to this study. First, I have come to believe that it is essential to manage online programs using staff, infrastructure, and other resources that are differentiated from existing face-to-face resources. I also developed a belief that online programming is managed most effectively by an administrator who has extensive experience with adult learning theory, instructional design, and online program management. Since online learning often relies on emerging technologies, I have also felt that effective online course design requires a strong fluency with technology. In relation 
to the advantages or disadvantages of managing online programs in statewide systems, I did not have an opinion about this issue before beginning this study.

Because I relied on a qualitative approach framework when designing this study, it is likely that I may not have correctly identified the full intent of some survey or interview responses. Since this study did not rely on discourse analysis or other linguistic techniques to analyze deeper layers of meaning in participant responses, it is possible that any referential interview meaning encoded in tone may not have been interpreted correctly. Similarly, some survey participants may have meant something other than what the researcher assumed was meant during data analysis. In order to minimize my biases and prejudices, I journaled while coding my survey and interview results. This allowed me to record my thought process and any opinions or biases that might have emerged during coding. As much as possible, I tried to bracket myself out of the study by minimizing my personal opinions as I developed the survey and interview questions and then analyzed data. Bracketing, as Creswell (2013) explains, does not take the researcher completely out of the study, but it does serve to identify personal experiences with the phenomenon and to partly set them aside so that the researcher can focus on the experiences of the participants in the study. (Phenomenological Research, Defining Features of Phenomenology, para. 5)

\section{Context of Study}

This study focused on the four universities that make up the University of New Hampshire system: The University of New Hampshire, Granite State College, Plymouth State University and Keene State College. Each institution in the statewide system has a different location and several have multiple campuses as illustrated in Table 2. 
Table 2. The University System of New Hampshire Institutions (2016)

\begin{tabular}{|l|c|c|c|c|}
\hline Name & $\begin{array}{c}\text { University of } \\
\text { New } \\
\text { Hampshire }\end{array}$ & $\begin{array}{c}\text { Granite } \\
\text { State College }\end{array}$ & $\begin{array}{c}\text { Keene State } \\
\text { College }\end{array}$ & $\begin{array}{c}\text { Plymouth } \\
\text { State } \\
\text { University }\end{array}$ \\
\hline Location & Durham, NH & Concord, NH & Keene, NH & Plymouth, \\
\hline Campuses & 1866 & 1972 & 1909 & 1871 \\
\hline Founded & 12,857 & 1,854 & 4,165 & 4,124 \\
\hline Undergraduate & state; $\$ 27,130$ & state; $\$ 9,810$ & state; $\$ 20,432$ & \\
\hline Enrollment & out of state & out of state & out of state & \\
\hline Cost of Undergraduate & $\$ 18,499$ in & $\$ 7,257$ in & $\$ 13,228$ in & $\$ 13,128$ in \\
Enrollment (including & state; $\$ 33,879$ & state; $\$ 8,025$ & state; $\$ 21,408$ & state; $\$ 21,208$ \\
fees) & out of state & out of state & out of state & out of state \\
\hline Graduate Enrollment & 2,331 & 287 & 117 & 925 \\
\hline Cost of Graduate & $\$ 13,840$ in & $\$ 9,216$ in & $\$ 11,468$ in & variable \\
\hline
\end{tabular}




\begin{tabular}{|l|c|c|c|c|}
\hline Enrollment & & & & \\
\hline Total Online & $4,500^{*}$ & 1,648 & 2,575 & 285 \\
Enrollment & & & & \\
Graduate) & & & & \\
\hline Percent of Total & $30 \%$ & $77 \%$ & $2 \%$ & $0 \%$ \\
Enrollment that is & & & & \\
Online & & & & \\
\hline Total Number of & 125 & 95 & & \\
Online Classes & & & & \\
(Annual) & & & & \\
\hline
\end{tabular}

*estimate based on data gathered from institutional websites and discussions with staff University of New Hampshire

The University of New Hampshire (UNH) is the system's flagship university and is located in Durham, New Hampshire. UNH also has additional campuses in Manchester and Concord, NH. Over 15,000 students--based in Durham, Concord and Manchester-attend UNH. The number of online students at UNH has grown 8-10\% over the last three years. UNH is the largest university in the state of New Hampshire and is one of only nine land, sea, and space grant institutions in the nation. James Dean is the current president of UNH. When data were gathered for this study, Mark Huddleston was the UNH president. 
Online programs are administered by four UNH Online employees in a unit under the larger UNH Academic Technology organization. UNH Online is managed by an Associate Director who reports to the Academic Technology Vice President. UNH Online depends on a group of instructional designers, LMS administrators and other back-office staff within the larger Academic Technology organization. These UNH Academic Technology staff support UNH online with infrastructure, marketing and other services. UNH Online receives funding from UNH's central administration to cover staffing, marketing and other expenses as opposed to revenue sharing with academic departments.

As of Fall 2018, UNH's resident tuition was $\$ 650$ for an undergraduate credit and $\$ 770$ for a graduate credit. Nonresident tuition was $\$ 1270$ for an undergraduate credit and $\$ 1270$ for a graduate credit. UNH Online charges the following fees for students: 1-4 credits $\$ 26.00,5-8$ credits, $\$ 51.25,9-16$ credits $\$ 102.50$.

A total of 2,015 undergraduate students were enrolled in 46 different online classes during the Fall 2018 term. During the same period, 830 graduate students were enrolled in 104 different online classes.

\section{Granite State College}

Granite State College (GSC) is the newest institution in the system. As of 2017, 2,141 students were enrolled at GSC. Granite State College offers courses at nine different New Hampshire locations: Claremont, Conway, Lebanon, Littleton, Nashua, Manchester, Portsmouth, and Rochester. Granite State College has numerous partnerships with the community college system in New Hampshire (which is not affiliated with the University System of New Hampshire) and maintains a robust online program. 
According to the Granite State College website, the mission of the college is to "expand access to public higher education to adults of all ages throughout the state of New Hampshire and beyond." Overall 65\% of the undergraduate courses are completed online and $95 \%$ of the graduate courses are completed online.

Approximately 13\% of GSC's students are veterans and service members. GSC also has a high percentage of transfer students; because GSC accepts up to 90 transfer credits towards a Bachelor's degree and 44 credits toward an Associate's degree, $87 \%$ of their students are transfers.

Online programs at GSC are administered by the Academic Affairs office. A Director of Educational Technology and a Director of Faculty Development manage online programming with the support of instructional designers and additional staff. As of 2017, Granite State College enrolled 1,648 online students. The number of online students at GSC has grown approximately $12 \%$ annually over the last three years. Mark Rubinstein is GSC's current president.

As of Fall 2018, GSC's resident tuition was $\$ 314$ for an undergraduate credit and $\$ 538$ for a graduate credit. Nonresident tuition was $\$ 355$ for an undergraduate credit and $\$ 575$ for a graduate credit.

Plymouth State University

Plymouth State University (PSU), formerly Plymouth State College, is a coeducational, residential university located in Plymouth, NH. Donald Birx is PSU's current president. Plymouth State University has approximately 4,200 undergraduate students and 2,100 graduate students. PSU offers 52 undergraduate majors in education, 
business, humanities, arts, natural and social sciences and other programs. Currently, PSU does not offer any online undergraduate or graduate programs.

\section{$\underline{\text { Keene State College }}$}

Keene State College was founded in 1909 and has a total undergraduate enrollment of 4,165. Keene State College is located in Keene, New Hampshire. Keene State College offers more than 40 areas of undergraduate study in the liberal arts, social sciences, sciences, and professional programs, as well as select graduate degrees. Melinda Treadwell is the current president of Keene State College.

Recently, Keene State College launched a fully online Master's degree in Safety and Occupational Health Applied Sciences. This is currently the only online degree offered by Keene State College. Keene State College charges $\$ 530$ per credit for New Hampshire residents and $\$ 580$ per credit for out-of-state students. Since Keene State College does not employ instructional designers or staff dedicated to online programming, their new online Master's degree was developed with the assistance of Granite State College.

\section{Data Collection}

This study involved two phases of data collection. I will describe the sample of the study and each phase of the study in more detail below.

\section{Study Sample}

To answer the research questions, this study focused on a group of high-level administrators working at the four institutions mentioned above. Overall, 22 high-level administrators were purposefully identified to participate in the survey; 18 ended up completing the survey for an $81.8 \%$ response rate (see Table 3 ). These administrators 
were selected based on their affiliation with their institution's online programs and based on their initial willingness to participate in the study. In most cases, participants were directly responsible for the management of their institution's online degree programs or they were in roles such as president, provost or associate vice provost, and indirectly responsible for online degree programs as an executive leader at their institution. After the surveys were completed, interviews were completed with six high-level administrators from one of the USNH institutions or the USNH system office (see Table 4). Interview candidates were selected based on the nature of their survey responses, their level of experience managing online programs and their level of authority to influence strategic decision making at their institution or within the statewide system.

Table 3. Online Survey Participants

\begin{tabular}{|l|l|l|l|l|}
\hline University of & Keene State & Plymouth & Granite State & USNH System \\
Hampshire & College & State & College & Office \\
\hline President did & President & President & President & Provost did not \\
\hline Provost & Provost & Provost & Provost & Participate \\
& & & & Associate Vice \\
Chancellor of \\
\end{tabular}




\begin{tabular}{|l|l|l|l|l|}
\hline & & & & Initiatives \\
\hline Director & Director & Director & Director & Director of \\
Technology & Academic & Academic & Academic & Shared \\
Director of & & Technology & Technology & Services \\
Online & & & Director of & Vice \\
Programs & & Online & Chancellor for \\
& & & Programs & Financial \\
\hline CIO & CIO & CIO & Affairs and & Treasurer \\
\hline
\end{tabular}


Table 4. Interview Participants

\begin{tabular}{|l|l|}
\hline Role & Institution \\
\hline President & Granite State University \\
\hline Associate Vice Chancellor for Partnerships & University System of New \\
and Shared Services Initiative & Hampshire \\
\hline 2 Deans & University of New Hampshire \\
\hline Associate Director & UNH Online, University of New \\
& Hampshire \\
\hline Associate Director & UNH, Academic Technology \\
\hline
\end{tabular}

Phase One: Survey

The researcher created the survey based on the work of Rovai (2003) and Rovai and Downey (2010). Table 4 lists a few examples of how survey questions were constructed and how they aligned with the research questions, Rovai's (2003) suggested interview questions, and the theoretical framework used by Rovai and Downey (2010). While Rovai (2003) provided some example questions for most of his online program evaluation factors, this study adapted his suggested questions since Rovai's study was one of a few that included interview questions and drew on a robust theoretical framework to create these questions. For example, to assess the marketing factor, Rovai (2003) encouraged institutions to assess student satisfaction as a means to understand the 
effectiveness of marketing efforts. This study focused more narrowly on certain aspects of marketing such as the financial support allocated for marketing campaigns, as opposed to student satisfaction, since the participants in this study were able to more accurately speak to their unit's level of financial support than issues related student perception. As stated above, Rovai and Downey (2010) suggest that funding for marketing activity budget is the most often overlooked aspect of entry into the online market. They also assert that without appropriate levels of funding, an online program will often struggle to succeed.

Table 5. Survey Question Alignment

\begin{tabular}{|l|l|l|l|}
\hline Survey Questions & \multicolumn{1}{|c|}{$\begin{array}{c}\text { Rovai (2003) } \\
\text { Survey Questions }\end{array}$} & $\begin{array}{c}\text { Theoretical } \\
\text { Framework }\end{array}$ & \multicolumn{1}{c|}{$\begin{array}{l}\text { Research } \\
\text { Questions }\end{array}$} \\
\hline is strategy in & & & Factor \#1: Planning \\
terms of & & & How are online \\
administering & & & administered by \\
your online & & & affiliated with a \\
program & & & public \\
successfully? & & & statewide \\
& & & system? \\
\hline
\end{tabular}




\begin{tabular}{|c|c|c|c|}
\hline $\begin{array}{l}\text { Does your } \\
\text { online program } \\
\text { receive at least } \\
10 \% \text { of its gross } \\
\text { revenue to be } \\
\text { used for } \\
\text { marketing? }\end{array}$ & $\begin{array}{l}\text { Are there } \\
\text { characteristics } \\
\text { that distinguish } \\
\text { satisfied and } \\
\text { dissatisfied } \\
\text { students? } \\
\text { Does the school } \\
\text { apply this } \\
\text { information to } \\
\text { admission and } \\
\text { recruiting } \\
\text { policies and } \\
\text { decisions? }\end{array}$ & $\begin{array}{l}\text { Factor \#2: } \\
\text { Marketing }\end{array}$ & $\begin{array}{l}\text { - How are online } \\
\text { programs } \\
\text { administered by } \\
\text { institutions } \\
\text { affiliated with a } \\
\text { public } \\
\text { statewide } \\
\text { system? }\end{array}$ \\
\hline $\begin{array}{l}\text { Is your online } \\
\text { program } \\
\text { sufficiently } \\
\text { funded? If not, } \\
\text { why? }\end{array}$ & $\begin{array}{l}\text { What are the } \\
\text { effects of the } \\
\text { program on } \\
\text { graduates? } \\
\text { As a result of } \\
\text { completing the } \\
\text { program did } \\
\text { they receive }\end{array}$ & $\begin{array}{l}\text { Factor \#3: Financial } \\
\text { Management }\end{array}$ & $\begin{array}{l}\text { - How are online } \\
\text { programs } \\
\text { administered by } \\
\text { institutions } \\
\text { affiliated with a } \\
\text { public } \\
\text { statewide } \\
\text { system? }\end{array}$ \\
\hline
\end{tabular}




\begin{tabular}{|c|c|c|c|}
\hline & $\begin{array}{l}\text { increased pay, } \\
\text { acquired } \\
\text { professional } \\
\text { certifications, } \\
\text { received } \\
\text { promotions, } \\
\text { etc.? } \\
\text { Did the } \\
\text { program have } \\
\text { any unintended } \\
\text { impacts? }\end{array}$ & & $\begin{array}{l}\text { What are the } \\
\text { advantages and } \\
\text { disadvantages } \\
\text { of } \\
\text { administering } \\
\text { online } \\
\text { programs in a } \\
\text { public } \\
\text { statewide } \\
\text { system? }\end{array}$ \\
\hline $\begin{array}{l}\text { List your three } \\
\text { top measures of } \\
\text { success in terms } \\
\text { of administering } \\
\text { your online } \\
\text { programs. }\end{array}$ & $\begin{array}{l}\text { What } \\
\text { evaluation and } \\
\text { methods does } \\
\text { the school use } \\
\text { to measure } \\
\text { student } \\
\text { learning? } \\
\text { How does the } \\
\text { program ensure }\end{array}$ & $\begin{array}{l}\text { Factor \#4: Quality } \\
\text { Assurance }\end{array}$ & $\begin{array}{l}\text { - How are online } \\
\text { programs } \\
\text { administered by } \\
\text { institutions } \\
\text { affiliated with a } \\
\text { public } \\
\text { statewide } \\
\text { system? } \\
\text { What are the } \\
\text { advantages and }\end{array}$ \\
\hline
\end{tabular}




\begin{tabular}{|c|c|c|c|}
\hline & $\begin{array}{l}\text { the integrity of } \\
\text { student work } \\
\text { and the } \\
\text { credibility of } \\
\text { the degrees and } \\
\text { credits } \\
\text { awarded? }\end{array}$ & & $\begin{array}{l}\text { disadvantages } \\
\text { of } \\
\text { administering } \\
\text { online } \\
\text { programs in a } \\
\text { public } \\
\text { statewide } \\
\text { system? }\end{array}$ \\
\hline $\begin{array}{l}\text { - Do you assess } \\
\text { student } \\
\text { satisfaction } \\
\text { regularly? }\end{array}$ & $\begin{array}{l}\text { How well are } \\
\text { students } \\
\text { satisfied with } \\
\text { the program? } \\
\text { How does } \\
\text { student } \\
\text { satisfaction } \\
\text { compare with } \\
\text { that of courses } \\
\text { offered on- } \\
\text { campus? } \\
\text { What is the } \\
\text { level of }\end{array}$ & $\begin{array}{l}\text { Factor \#5: Student } \\
\text { Retention }\end{array}$ & $\begin{array}{l}\text { - How are online } \\
\text { programs } \\
\text { administered by } \\
\text { institutions } \\
\text { affiliated with a } \\
\text { public } \\
\text { statewide } \\
\text { system? } \\
\text { What are the } \\
\text { advantages and } \\
\text { disadvantages } \\
\text { of }\end{array}$ \\
\hline
\end{tabular}




\begin{tabular}{|c|c|c|c|}
\hline & $\begin{array}{l}\text { interaction } \\
\text { between } \\
\text { students and } \\
\text { instructors and } \\
\text { among } \\
\text { students? }\end{array}$ & & $\begin{array}{l}\text { online } \\
\text { programs in a } \\
\text { public } \\
\text { statewide } \\
\text { system? }\end{array}$ \\
\hline $\begin{array}{l}\text { Does your } \\
\text { institution have } \\
\text { sufficient } \\
\text { faculty support? }\end{array}$ & $\begin{array}{l}\text { Are instructors } \\
\text { qualified to } \\
\text { teach the } \\
\text { content of their } \\
\text { courses? } \\
\text { Are instructors } \\
\text { qualified to } \\
\text { teach online? } \\
\text { What is the } \\
\text { extent to which } \\
\text { instructors } \\
\text { control the } \\
\text { content of their } \\
\text { courses? }\end{array}$ & $\begin{array}{l}\text { Factor \#6: Faculty } \\
\text { Development }\end{array}$ & $\begin{array}{l}\text { - How are online } \\
\text { programs } \\
\text { administered by } \\
\text { institutions } \\
\text { affiliated with a } \\
\text { public } \\
\text { statewide } \\
\text { system? } \\
\text { What are the } \\
\text { advantages and } \\
\text { disadvantages } \\
\text { of } \\
\text { administering } \\
\text { online }\end{array}$ \\
\hline
\end{tabular}




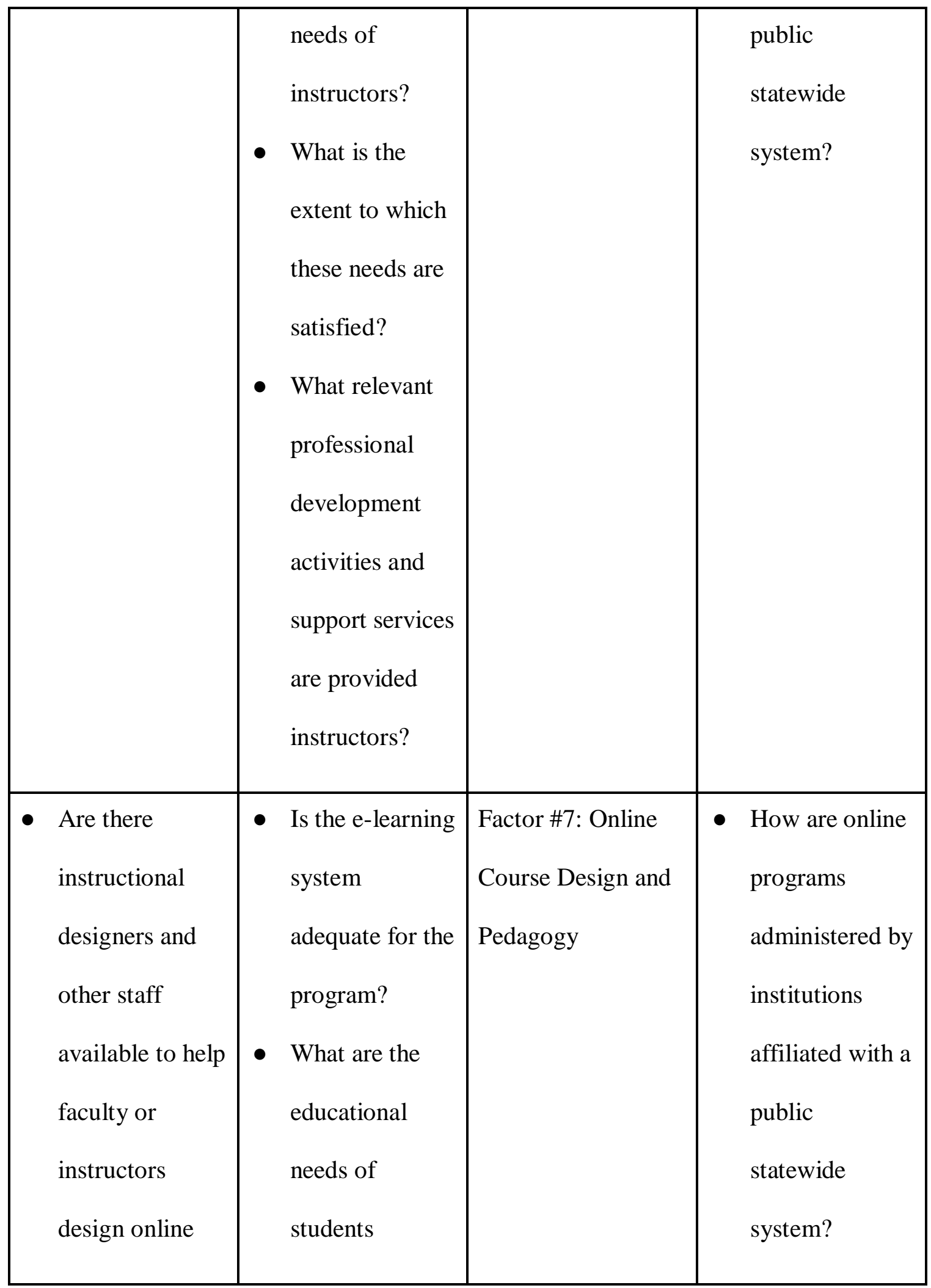




\begin{tabular}{|c|c|c|}
\hline programming? & $\begin{array}{l}\text { targeted by the } \\
\text { program? } \\
\text { - Are program } \\
\text { and course } \\
\text { objectives } \\
\text { sufficiently } \\
\text { responsive to } \\
\text { these needs? } \\
\text { Are course } \\
\text { materials } \\
\text { current? } \\
\text { How efficient is } \\
\text { the course } \\
\text { development }\end{array}$ & $\begin{array}{l}\text { What are the } \\
\text { advantages and } \\
\text { disadvantages } \\
\text { of } \\
\text { administering } \\
\text { online } \\
\text { programs in a } \\
\text { public } \\
\text { statewide } \\
\text { system? }\end{array}$ \\
\hline
\end{tabular}

The survey was conducted via the Internet using Qualtrics. The first email requesting participation in the survey was sent out in late February 2018 (see Appendix for supporting documents). Because the administrators engaged in this study were very busy, they were given several months to complete the survey. After two weeks, I sent reminders to encourage participants who had not completed the survey to do so see Appendix A). I sent out additional reminders as needed. To help improve survey 
completion rates, I attempted to interview any individuals in person who were asked to complete the online survey but were unable to do so. Two of the 18 survey participants were asked the survey questions in person. In some cases, it took more than seven follow up emails and multiple calls over three to four months for a few survey respondents to complete the survey.

The online survey consisted of 20 questions (see Table 6). Survey questions were closed or semi-closed with some opportunity for respondents to provide clarification or additional commentary using text fields at the ends of the survey. The survey questions were based on the work of Rovai (2003) and Rovai and Downey (2010).

\section{Table 6. Survey Questions}

1. What is your name? What is your role at your institution? What institution do you work at? How long have you worked with online programs?

2. How important is strategy in terms of administering your online program successfully? Does your institution have a strategy for administering online programs? If so, are you familiar with it? (PLANNING)

3. Does your statewide system have a strategy for administering online programs? (PLANNING)

4. Are there policies at your institution that influence how online programs are administered? Are those policies supporting or hindering the growth and success of your online programs? (PLANNING)

5. What improvements could be made across your statewide system to help individual institutions in the system improve collaboration? (PLANNING) 
6. Do you think there are potential opportunities to collaboratively administer online programs within your statewide system? Do you think the administration of online programs should be more centralized? If so, how? (PLANNING)

7. Does your institution have sufficient faculty support? (FACULTY DEVELOPMENT)

8. Do faculty receive ongoing training to help them improve the quality of their online teaching? (FACULTY DEVELOPMENT)

9. List your three top measures of success in terms of administering your online programs. (QUALITY ASSURANCE)

10. Does your institution regularly measure quality indicators or online program outcomes? (QUALITY ASSURANCE)

11. Is your online program sufficiently funded? If not, why? (FINANCIAL

\section{MANAGEMENT)}

12. Do faculty receive sufficient financial support for their time spent teaching online courses? (FINANCIAL MANAGEMENT)

13. Do you have the appropriate funding to reinvest in your online program?

14. Do you assess student satisfaction regularly? If so, do you have goals or targets for this measure? (STUDENT RETENTION)

15. Are students able to provide ongoing input about their experience and are there resources to facilitate quick intervention when support is requested? (STUDENT RETENTION) 
16. Are there instructional designers and other staff available to help faculty or instructors design online programming? (ONLINE COURSE DESIGN)

17. Does your institution have the appropriate technical infrastructure and media development resources to effectively design online courses? (ONLINE COURSE DESIGN)

18. Rank the following factors (list Rovai and Downey's 7 factors and the subsidiarity principle) based on which factors are most important to successfully administer an online program.

19. Are there additional factors that you would add to this list?

20. What are the advantages and disadvantages of administering online programs in a public statewide system?

21. Additional comments?

Data analysis was conducted manually by first downloading data from Qualtrics and then transferring that content to Excel spreadsheets. This transfer of data to Excel facilitated the organization, coding and collation of survey results since data downloaded directly from the Qualtrics were not well organized. Porting data from Qualtrics to Excel allowed the researcher to separate each survey question into a separate tab, which simplified access to the data and allowed for improved toggling between questions as constant comparison analysis occurred (see Figure 1).

Each survey question had its own sheet where the question was listed at the top, with each response under it. Column headings were then added named initial code, 
category, final categories, and memos (see Figure 1). After the survey questions were formatted and moved to the appropriate sections, data were examined for outliers or missing responses. Additionally, the researcher denaturalized the data (Halcomb \& Davidson, 2006) by correcting spelling errors and punctuation that deterred from the respondent's intended meaning. After a thorough examination, data were found to be normally distributed and missing data were minimal. However, two respondents answered only 18 questions as opposed to all 20 of the questions.

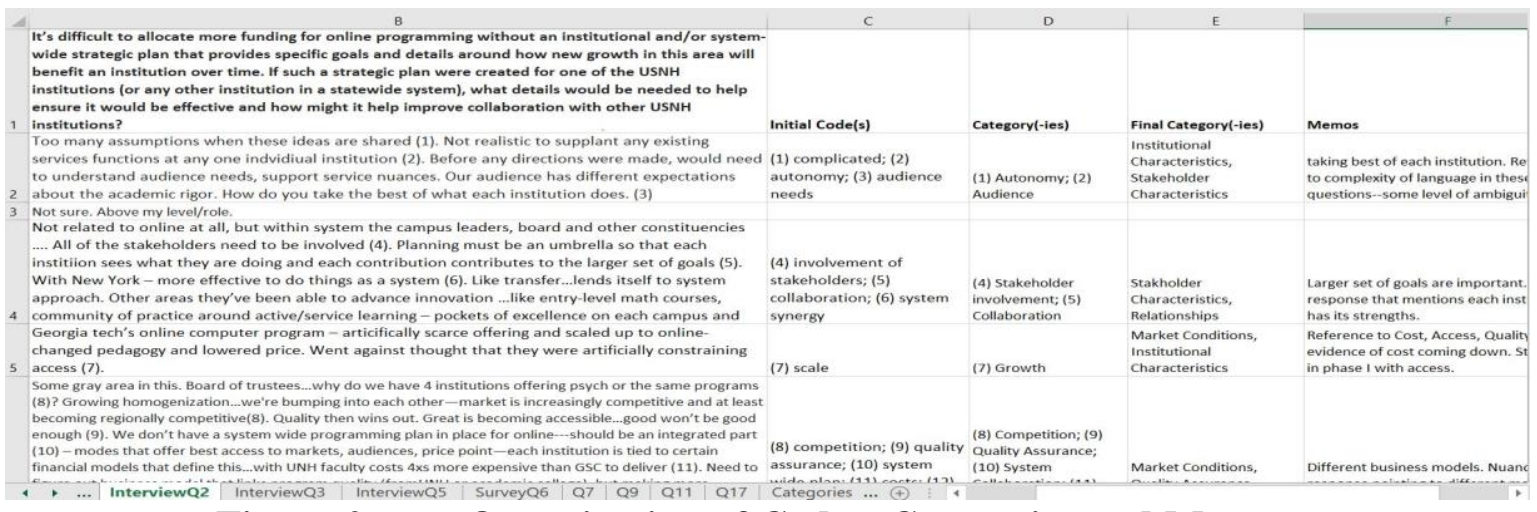

Figure 2. Organization of Codes, Categories and Memos

Phase Two: Follow-up Interviews

Stake (1995) recommends that qualitative case study researchers prepare questions for interviews and then let the conversation flow as the interviewee explores different ideas and offers input about initial questions. Following this recommendation, I wrote five initial interview questions (see Table 6) based on themes that emerged from analyzing the survey responses. For example, one survey respondent mentioned that online programs were developed based on high demand majors. This statement led to a follow-up interview question about how demand for programs is assessed. More specifically, is demand for new programming determined by student or faculty interest? 
In the same survey question, a different respondent commented on the "tactical onboarding and management approach" used to develop new online programs. This statement, in conjunction with the aforementioned comment about demand, resulted in another follow-up interview question seeking to understand whether "tactical onboarding" includes a qualification step such as market analysis.

After analyzing the survey results, the researcher conducted follow up interviews with six additional participants. Five interviews were conducted via phone and one in person. Results from individual respondents were anonymized by replacing the interviewee's name with a number in the Excel spreadsheet. During each interview, the researcher typed each sentence almost word for word. The researcher also took notes or memos immediately after each interview to help generate follow up questions. According to Glaser (2017), taking notes during interviews and while coding data can help researchers focus without being overwhelmed by descriptive detail. Since study participants were in most cases high-level administrators at each institution who were discussing politically-charged topics, the researcher chose to avoid recording conversations to help put interviewees at ease. Each interviewee was also assured before, during and after the interview that their responses would be anonymous.

\section{Table 7. $\quad$ Interview Questions}

\begin{tabular}{|l|l|}
\hline Sample Interview Question & Research Question \\
\hline This study draws on eight principles of online program & How are online \\
administration (King, 2013; Rovai \& Downey, 2010) to help & $\begin{array}{l}\text { programs administered } \\
\text { by institutions affiliated }\end{array}$ \\
\hline
\end{tabular}




\begin{tabular}{|c|c|}
\hline $\begin{array}{l}\text { university systems are administered. After reviewing how } \\
\text { this study's survey respondents ranked these eight principles, } \\
\text { do you agree with these rankings? Why or why not? Which } \\
\text { three factors do you feel are most important in the context of } \\
\text { a statewide system like USNH where enrollment growth and } \\
\text { reduction of expenses are top priorities? }\end{array}$ & $\begin{array}{l}\text { with a public statewide } \\
\text { system? }\end{array}$ \\
\hline $\begin{array}{l}\text { Based on this study's survey responses, the lowest ranking } \\
\text { factors were marketing, financial management and local } \\
\text { control of decision making. Since marketing is such an } \\
\text { essential factor in terms of student recruitment, why do you } \\
\text { think it was in the bottom three or eight factors? }\end{array}$ & $\begin{array}{l}\text { How are online } \\
\text { programs administered } \\
\text { by institutions affiliated } \\
\text { with a public statewide } \\
\text { system? }\end{array}$ \\
\hline $\begin{array}{l}\text { How important is it to have faculty support at your institution } \\
\text { for the administration of your online programs? }\end{array}$ & $\begin{array}{l}\text { How are online } \\
\text { programs administered } \\
\text { by institutions affiliated } \\
\text { with a public statewide } \\
\text { system? }\end{array}$ \\
\hline $\begin{array}{l}\text { At this point, UNH focuses only on graduate-level online } \\
\text { programs. If UNH were to begin offering undergraduate } \\
\text { online programs, what do you think the potential would be } \\
\text { for enrollment growth and what obstacles would need to be }\end{array}$ & $\begin{array}{l}\text { What are the } \\
\text { advantages and } \\
\text { disadvantages of } \\
\text { administering online }\end{array}$ \\
\hline
\end{tabular}




\begin{tabular}{|l|l|}
\hline $\begin{array}{l}\text { overcome? How could collaboration with other USNH } \\
\text { institutions help with this endeavor? }\end{array}$ & programs in a public \\
\hline In many responses, Granite State College was mentioned as a & What are the \\
potential resource or partner for other USNH institutions who & advantages and \\
desire to grow their online programs. How might one & disadvantages of \\
institution in the larger statewide system benefit other & administering online \\
institutions based on that institution's lower cost structure & programs in a public \\
and historical success in this area? & statewide system? \\
\hline Is there anything else you'd like to add? & N/A \\
\hline
\end{tabular}

According to Yin (1981), it is reasonable to assume that a case study will include various levels of questions for different interviewees. Some questions focused on the individual case, some across the entire study, and other questions sought to draw out potential recommendations or conclusions from the interviewees. Drawing on Yin's logic, several interview questions were created as survey data were analyzed and core categories emerged.

\section{Data Analysis}

Fraenkel, Wallen and Hyun (1993) suggested that qualitative researchers "are especially interested in how things occur and particularly in the perspectives of the subjects of a study" (p. 531). Creswell (2013) encouraged researchers to think of data collection, data analysis, and report writing as integrated tasks and suggested that they 
often occur simultaneously. Following Creswell's suggestion and Maguire's example (2007), I combined data collection with my data analysis tasks. As data were gathered, they were analyzed using a constant comparison approach by identifying codes and grouping repeating instances with the same code. In order to analyze data using this method, notes from surveys and interviews were read and coded. Finally, consistencies and discrepancies across coded interviews were considered in light of the identified categories and emerging themes.

$\underline{\text { Phase One Data Analysis - Surveys }}$

The constant comparison technique involves connecting themes and categories with gathered data. Saldaña (2015) describes a code as follows, "a code in qualitative inquiry is most often a word or short phrase that symbolically assigns a summative, salient, essence-capturing, and/or evocative at tribute for a portion of language-based or visual data." (p.3). To help identify and refine categories in my data, I relied on Glaser's (1978) six C's (causes, contexts, contingencies, consequences, covariances and conditions), which helps the researcher focus on the relationship between ideas found in the data and the consequences of decisions or behaviors made in relation to these ideas (Saldaña, 2015).

Stake (1995) posits that "the search for meaning is often a search for patterns, for consistency, for consistency within certain conditions" (p.78). Subsequently, the coding process is cyclical and requires the researcher to pass the data through multiple cycles so that concepts, categories and themes can be identified (Saldaña, 2015). To help structure the initial coding process, I used a pre-coding process to help identify those portions of the surveys and interviews that seemed more important than others. In this study, pre- 
coding involved bolding significant quotes or passages as the participant responses were moved to the appropriate section of the Excel document before or while concepts were identified. This process typically took place as data were being denaturalized. See Figure 2 for an example of how select passages from the survey responses were bolded to show increased significance.

\section{Please describe the strategy used by your institution to administer online}

1 programs.

Our UNH Online team maintains operational and other documents that guide our daily work (1). As an institution, we are in the process of defining our online

2 strategy. (2)

Our focus is on Graduate Online Programs in our key areas of strength (3) and undergraduate courses that students take during the summers and winter break.

3 Hybrid courses are also very important now and increasingly so in the future.

UNH strives to offer online programs across several undergraduate and graduate disciplines. The distance offerings are intended to follow the same rigor, scheduling, and quality as on-campus versions (4). This allows students to take advantage of flexibility while maintaining manageable class sizes. (5) '

Figure 3. Pre-coding with Bolded Text

\section{Open Coding}

Survey data were coded and analyzed using an open coding approach (Glaser, 2017) with the goal of identifying a list of concepts that could later be used to help identify categories (see Figure 3). Grbich suggests that this process of applying and reapplying is important because it "permits the data to be segregated, grouped, regrouped and relinked to consolidate meaning and explanation" (2007, p.21). Although the goal of Grounded Theory studies is to reach theoretical saturation and develop a theory that is 
grounded in gathered data, many Grounded Theory studies achieve neither outcome (Aldiabat \& Navenec, 2018). Although this study made significant progress towards data saturation, the theoretical coding phase was not reached, and a theory did not emerge from gathered data. However, numerous categories were identified as the constant comparison method was used to analyze data, which informed the articulation of three findings.

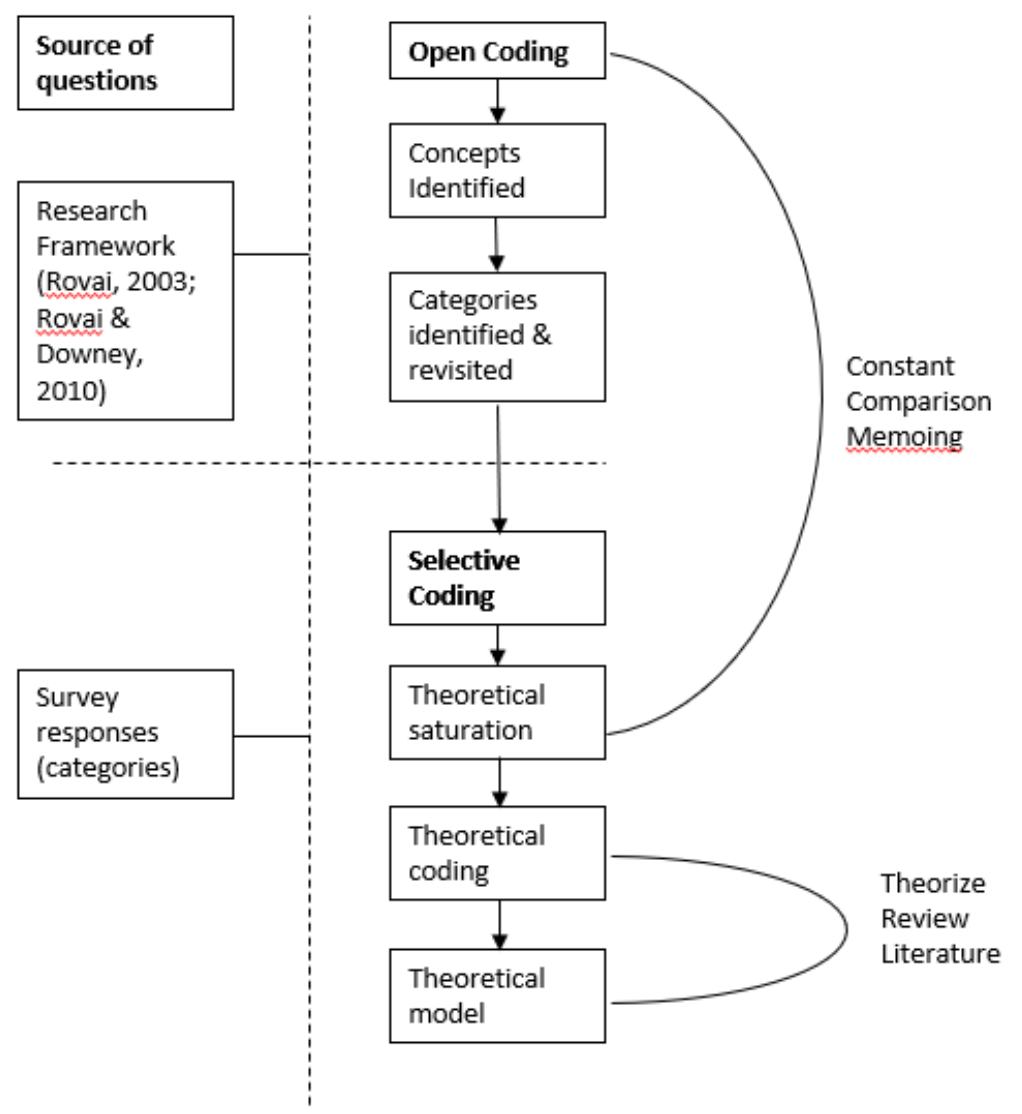

Figure 4. Glaser's Coding Process

Glaser (2017) refers to the initial ideas that are identified by the researcher during open coding as "concepts" or "incidents." As new concepts are identified, they are compared with existing concepts. As this process progressed, patterns emerged in the data, which resulted in the identification of categories and then themes. A constant 
comparison approach typically helps researchers identify patterns that can be compared with the emerging code list and categories. This method of coding and seeking out recurring patterns represents the core process for constant comparison (Glaser, 2017). Yin (1981) refers to this process of comparing newly gathered data with existing patterns or themes, "pattern-matching." As I reviewed survey data, field notes and institutional websites, repeated ideas or themes became apparent (Glaser, 2017; Saldaña, 2015). As more data were collected and reviewed, codes were grouped under categories and a master list of themes was generated using Excel so that future coding could draw on identified themes with the intent of validating or adding to that list as additional analysis occurred.

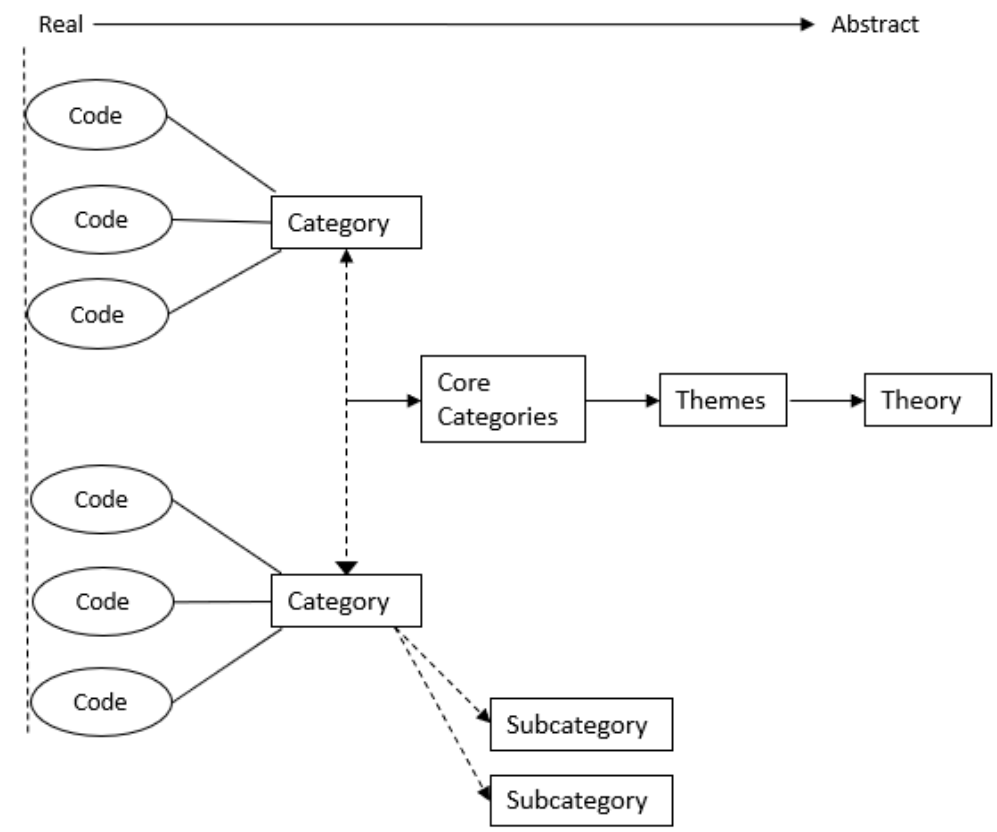

Figure 5. Identifying Themes \& Theories (Glaser, 2017) 
$\underline{\text { Identifying Categories }}$

In several cases, a single survey response included reference to multiple categories. For example, categories such as "policies" or "complexity" were linked to multiple core categories such as "system characteristics" and "governance." To help understand the interrelationship of categories and the factors that influence them, Glaser (2015) refers to the six C's: causes, contexts, contingencies, consequences, covariances, and conditions. Glaser encourages researchers to use the six C's as a filter that can be used to conceptualize relationships between ideas, categories and core categories. Figure five illustrates how one category in this study, "program cannibalization" was conceptualized in relation to Glaser's six C's.

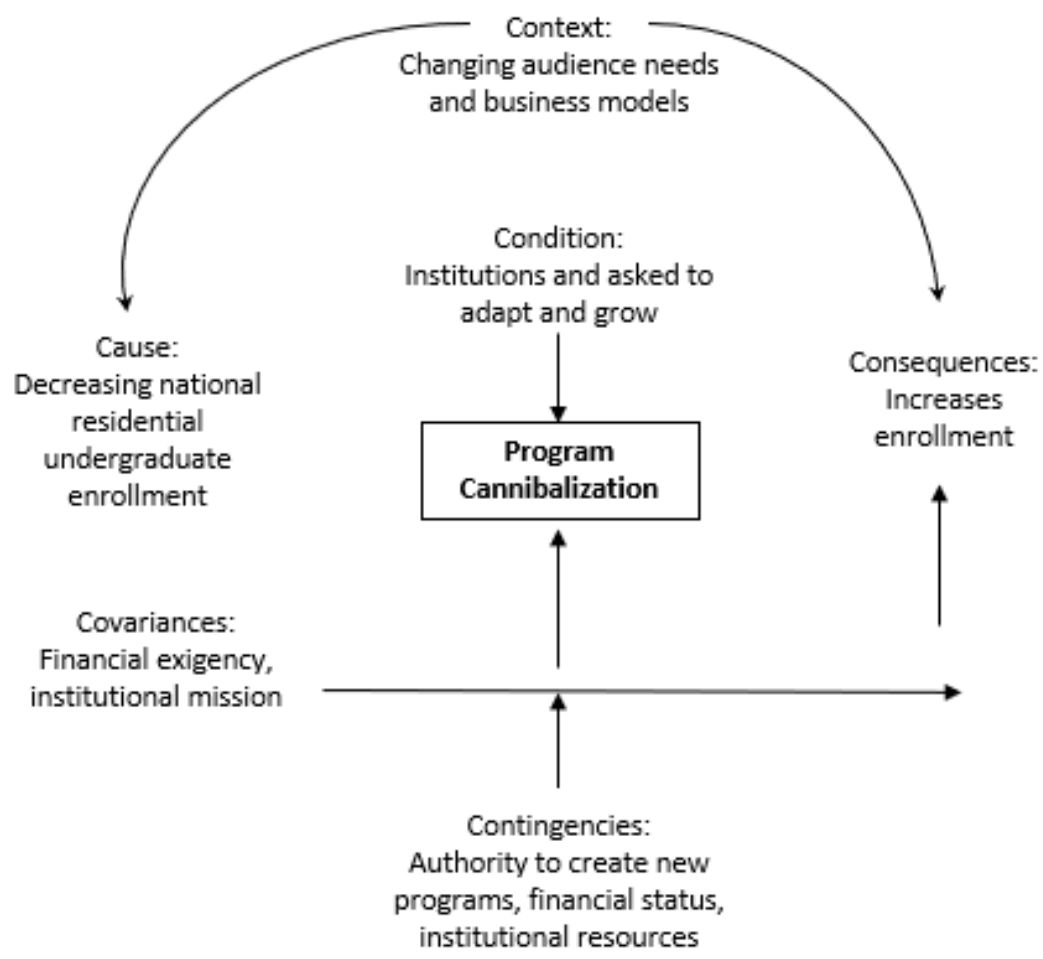

Figure 6. Glaser's Six C's Applied to Category Identification 
Changing audience needs and institutional business models shape or contextualize this category since postsecondary institutions have been adversely impacted by demographic changes. This is especially important in the Midwestern and Northeastern regions of the United States where birth rates and high school graduation rates are lower than the national average (Marcus, 2017). Unfortunately, this situation has been worsened for postsecondary institutions in the Northeast since almost half of the graduating high school students leave their home state to attend a college in another region of the United States (Marcus, 2017). This "cause" helps explain the source of the category context, but it is also influenced by covariances, contingencies and the larger context. Several covariances, or categories that are interrelated and influence each other, are "financial exigency and institutional mission." In other words, when an institution's need to generate more revenue under adverse conditions increases, it is more likely that the institution will revisit its mission and possibly adapt to changing marketing conditions. Subsequently, these covariances, together with "financial exigency and institutional mission," positively or negatively impact "program cannibalization" depending on the valence and interrelatedness of each factor. With each new category, this process of using Glaser's six C's to help understand the phenomenon with more granularity allowed me to identify the cause or causes related to each category and how the category related to other categories.

In addition to Glaser's six C's, I posed the following foundational questions of inquiry when coding: "What is this data a study of?" "What category does this information indicate?" "What is actually happening in the data?" "What is the main concern being faced by the participants?"(Glaser, 1978, p. 57). Asking these questions 
helped identify categories and themes from recurring patterns in the data. As categories were identified, I continued to use Glaser's six C's to help focus on intent or deeper psychological processes that might account for participant responses. As I asked these questions while analyzing data, I analyzed memos to revisit any earlier comments or ideas I may have recorded.

\section{$\underline{\text { Phase Two Data Analysis - Semi-Structured Interviews }}$}

Categories identified during phase one informed the creation of the semistructured interview questions. During this second phase of data collection and analysis, a clearer sense of the research problem emerged, which helped shift the data collection and analysis to a more deductive approach. For example, as I began to see a higher frequency of the code "no strategic planning" in the responses for a single question, I was able to analyze the responses in this question more closely using these categories as filters. After several more attempts to code answers under this question, I created several additional themes: emerging strategic plan and using face-to-face programs as strategy. Identifying the initial theme "no strategy" helped the researcher deduce other strategies found in the interview responses since I was certain each respondent relied on some form of strategy or direction when administering their online programs. Glaser reminds us that this type of deductive data analysis approach seeks to understand whether there is a core category and how that core category relates to other categories and themes (2017). In my case, the core category was "the status of an institution's strategic planning" and the themes were: no strategic plan, an emerging strategy and relying on face-to-face programs for strategy. 
$\underline{\text { Interview Memos \& Field Notes }}$

I wrote memos (i.e., short notes) throughout the research process (Creswell, 2013). Memos are helpful for making sense of the data and the coded categories. The compilation of memos is helpful for making sense of the data and the coded categories (Yin, 2009). Memos were written down throughout the data analysis process (and even the data collection process) to guide the development of the story of the research (Stake, 2006).

After typing out responses, I wrote additional notes as thoughts occurred, in an attempt to raise the data above mere descriptions to a conceptual level (Glaser, 1978). Subsequently, memos were generated from interview notes, reading in the field, and through reflection. Figure 6 also illustrates the iterative process of identifying and associating codes, writing memos and creating categories. Even though these survey responses had been evaluated many times, the researcher printed out response pages to simplify the process of writing notes and connecting ideas. In several instances, ideas are circled and connected via a line. Additionally, several new concepts and categories were added to the appropriate category. Although themes had already been identified at this point in the coding, this new coding information was used to help assess the validity of the existing themes. 


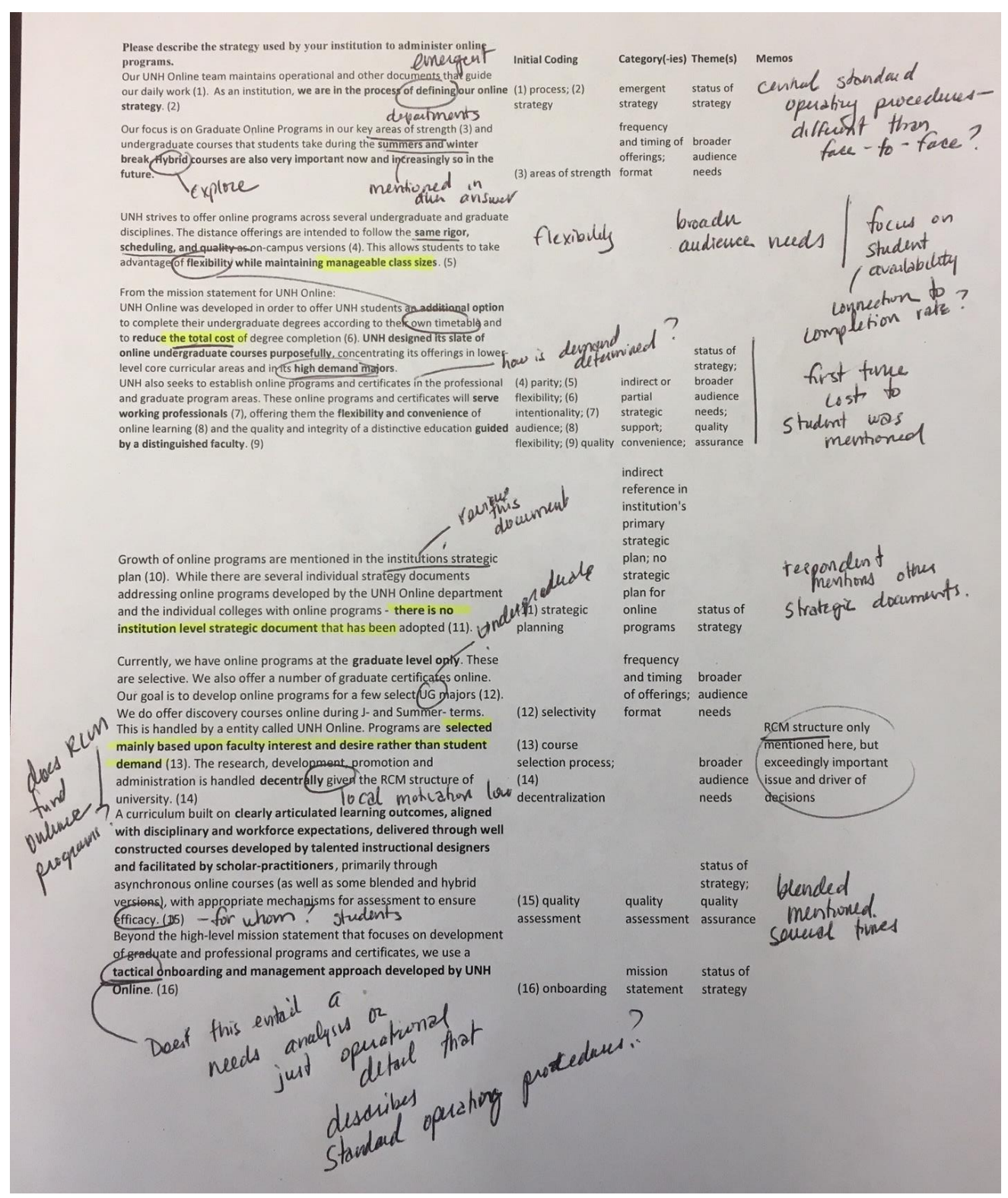

Figure 7. Creating Memos and Open Coding

\section{Coding of Qualitative Data}

Using the constant comparison approach, I identified codes after collecting data from the first online survey. As suggested by Glaser (2017), the number of codes expanded as more topics and themes were identified. Typically, there are three types of coding that are used while conducting qualitative research: 
- Open Coding - The process of breaking down, examining, comparing, conceptualizing, and categorizing data

- Axial Coding - A set of procedures whereby data are put back together in new ways after open coding, by making connections between categories. This is done by utilizing a coding paradigm involving conditions, context, action/interactional strategies and consequences

- Selective Coding - The process of selecting the core category, systematically relating it to other categories, validating those relationships, and filling in categories that need further refinement and development For this study, I used primarily open coding and selective coding without reaching the theoretical coding phase. With each successive phase of data analysis, new themes and conclusions helped refine the next phase of analysis. Glaser (2017) suggests that this iterative process continues until a strong theoretical understanding of an event, object, setting or phenomenon has emerged. To help structure my survey questions and align them with the existing online program management literature, this study followed Strauss and Corbin's suggestion (1990) to draw on the existing literature that identified principles of online management when creating my survey questions. This approach helped ensure that the questions asked in the survey were relevant to the research questions and what is already known about what constitutes a well-managed online program. Relying on an existing framework or schema to develop survey questions is different than many classical grounded theory studies that begin their research without a central theme or research questions (Glaser, 2017). 


\section{Core Categories \& Themes}

After identifying basic concepts or ideas in a data set, researchers then begin to identify categories. A category relates to several concepts or ideas and is central to the larger data set (Glaser, 2017). Accordingly, a category helps account for a large portion of the variation in a pattern of behavior. In other words, a category recurs frequently in the data and helps cohere ideas across the larger data set or pool of responses (Glaser, 2017). After categories have emerged from the data, themes often emerge (Saldaña, 2015). Rossman and Rallis explain the difference between a category and a theme as follows: "think of a category as a word or phrase describing a segment of your data that is explicit, whereas a theme is a phrase or sentence describing more subtle and tacit processes" (2003, p. 282). In some cases, a theory that characterizes the central idea or ideas of the study will also emerge.

In some studies, themes emerge from core categories and these in turn inform the articulation of a theory. The themes that emerged from the data are discussed in in chapter 4.

\section{Reliability, Validation, Trustworthiness, and Credibility}

Following Creswell's (2013) suggestion to build the narrative of the research effort around a subset of research questions, I focused the initial part of the study on setting the stage for my research agenda. Where possible, I tied my research questions to real-world, contemporary issues or problems facing administrators of online programs. When using a naturalistic research approach, Guba suggests that the validity of a study is enhanced when chronological and situational variations irrelevant to the findings (1981). 
When this condition is met, generalizations made in a study are more reliable (Guba, 1981).

For example, understanding where best to situate an online distance education program in an institution and then setting reasonable goals for growth over time are essential — and highly relevant--tasks since many postsecondary institutions are integrating online operations with their institution's strategic plan.

\section{Case Study Descriptions}

Well-designed case studies draw on in-depth analysis of the person, group, place or phenomenon being studied (Creswell, 2013). To that end, this study includes a description of each institution being studied along with mention of key issues or themes from the literature about the management of online programs. Perhaps most importantly, this case study description connects to a historical timeline since each institution's narrative is influenced by past events. This is especially true when analyzing online learning programs that are subject to macro-level economic, political and technological forces. To that end, this study is partially validated using the "substantive case report" format provided by Lincoln and Guba (1985). This format requires an explanation of the problem, a detailed description of the context or setting and processes observed and a focus on any important themes observed. This approach then summates with a discussion about lessons learned.

\section{$\underline{\text { Validity }}$}

Emerging themes, such as online enrollment totals, were probed; where appropriate, confirming and disconfirming evidence was used to further explore the validity of survey and interview questions. After publicly available data about each 
institution were gathered from each institution's website, interviews with several survey participants occurred via phone or in person to clarify their answers. Gaining access to these data was difficult because some institutional administrators were at times hesitant to share sensitive or proprietary information (e.g., online enrollment data at UNH). Because online programs are often sources of revenue generation, data gathered from this report was reviewed by each participating institution to ensure no problematic or damaging information is released to the public.

To help ensure data analysis was aligned with standard approaches, Yin's fivephase cycle of qualitative data analysis to find patterns, themes and categories of information with the data set was used (Yin, 2009). Drawing on Lincoln and Guba's (1985) framework for evaluating trustworthiness, this study demonstrated methodological rigor by establishing a research audit trail, confirming results with participants, and relying on peer debriefing and structural collaboration. Other elements of Lincoln and Guba's framework for evaluating qualitative research such as negative case analysis were considered as data are gathered and categorized.

To further validate my study, I ensured that my data analyses plans incorporated additional steps suggested by Morse, Barrett, Mayan, Olson and Spiers (2002). Morse et al. suggest that the strategies to ensure rigor must be built into the qualitative research process itself as opposed to be applied at the end of a study. This includes remaining responsive to the changing conditions of the study context as well as documenting an audit trail and assessing the adequacy of sampling while the study is still in progress. In addition to the methodological standards discussed by earlier researchers (Lincoln \& Guba, 1985; Morse, et al, 2002), I invested the needed time and adhered to logical 
inquiry with the hope that the study narrative is clear and relevant. This requires attention to detail with planning, interview protocol and the coding, analysis and archiving of data. It also involves a willingness to explore my own biases and the influence of other stakeholders on the study's findings (Finlay, 2002). Since I am an employee at one of the USNH institutions being studied, this required additional effort and strategy to ensure that any potential biases were addressed.

Member Checking

Member checking helps affirm that the results accurately reflect the participants' views and experiences (Creswell, 2013; Lincoln \& Guba, 1985; Stake, 1995; Stake, 2006). Lincoln and Guba (1985) consider member checking "the most critical technique for establishing credibility" (p. 314). Stake (2006) also advocates for member checking, among other validation techniques, to ensure the most credible interpretation possible. Since there are no established guidelines for determining how many study participants should participate in member checking, I selected two study participants who were the most familiar with the day-to-day operational details at UNH and GSC, since these two institutions manage the largest online programs in the system. While it may have been beneficial to engage additional study participants in this process, it would have been unreasonable to assume that this larger group would have agreed to additional tasks based on their limited availability. The two interview participants who were selected for member checking were asked to verify the results of this study by assessing chapter five of this study. They were then asked to provide input.

After notes from the interviews were generated and initial themes emerged, the results of this study, Chapter 4, was shared with two participants for their reaction and 
feedback, giving them the opportunity to fill in any gaps, add further information, and address my understanding of their experiences and beliefs. Neither member responded to my request. Since UNH and GSC managed the largest online degree programs within USNH, a study participant from each institution was selected for this member checking. Member checking is specifically encouraged by Creswell (2013) as if often offers further insights while bolstering the study's validity.

\section{$\underline{\text { Triangulation }}$}

Triangulation is considered an effective approach for helping ensure trustworthiness in case study research (Creswell, 2013; Lincoln \& Guba, 1985; Stake, 2006; Yin, 2009). Triangulation involves drawing data from multiple sources using multiple methods to generate corroborating evidence (Creswell, 2013). As researchers triangulate data from various data sources, they are often able to strengthen a study by demonstrating a convergence of evidence (Yin, 2009). To that end, I compared the results from the survey and interviews as part of the data analysis process. For the most part, this entailed comparing the categories from both data sets and looking for similarities and differences (see Table 14). Overlapping categories were: strategy, terminology and brand cachet or system identify.

\section{Chapter Summary}

In this study, I relied primarily on methodological guidelines for case study research developed by Yin $(1981,2003,2009)$ and Stake $(1995,2006,2010)$. Within my case study framework, I used the constant comparison approach to code, sort, and analyze data. To ensure survey questions would capture responses that spoke to each facet of administering online programs, Rovai (2003) and Rovai and Downey’s (2010) research 
models were used when creating survey questions. Since this study sought to understand how online programs in statewide systems are administered, stakeholders within the USNH system who have direct or indirect authority over these programs were surveyed and interviewed. This study relied heavily on Rovai (2003), Rovai and Downey's (2010) factors of successful online programs as well as King's (2013) subsidiarity principle to create survey questions. Where data support an extension of Rovai (2003) and Rovai and Downey's (2010) models, additional factors of analysis were added and justification for each factor was provided in light of this study's findings. 


\section{CHAPTER FOUR: RESULTS}

The purpose of this study was to understand how administrators within a fouryear statewide university system manage online programming at their respective institution and how this activity is influenced by their institution's association with their statewide system. More specifically, this study sought to answer the following research questions:

- How are online programs administered by institutions affiliated with a public statewide system?

- Based on the perspective of institutional administrators, what are the advantages and disadvantages of administering online programs in a public statewide system?

- Do study participants prioritize some features or characteristics of their online program over others?

The following chapter summarizes survey responses gathered from 18 administrators at the University of New Hampshire, Keene State College, Granite State College, Plymouth State University and the central University of New Hampshire System office. These responses are summarized with a focus on identifying the themes that emerged from six interviews.

After data were analyzed from both surveys and interviews, member checking (Lincoln \& Guba, 1985) was used to gather additional feedback from two survey 
participants about the categories and themes identified by the researcher. This provided these particular survey participants with another opportunity to fill in any gaps and validate the intent of their original survey answers. Where possible, triangulation of data (Creswell, 2013) and memos were used to help further validate data analysis (Stake, 2006). Since data were gathered using an online survey management tool, Qualtrics, a detailed audit trail exists that documents when each survey participant completed the survey. The combination of triangulation, memo creation and archival rigor helped validate the data collection process (Morse, Barrett, Mayan, Olson and Spiers, 2002).

\section{Phase One: Survey Results}

The results from phase one of the study are described below. The survey question was an informed consent to participate in the study.

\section{Survey Question 2}

How long have you been in your current position?

Based on 18 survey responses, the longest duration a respondent had been in his or her position was 15 years and the shortest duration was 1.5 years. The average length of time respondents worked in their current position was 4.9 years (see Table 8).

\section{Survey Question 3}

How long have you worked in higher education?

Based on survey responses, the longest duration a respondent had worked in higher education was 39 years and the shortest duration was 6 years. The mean value was 23.3 years (see Table 8 ). 
Table 8. Respondent Length of Employment

\begin{tabular}{|l|l|l|}
\hline Question & Range & Mean \\
\hline How long have you been in your current position? & 1.5 years to 14 years & 5.7 years \\
\hline How long have you worked in higher education? & 6 years to 39 years & 23.3 years \\
\hline
\end{tabular}

\section{$\underline{\text { Survey Question } 4}$}

Please describe the strategy used by your institution to administer online programs.

This question sought to understand whether administrators at each of the USNH institutions draw on a formal strategy to manage their institutions' online programs. Three respondents stated that there was no specific strategy used when administering their institution's online program, three respondents mentioned their institution's strategy to administer online programs was still emerging and five respondents pointed to some type of indirect or partial strategy, e.g. institutional mission, accreditation that provided guidance. After coding survey questions, several themes emerged:

Theme 4.1: Emerging Strategic Plan

Several participants mentioned that their institution's strategic plan for administering online programs was still emerging. Survey respondent \#1 from UNH stated, "As an institution, we are in the process of defining our online strategy." Similarly, survey respondent \#18 from Granite State College stated, "As an institution, we are in the process of defining our online strategy." Since strategic planning is by nature adaptable and evolving, it's not surprising to see answers that point to the need for 
an adaptive mindset. In addition, survey respondent \#17 from Plymouth State University mentioned that although strategic thinking in this area is evolving, their operational decisions are still intentional, "Our strategy is evolving, but is coming with a lot of thought."

\section{Theme 4.2: No Strategic Plan}

Survey respondent \#9 from UNH noted that while there were general rules for how to manage online programming, there is currently no specific strategy document in place. As stated by the respondent, "There isn't a single coherent strategy for online learning. There are broad rules that define how we manage courses--governance via faculty oversight." Survey respondent \#18 from Granite State College described a similar situation at his institution. He specifically stated that "there is not a specific strategy or policy document for administering online programs."

\section{Theme 4.3: Managing Online Programs like Face-to-Face Programs}

In most responses, the survey participant mentioned that there was some source of strategic planning that helped guide their online program management decisions. A comparison with face-to-face courses was made in several survey responses with the following sources of face-to-face quality management being referenced:

- Accreditation

- Local institution's general strategic plan and

- Standard operating procedures

Survey respondent \#3 from UNH pointed to parity with onsite credit-based courses as a means to guide strategic planning for online programs. As stated by the respondent, "The 
distance offerings are intended to follow the same rigor, scheduling, and quality as oncampus versions."

Similarly, survey respondent \#14 from UNH also mentions parity between onsite and online programs as a means to define or guide strategy, "I would say that the general philosophy underpinning our approach to online education is that the quality and experience must be comparable to that of our residential programs." Survey respondent \#16 from UNH reinforced this idea by pointing out that the faculty and curricula used for both online and onsite programs are well integrated. The respondent stated, "Online at our institution is a modality, it is integrated with our academic programs, same faculty, same curriculum." This parity between online and onsite programs is most apparent when considering regional accreditation requirements that govern how credit-bearing programs--regardless of modality--are conceived, approved, launched, evaluated and managed. Survey respondent \#11 from USNH pointed out, "For credit-based online programs, any requests for new online programs go through the Provost's Office and are subject to the terms of accreditation."

\section{Theme 4.4: Broader Audience Preferences}

"Broader audience preference" refers to the interests and preferences of potential or prospective students. This theme speaks to a university's ability to adapt its program areas, outreach activity and value proposition to the needs of a changing audience and reinforces Berge's (2007) notion that institutions administering online programs must adapt their strategic planning to the changing needs of online students. When responding to this survey question, eight of 18 responses included a reference to their online program audience. References to the "market," to the flexibility or responsiveness of online 
programs or to the "broader demographic," ultimately pointed to prospective students or to the online program "audience" and their preferences. When discussing their prospective audience, survey respondent \#17 stated, "Keene State is focused on residential students, but the demographic decline means that we need to reach a broader demographic. How do we leverage online programs to reach a larger population?" This statement captures the connection between strategic planning, online programs and an institution's "broader demographic." This statement also emphasizes that strategy depends on understanding audience preferences in light of what constitutes priority in the larger educational milieu. In the context of many postsecondary institutions and their systems, enrollment and revenue generation are typically very high priority (Legon \& Garrett, 2017). When priority is identified, urgency can then be used to help advance strategic planning more effectively.

Survey respondent \#2 from UNH mentioned that undergraduate students enroll in online programs during the summer and winter break due to convenience. The survey respondent stated, "Our focus on graduate online programs is our key area of strength-and undergraduate courses that students take during the summers and winter break. Hybrid courses are also very important now and increasingly so in the future." When discussing the market and its saturation, survey respondent \#17 remarked that their institution must adapt to the challenge, "The market is pretty saturated, so we need to deliver a Keene State experience with unique programs." Respondent \#3 from UNH also pointed out that even quality assurance translates to increased flexibility for students, "The distance offerings are intended to follow the same rigor, scheduling, and quality as on-campus versions allows students to take advantage of flexibility while maintaining 
manageable class sizes.” The same survey respondent referenced UNH Online's mission as being primarily focused on audience needs, i.e. flexible scheduling and cost, "UNH Online was developed in order to offer UNH students an additional option to complete their undergraduate degrees according to their own timetable and to reduce the total cost of degree completion.”

When online programs aren't developed with the student in mind, this can adversely impacts a program's effectiveness and sustainability (Berg, 2002). In a statement about how online program topics are selected at $\mathrm{UNH}$, one survey respondent suggested that this decision is based on faculty interest rather than student needs or interests, "Online programs are selected mainly based upon faculty interest and desire rather than student demand." Citing UNH's mission, survey respondent \#3 from UNH mentioned that "UNH Online was developed in order to offer UNH students an additional option to complete their undergraduate degrees according to their own timetable and to reduce the total cost of degree completion. UNH designed its slate of online undergraduate courses purposefully, concentrating its offerings in lower-level core curricular areas and in its high demand majors." While this statement suggests UNH is focused on offering UNH undergraduate students more flexibility with scheduling, it doesn't address those potential students who would like to complete a degree entirely online. This statement also doesn't consider the needs of graduate students or working professionals whose program interests are secondary to the availability or interests of UNH faculty. 


\section{Theme 4.5: Quality Assurance}

Based on several responses to this survey question, quality assurance included several programmatic factors: compliance with accreditation, alignment with student preferences and positive pedagogical outcomes. These factors align with Rovai and Downey's (2010) research focusing on the factors of successful online program. When discussing the day-to-day management of quality assurance, several respondents referenced policy, standard operating procedures, technical infrastructure and alignment with faculty and administrative priority. Because "quality" "is such a multi-dimensional concept, it is used in different contexts with different meanings or contexts. Survey respondent \#7 from Granite State College summed up quality in this way,

A curriculum built on clearly articulated learning outcomes, aligned with disciplinary and workforce expectations, delivered through well-constructed courses developed by talented instructional designers and facilitated by scholar-practitioners, primarily through asynchronous online courses (as well as some blended and hybrid versions), with appropriate mechanisms for assessment to ensure efficacy.

Visible in this definition are positive outcomes, expectations, instruction, course design, format and learning management tools. Survey respondent \#1 from UNH mentions their group manages online programming using "operational and other documents guide our daily work.

\section{$\underline{\text { Survey Question } 5}$}

Does your institution regularly collaborate with other USNH institutions when administering your institution's online degree programs? 
Five respondents indicated that their institution collaborates with other USNH institutions when administering their online programs, eight indicated their institution does not collaborate with other USNH institutions when administering online programs and five were unsure.

Survey Question 6

Do you believe that there are unrealized opportunities for different institutions in USNH to collaborate more effectively around the administration of online degree programs?

This question focused on opportunities to collaborate with other institutions in the statewide system. The goal of this question was to see whether respondents' answers aligned with Zimpher's (2013) definition of “systemness," which states that collaboration within a statewide system can result in three positive outcomes:

- Institutions leverage each other strengths

- Collaborating institutions improve student access, reduce program cost and enhance operational productivity

- Institutions are able to align their goals more closely with state- and community-level priorities

Several themes emerged in the data: alignment with other USNH institutions, strategic partnerships and system identity and function; each of these will be described in more detail in the following paragraphs

Theme 6.1: Alignment with other USNH Institutions

One or more aspects of collaboration among USNH institutions were described by survey respondents. For the most part, descriptions were framed by whether institutional 
characteristics were similar or dissimilar to each other. Some of the institutional characteristics compared were: back-office services such as enrollment management, reputation, research focus, student demographics and overhead costs. These responses support Zimpher's (2013) first and second outcomes of system collaboration: institutions leveraging each other strengths and collaborating institutions reduce program cost and enhance operational productivity.

Participant \#1 from UNH offered the most descriptive response when discussing this topic,

The missions of Keene State College and Plymouth State University seem to be more similar than Granite State College and UNH. GSC and UNH attract somewhat different students than KSC and PSU. The research focus of UNH is dissimilar to the other USNH institutions and influences the types of courses taught and therefore the types of administrative supports that may be needed. There would be similarities across the system in terms of application processes and billing for instance. In terms of curriculum, KSC and PSU seem most similar, which may suggest opportunities for collaboration.

In this response, the survey participant references back-office services, students, research focus and administrative support.

In another response, a survey participant pointed to Granite State College's "strong reputation with online programming vis-a-vis the accreditor." In the same response, this administrator also suggested that overhead costs at some universities were lower than others, which could be leveraged to expand online programs. As stated by the respondent, 
We need to think about lowering overhead costs. For low enrolled courses, we might be able to increase enrollment when the course is important to their mission (like liberal arts for Keene State or language). Learning depth isn't any different for online for classes like these.

Similar to the other responses for this question, the survey respondent supports Zimpher's first and second outcomes of "systemness" (2013). Missing from participant responses is reference to Zimpher's third outcome of system collaboration, "Institutions aligning their goals more closely with state- and community-level priorities."

\section{Theme 6.2 Strategic Partnerships}

Strategic partnerships refer to intentional relationships formed between an institution's online program and other on- or off-campus organizations. Although the most direct way of understanding the nature of an institution's level of collaboration with other system institutions is by analyzing the alignment and activity between each institution, it is also helpful to consider each institution's strategic partnerships. Strategic relationships often contribute to increased capacity, new revenue streams, and additional support for key initiatives. Understanding the nature of these relationships helps determine an institution's willingness to enter into other partnerships.

Speaking to this issue, survey respondent \#17 from Keene State University suggested such partnerships are valuable. The respondent stated, "We need to consolidate resources and services for online programs. This will involve more partnerships with vendors like Wiley." In light of this partnership with an external vendor, the participant points to Granite State College as an institution within the system that is capable of offering support in, "instructional design, initial marketing support, faculty development 
and some call center support." One of the more meaningful institution-to-institution relationships that was referenced was the support Granite State College provided Keene State to develop a new online master's degree in Safety and Occupational Health Applied Sciences. Survey respondent \#11 mentioned this partnership, "Yes, like Keene State where they lack the infrastructure to offer online programs. They were able to create new online programs in partnership with Granite State College.” A respondent from Keene State College pointed to this partnership and suggests that "Granite State has a strong reputation with online programming vis-a-vis their accreditor. Granite State College can support instructional design, initial marketing support, faculty development and some call center activities." In the context of intra-system institutions, the respondent from Plymouth State University also answered this question, "Yes, while there is limited collaboration now, we could take this much further. This discussion has started with GSC KSC and PSU, but I am hopeful UNH will join us more in the future.”

\section{Theme 6.3 System Identity and Function}

A new theme, "system identity and function," emerged in answers to this question. Since this question asked survey participants whether they believe there are opportunities for collaboration within the statewide system, it required each survey participant to consider each institution's function within the system more carefully. This often resulted in strong opinions regarding each institution's strengths and weaknesses and their unique function within the statewide system; especially in relation to the administration of online programming.

One facet of an institution's identity relates to the overall prestige or brand of the institution in relation to the other institutions in the system. In that light, one survey 
respondent referred to UNH as the "big dog" in the system. The survey respondent suggested, "UNH is the big dog among smaller institutions. The opportunity to collaborate may not be there." As stated by the survey respondent, because UNH is seen as having a superior reputation and more resources than the other institutions, survey respondents affiliated with UNH believed that the benefits for UNH to participate with other USNH institutions in administering online programs were most likely minimal. Survey respondent \#10 focused on the financial challenges inherent in intra-system collaboration, "The main obstacle, in my opinion, is the current financial struggle felt by higher education in $\mathrm{NH}$ and more broadly. Every partnership would result in a division of an ever-shrinking pie.”

\section{Survey Question 7}

Do you think it's preferable to administer online programs using a central or local model (at the institutional level)?

This question probed respondents' perspectives about whether they felt online programs should be administered by their local institution or by a central organization. Themes identified in survey responses for this question are as follows:

- Shared understanding of key terms

- Shared tools

- Gaining competitive advantage via strategic partnerships

- Competent leadership

- Curricular governance

- A both/and model for online program management 


\section{Theme 7. 1 Shared Understanding of Key Terms}

As survey respondents answered this question, several respondents pointed to terms that were difficult to define, such as "administration." Subsequently, this question was at times challenging for survey participants to answer. Several respondents felt that the question itself limited their ability to respond since they believed there was no clear definition around what it means to administer an online program "centrally" or "locally." As expressed in several responses, survey participants felt that there were many different permutations of how an organization can structure its staff and infrastructure with varying levels of dependence on local or central resources. Similar to question \#5, the issue of “identity" was prevalent as respondents pointed to organizational characteristics at the institutional level that determine an institution's ability to manage online programs. For example, when speaking about central administration, respondent \#1 from UNH asked, "Does this include any management of curriculum or are you including only admission, registrar, billing, and similar functions?” Respondent \#4 from UNH also sought clarification when sizing the scope of the question, "My personal feeling is that it depends greatly on the institutions and the systems being considered." In each of these responses, survey participants were seeking a shared understanding of key terms so that they could frame their response appropriately.

Theme 7.2 Shared Tools

Since this question was about the locus of control for online programs administration--local or central--survey respondents discussed key strategic assets, such as learning management systems, that would need to be managed differently depending 
on whether online programs were administered locally or centrally. When assessing the value of either local or central control, respondent \#6 from UNH remarked,

There are positives and negatives to both. At a minimum centrally within an institution. And some shared across a system. For example, course development, the LMS and perhaps promotion and admissions could be shared and more efficient.

\section{Theme 7.3 Gaining Competitive Advantage via Strategic Partnerships}

Although this question asked survey participants to consider how organizations

that administer online programs are structured, several survey respondents pointed not to their own organization's characteristics, but to external organizations who could provide strategic or operational support. One survey respondent suggested, "Some general education courses might be better administered from a central perspective. This might even mean reaching beyond USHN and gaining materials or administration from regional or national collectives." This response highlights a perspective shared by many survey participants that the type of organizational structure used to manage online programs need not be either local or central since there are benefits and obstacles inherent in both approaches. As it becomes more complicated to manage large online programs, the ability to contract or partner with external groups to help with management, curricula development and staffing is often an attractive option for institutions.

Theme 7.4 Competent Leadership

Because successful management requires competent leadership, several survey respondents mentioned the need for the right type of leaders who have extensive experience managing online programs. One survey respondent illustrated this idea by discussing leadership requirements, 
My personal feeling is that it depends greatly on the institutions and the systems being considered and the level of expertise they have in the space. While online learning has been around for decades, there are still few expert practitioners and leaders in the field. Strong strategic and operational leadership at the system or institution level--with extensive knowledge and experience of online learning--is required first before even embarking on a decision regarding organizational administration. Following that, my personal opinion is that a centralized approach is best to create a consistent experience for the student, the faculty, and the administration. I am still undecided on if that centralization should be at the system level or at the institutional level.

This respondent also points out that finding leaders who have a deep knowledge of how to manage online programs is difficult.

A different respondent also suggests that while there is excellent leadership at UNH, there isn't a dedicated leader at the Associate Vice Provost or Vice President level who focuses exclusively on online programming, "I think UNH should have a central model for administering online programs. UNH Online is an attempt at this but currently lacks an executive-level leader whose sole responsibility is to expand online programming."

\section{Theme 7.5 Curricular Governance}

While it's important to understand how the units that administer online programs are organized in terms of staffing, funding and infrastructure, it's also important to determine how decisions about curriculum are made. Additionally, this question sought to understand whether survey participants felt that online programs should be administered differently than face-to-face programs (Berge, 2007) with the potential for 
different outcomes related to program cost, access and rigor (Legon \& Garrett, 2017; Rovai \& Downey, 2010). In several responses, survey participants discussed curricular governance. One survey participant stated,

I believe the key is to have online programs integrated into the general program offerings. Program faculty have ownership over the curriculum and they have administrative support. If that support is local there is more of an opportunity to build relationships with the faculty and the programs, but some of the tech support could be done at more of a distance.

In this response, a rationale for managing online programs locally is tied to faculty ownership of curriculum. When respondents suggested specific factors or aspects of online program management should be handled centrally, they reinforced one facet of Zimpher's (2013) concept of "systemness" that states collaboration among system institutions is most productive when each institution recognizes and leverages each other's strengths.

\section{Theme 7.6 A Both/And Model for Online Program Management}

Because many survey respondents were struggling to choose either "local" or "centralized" as an answer to this question, there were responses that pointed to a lack of understanding of key terms and a need for a third model that can be used to manage online programs: the both/and or hybrid model. In this model, some aspects of online programming are managed locally while other aspects of online programming are managed centrally. One survey respondent described how a "both/and" model could more effectively leverage strengths across the system, 
I recommend a both/and model. We need to draw on content experience from all campuses. The best opportunity in the system is to leverage content expertise across the system--faculty then work as a learning community. Services can then be shared--like marketing--can be centralized at a much more cost-effective rate. So, we can have system programs managed in a network system. Lots of systems have gone to a central spine curriculum--we could brand ourselves as a network.

\section{$\underline{\text { Survey Question } 8}$}

How does your institution support faculty who design and teach online courses?

This question asked survey participants to identify resources that are used to help support faculty with the development and delivery of online courses. Respondents discussed services, workshops, mentoring programs and different financial rewards that are used to support and incentivize faculty who teach online programs. Participant \#4 from UNH pointed out the many different types of support available to instructors teaching online,

We have several programs available to support faculty involved in online education. We require all online faculty to attend FOI or FOA (online courses covering online course development and instructional pedagogy), professional development support via and institutional membership to the Online Learning Consortium, department support, Instructional Designers available to assist in course development, FITSI - an annual conference, and additional Master Course Development funding to incentivize faculty to develop online courses. 
In this response, the survey participant referred to workshops, professional development, instructional design support, access to a professional conference and financial support.

In another response, the survey participant discussed some of the cutting-edge movements in online learning and suggests faculty can become more engaged with online teaching by understanding the power of online learning and how it fosters improved collaboration.

Academic Technology Institutes have helped; as well as the Open Education movement. These are all helping transform thinking and new collaborations. We need to bring this together more cohesively, so faculty understand the connectivity of technology, goals. There are many new modalities and new platforms that can provide improved coherence in our work.

In many responses, references to new technologies or program development led to discussion about collaboration or partnerships. This connection between faculty development and partnership was apparent as study participants pointed to external groups or groups advocating new pedagogy.

\section{Survey Question 9}

From your perspective, are your institution's online degree programs sufficiently funded for growth and ongoing program improvement?

Twelve survey respondents indicated their institution's online degree program was not sufficiently funded while six respondents indicated their institution's online programing was sufficiently funded. 


\section{Administrator perception of funding for online programming}

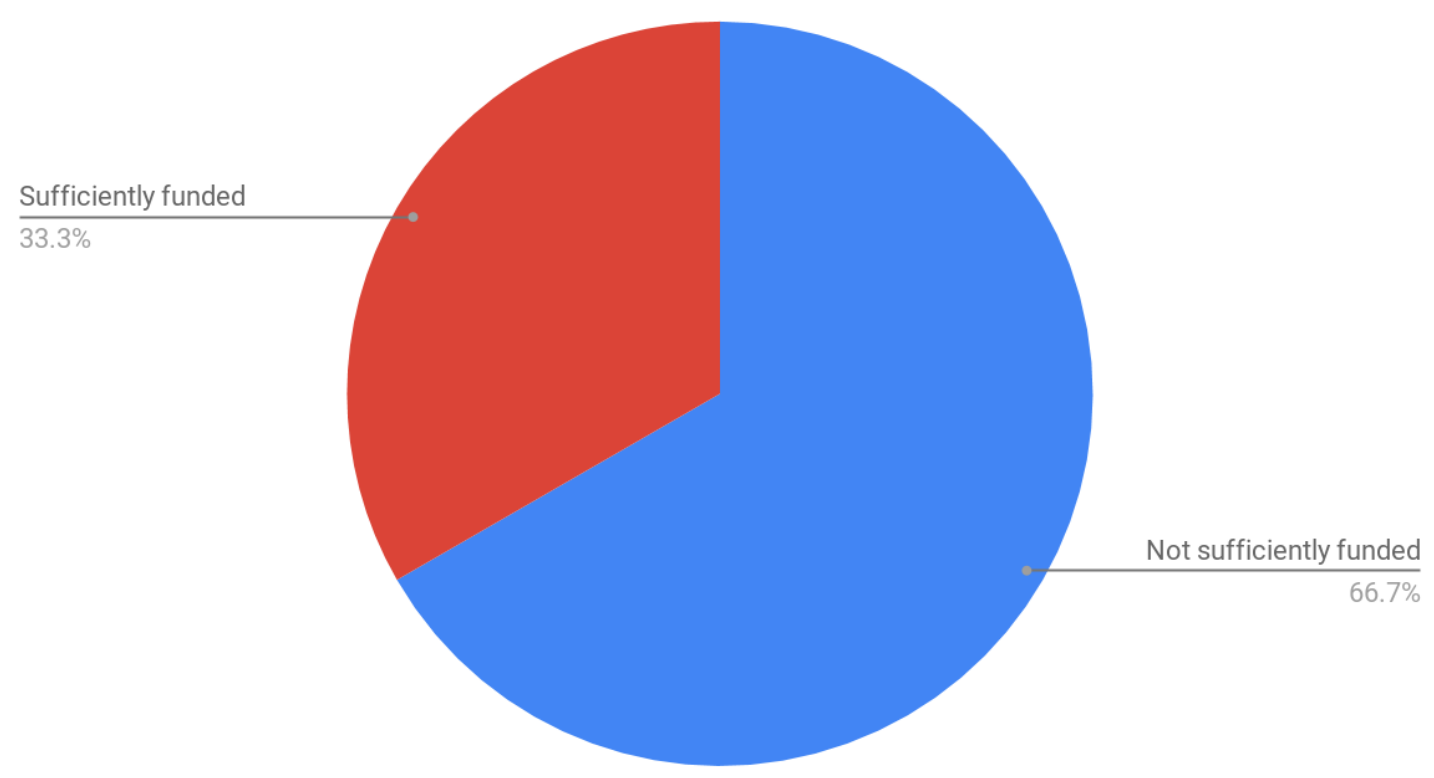

\section{Survey Question 10}

How do you collect end-of-course evaluation for your online programs?

Survey respondents indicated that end-of-course evaluations were administered for all of their online courses using mostly digital or online evaluations and some inperson evaluations. UNH administrators noted that the end-of-course evaluations were sent to the academic department that was responsible for each respective program.

\section{Survey Question 11}

Please rank the following factors from the most important to the least important by_ordering the responses using drag and drop. Select your ranking order based on which factors you believe contribute most heavily to the overall success of your institution's online degree program(s).

To simplify the interpretation of data from this question, the 1-8 scale used by survey respondents was inverted: a ranking of 1st place by survey participants is 
weighted as an 8 and a score of 8 th by survey participants is reported below as a 1 . After each score in each category was totaled using survey participant responses (See Table 9), the total score was divided by the number of survey participants $(\mathrm{N}=17)$ to arrive at a mean score per factor. After adding up the total potential score for each category based on a total of eight factors ( 8 points) multiplied by the total number of survey participants $(\mathrm{N}=17)$, the total possible score for each factor is 144 points $(\mathrm{N}=144)$. This resulted in a factor total of 90 points for strategic planning or an average score of 6.25 .

Table 9. Factor Totals

\begin{tabular}{|l|c|c|c|c|c|c|c|c|c|c|}
\hline Factor & 1st & 2nd & 3rd & 4th & 5th & 6th & 7th & 8th & Total & $\begin{array}{c}\text { Mean } \\
\text { Score }\end{array}$ \\
\hline $\begin{array}{l}\text { Strategic } \\
\text { planning }\end{array}$ & 10 & 1 & 1 & 1 & 1 & 0 & 1 & 2 & 90 & 6.25 \\
\hline $\begin{array}{l}\text { Faculty support/ } \\
\text { development }\end{array}$ & 1 & 4 & 6 & 0 & 2 & 3 & 1 & 0 & 90 & 6.25 \\
\hline Quality assurance & 1 & 1 & 4 & 6 & 1 & 3 & 0 & 0 & 82 & 5.6 \\
\hline $\begin{array}{l}\text { Online course } \\
\text { design and } \\
\text { pedagogy }\end{array}$ & 1 & 5 & 0 & 2 & 1 & 2 & 4 & 2 & 68 & 4.7 \\
\hline Student retention & 2 & 0 & 1 & 3 & 4 & 2 & 3 & 1 & 66 & 4.5 \\
\hline Marketing & 0 & 3 & 1 & 3 & 1 & 2 & 5 & 2 & 64 & 4.4 \\
\hline
\end{tabular}




\begin{tabular}{|l|c|c|c|c|c|c|c|c|c|c|}
\hline Financial & 0 & 0 & 3 & 1 & 4 & 1 & 3 & 4 & 52 & 3.6 \\
management & & & & & & & & & & \\
\hline Local control of & 1 & 1 & 1 & 1 & 0 & 4 & 0 & 6 & 44 & 3.0 \\
\hline
\end{tabular}

Based on survey responses, the following three responses were perceived as being the most important factors of online program management: strategic planning (6.25), faculty support (6.25) quality assurance (5.6), online course design and pedagogy (4.7), student retention (4.5), marketing (4.4), financial management (3.6), local control of operations (3.0).

Table 10. Factor Priority

\begin{tabular}{|l|c|c|}
\hline Factor & Ranking & Frequency included in top 4 ranking by \\
& survey respondents \\
\hline Strategic planning & 1 & $77 \%$ \\
\hline Quality assurance & 2 & $72 \%$ \\
\hline Faculty support & 3 & $65 \%$ \\
\hline Online course design /pedagogy & 4 & $47 \%$ \\
\hline Student retention & 5 & $36 \%$ \\
\hline Marketing & 6 & \\
\hline
\end{tabular}




\begin{tabular}{|l|c|c|}
\hline Financial management & 7 & $23 \%$ \\
\hline Local control of operations & 8 & $18 \%$ \\
\hline
\end{tabular}

The last ranking item asked respondents if they had any additional factors that should be included in this response. Additional factors mentioned by survey participants:

- Personal connections

- Market analysis

- Technical support

- Basic understanding of online programming

- Learner student success model

When comparing these three factors to the factors used in this study (King, 2013;

Rovai \& Downey, 2010), "market analysis" could be subsumed under the marketing factor, but the other factors cannot be easily categorized using Rovai and Downey's factors without additional qualification of the term used by the respondent.

\section{Survey Question 12}

Do you feel that your institution has the appropriate infrastructure to manage

\section{their online programs?}

Ten survey respondents felt that their institution has the appropriate level of infrastructure to support online programming, five felt their institution lacked sufficient infrastructure and three respondents were unsure. 


\section{Infrastructure for Online Programming}

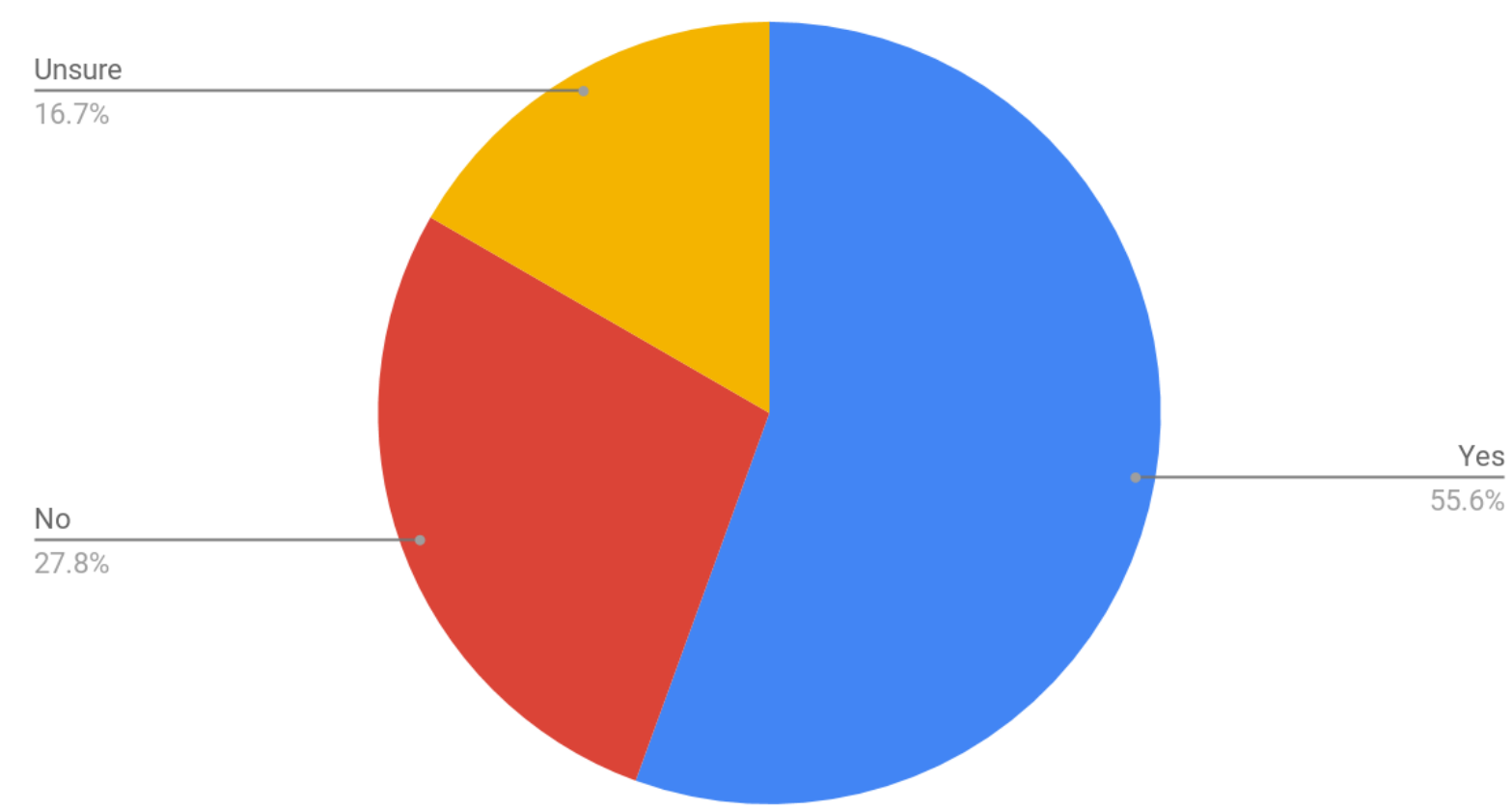

\section{Survey Question 13}

Does your institution regularly assess online degree student satisfaction?

Eighteen survey participants responded to this question. Fourteen respondents indicated their institution assesses online degree student satisfaction and four respondents were unsure.

\section{Survey Question 14}

Are there any additional thoughts you'd like to share about the administration of online degree programs at your institution or within the University System of New Hampshire?

The last survey question gave respondents an opportunity to offer open-ended input about administering online programs at their institution or within the New Hampshire statewide systems. Responses from this question illustrated some of the 
themes identified in previous questions such as faculty support, emerging strategy, broader audience preferences and the both/and model for administering online programs.

In one response, the survey respondent suggested that financial support for online programs is currently insufficient to support their desired growth over time,

There is great potential for online programs within $\mathrm{UNH}$ and the system as a whole. However, until dedicated financial and strategic support is in place, there will be limited ability for long-term scalable success. Additionally, understanding and supporting the online student experience--and adjusting to their unique need--is also required.

Another survey respondent also reinforced the idea of online programs being sustainable over time if more financial support is allocated to these programs, "We assess all our programs regularly. Online programs are no different. Clearly, there is scope for expansion of online programs, and it will be great if we had strategic funds to invest in online programs."

\section{Phase One Summary}

In summary, the phase 1 survey results suggest that managing online programs effectively in any postsecondary institution depends on unique skills, extensive experience, technology, strategic planning, faculty support and a host of other resources. The themes identified from the survey results are shown below in Table 11.

\section{Table 11. Survey Themes, Definition \& Categories}

\begin{tabular}{|l|l|}
\hline Theme(s) \& Definitions & Supporting Categories \\
\hline 4.1 Emerging strategic plan & Indirect or partial strategic \\
& support, mission statement, \\
\hline
\end{tabular}




\begin{tabular}{|c|c|}
\hline $\begin{array}{l}\text { The institution relies on secondary forms of } \\
\text { strategy, i.e. university mission, standard operating } \\
\text { procedures }\end{array}$ & $\begin{array}{l}\text { evolving, demographics, process, } \\
\text { standard operating procedures, } \\
\text { needed financial resources, room } \\
\text { for growth, obstacles }\end{array}$ \\
\hline $\begin{array}{l}\text { 4.2 No strategic plan } \\
\text { The institution does not have a strategic plan that } \\
\text { focuses exclusively on online programming }\end{array}$ & No specific strategy document \\
\hline $\begin{array}{l}\text { 4.3 Managing online programs like face-to-face } \\
\text { programs } \\
\text { The institution manages their online programs just } \\
\text { as they would their face-to-face programs }\end{array}$ & $\begin{array}{l}\text { Limited strategy, parity, student } \\
\text { experience }\end{array}$ \\
\hline $\begin{array}{l}\text { 4.4 Broader audience preference } \\
\text { The interests and preferences of potential or } \\
\text { prospective students }\end{array}$ & $\begin{array}{l}\text { Frequency and timing of } \\
\text { offerings, format }\end{array}$ \\
\hline $\begin{array}{l}\text { 4.5 Quality assurance } \\
\text { Programmatic factors that contribute to positive } \\
\text { learning outcomes for students: compliance with } \\
\text { accreditation, alignment with student preferences } \\
\text { and positive pedagogical outcomes }\end{array}$ & $\begin{array}{l}\text { Convenience, quality assessment } \\
\text { housed in a school, market, } \\
\text { faculty support, vision, service } \\
\text { support, metric driven }\end{array}$ \\
\hline \begin{tabular}{|l}
6.1 Alignment with other USNH institutions \\
\end{tabular} & $\begin{array}{l}\text { Demographic, collaboration, } \\
\text { differentiation, admission }\end{array}$ \\
\hline
\end{tabular}




\begin{tabular}{|c|c|}
\hline $\begin{array}{l}\text { The similarity or dissimilarity between USNH } \\
\text { institutions }\end{array}$ & $\begin{array}{l}\text { pipelines, centralization, sharing } \\
\text { courses, balkanization, flagship } \\
\text { status, efficiencies }\end{array}$ \\
\hline $\begin{array}{l}\text { 6.2 Strategic partnerships } \\
\text { Intentional relationships formed between an } \\
\text { institution's online program and other } \\
\text { organizations }\end{array}$ & Consolidation, accreditation \\
\hline $\begin{array}{l}\text { 6.3 System identity and function } \\
\text { An institution's strengths, weaknesses and primary } \\
\text { function within the larger system }\end{array}$ & $\begin{array}{l}\text { Financial pressures, flagship } \\
\text { status, alignment with other } \\
\text { institutions, political obstacles }\end{array}$ \\
\hline $\begin{array}{l}\text { 7.1 Shared understanding of key terms } \\
\text { Key terms that were difficult for survey } \\
\text { participants to define }\end{array}$ & Terminology \\
\hline $\begin{array}{l}\text { 7.2 Shared tools } \\
\text { Tools and technologies that are or could be shared } \\
\text { by system institutions, e.g. learning management } \\
\text { systems }\end{array}$ & Common LMS, tailoring content \\
\hline $\begin{array}{l}\text { 7.3 Gaining competitive advantage via strategic } \\
\text { partnerships } \\
\text { Improved competitive strength achieved by partneri } \\
\text { with other individuals, groups or institutions }\end{array}$ & Strategic partnerships \\
\hline
\end{tabular}




\begin{tabular}{|l|l|}
\hline 7.4 Competent leadership & Expertise, leadership, \\
Appropriate leadership for online program & future vision of online \\
7.5 Curricular governance & \\
How decisions about curricula are made & Integration of programs, \\
\hline 7.6 A both/and model for online program & Major driving forces, learning \\
management & community \\
Some aspects of the online program are managed & \\
centrally, while others are managed locally, i.e. & \\
hybrid model
\end{tabular}

While one respondent frequently referred to online programming as simply another "modality," most survey respondents felt that managing online programs is very different than managing face-to-face programs. In that context, many survey respondents at each institution pointed to a lack of resources and a general lack of awareness for what type of collaborations might exist with other USNH institutions. Similar to responses in survey question \#6, when study participants were asked to identify opportunities for system-level collaboration, very few respondents mentioned one or more of Zimpher's three benefits of "systemness" (2013) with no respondents mentioning communityrelated benefits. In short, there seemed to be a lack of awareness or focus on what type of positive outcomes could emerge from intra-system collaboration. With the exception of a productive partnership between Granite State College and Plymouth State College, most 
respondents felt that productive collaboration with other system institutions would be too difficult. According to several survey participants, the most challenging obstacles to overcome are political in nature. Even though several survey participants from UNH pointed out the lack of incentives to participate in a more centralized administration model, most participants acknowledged the potential benefits of centralizing back-office services such as enrollment management, IT support, marketing and student support. Because of the perceived disincentives for those at the "big dog" institution, UNH, there were very few visionary statements about how collaboration among system institutions could be mutually beneficial. However, one survey respondent from outside UNH offered the following insightful statement,

We need to get real about the current and future challenges. We won't make up for enrollment deficit with new residential growth. The growth opportunities for our institution will come via low residential programs along with hybrid and fully online programs. We need to reach more out-of-state students with our unique programs. We also need to make a 3-year investment at the system level to ensure we have the right resources in place along with a clearly articulated brand and cost or value proposition.

This respondent recognizes online programming as a tool to help overcome declining residential enrollment by targeting more nontraditional out-of-state students and reinforcing Zimpher's notion of the system being more effective than the sum of its parts (2013). This response also demonstrates leadership by chiding colleagues to "get real" about the current and future challenges. 


\section{Phase Two: Interview Results}

In this study, the second phase of data collection involved interviewing six individuals with six questions. These individuals are directly responsible for administering online learning at their USNH institution and were participants in the online survey as well. Each participant was purposely selected based on their knowledge of key categories that emerged in survey questions. Accordingly, four participants work at UNH, one at the USNH office, and one at Granite State University (see Table 12). Only one participant from GSC agreed to participate in the interview phase of the study and no participants from KSC or PSU were asked to participate since both institutions offer little or no degree programming; a fact the researcher did not learn until the survey phase of the study was underway.

The iterative process of refining categories led to more memos and the identification of new categories. As these new categories were validated by additional data, selective coding was used to help define the questions used in the interviews.

\section{Table 12. Interview Participants}

\begin{tabular}{|l|l|}
\hline Role & Institution \\
\hline President & Granite State University \\
\hline Associate Vice Chancellor for Partnerships and & University System of New \\
\hline Shared Services Initiative & Hampshire \\
\hline 2 Deans & University of New Hampshire \\
\hline
\end{tabular}




\begin{tabular}{|l|l|}
\hline Associate Director & $\begin{array}{l}\text { UNH Online, University of New } \\
\text { Hampshire }\end{array}$ \\
\hline Associate Director & UNH, Academic Technology \\
\hline
\end{tabular}

Five new themes emerged from the interview responses. These themes are described below (see Table 13) and include supporting categories that emerged during open coding. A summary of each interview is provided below.

Table 13. Interview Themes, Definition \& Categories

\begin{tabular}{|l|l|}
\hline Theme(s) \& Definitions & $\begin{array}{l}\text { Supporting } \\
\text { Categories }\end{array}$ \\
\hline 1.1 Local priorities and identity supersede system & Faculty support, \\
opportunities & financial \\
This theme refers to each institution's need to prioritize the most & priorities \\
urgent operational issues on a day-to-day basis, e.g. enrollment & \\
growth, compliance with accreditation, communication with & \\
governance bodies, over and above any potential benefits that & \\
might be realized through external partnerships. & \\
\hline 2.1 Shared understanding of key terms & Terminology, \\
Key terms that were difficult for survey participants to define & “online" as \\
\hline
\end{tabular}




\begin{tabular}{|l|l|} 
3.1 A market-driven guide for intra-system collaboration & Different models \\
need to be clarified if system institutions were to seek out & \\
increased collaboration with other system institutions & \\
\hline 4.1 Belief in a statewide system & Unique function, \\
System stakeholders' belief and willingness to participate in & business model, \\
system-level collaboration & curricular \\
4.2 Brand cachet & governance \\
The reputation or strength of brand for each institution in the & responsiveness, \\
system & reputation \\
\hline
\end{tabular}

Interview Question 1

This study draws on eight principles of online program administration (King, 2013; Rovai \& Downey, 2010) to help understand how online programs in large-scale contexts like university systems are administered. After reviewing how this study's survey respondents ranked these eight principles, do you agree with these rankings? Why or why not? Which three factors do you feel are most important in the context of a statewide system like USNH where enrollment growth and reduction of expenses are top priorities? 
There was a wide variety of responses to this question. For the most part, interviewees weren't surprised by the results. One theme emerged in the responses for this question: "local priorities and identity supersede system opportunities."

Theme 1.1: Local Priorities and Identity Supersede System Opportunities

This theme refers to each institution's need to prioritize the most urgent operational issues on a day-to-day basis (e.g. enrollment growth, compliance with accreditation, communication with governance bodies), over and above any potential benefits that might be realized through external partnerships. This theme also acknowledges that in the current system model, each institution is responsible for its own revenue generation with very little cross subsidization of programs or functions occurring across the system.

One participant didn't agree with other UNH respondents who ranked "local control of operations" as the least important factor but acknowledged that such responses were logical since online programs at each of the USNH institutions are already administered locally with no connection to other system institutions.

We have a new world older. Flexibility and hybrid are important approaches—-so, implementing programs with the appropriate strategy is important. Seeing 'local control of operations' at the bottom of the list confuses me since we at UNH embed our online programs in our departments. We deliberately chose to own this locally and not work with a vendor. This might be a misunderstanding of the function. But we also have different models at play within the USNH system. GSC uses a lot of adjuncts and partner with groups that have pre-canned curriculum. 
In this response, interviewees strengthen the belief that local control is a foregone conclusion--and therefore less prioritized--because each institution in the USNH system relies on its own local operational. Another interviewee points out that,

Strategic planning makes sense at the top of the list. This connects an institution's mission to the market. Most importantly, it helps answer the question: How do you deliver your mission in a changing world? Moving courses online should be an outgrowth of strategic mission. And, any decision must go through academic governance. There is always a role of faculty in governance. The amount of faculty buy-in depends on the type of school--it's a continuum.

Similar to the other response discussed earlier, this interviewee suggests that the ranking of the eight factors is understandable. Moreover, the interviewee believes that the second most highly ranked factor--governance--was appropriately ranked.

Perhaps the most poignant expression of this theme was shared by one interviewee from UNH, "I think it's hard for people who are administering online programs to prioritize some of these other factors when the most pressing issues are securing faculty support and so on." Similar to the aforementioned responses, this interviewee believes that it's difficult to prioritize anything other than the most urgent needs such as gaining faculty acceptance.

Interview Question 2

Based on this study's survey responses, the lowest ranking factors were marketing, financial management and local control of decision making. Since marketing is such an essential factor in terms of student recruitment, why do you think it was in the bottom 3 of 8 factors? 
The intent of this question was to understand why marketing was ranked in the bottom three of eight factors when it is important to recruit students for both online and onsite programs.

\section{Theme 2:1 Shared Understanding of Key Terms}

One theme that emerged from this question--shared understanding of key terms-was also evident in survey question \#7. In the following response, the interviewee suggests that the terminology used matters since it's at times difficult to find a shared understanding of terminology, "This makes sense that it's lower, but the term that's used matters. What kind of 'marketing' are we talking about? In many cases, this term has a negative connotation for faculty. This could be lower because it's sequential...other factors precede it. We definitely need quality and faculty support first." Interview Question 3

It's difficult to allocate more funding for online programming without an institutional and/or system-wide strategic plan that provides specific goals and details around how new growth in this area will benefit an institution over time. If such a strategic plan were created for one of the USNH institutions, what details would be needed to help ensure it would be effective and how might it help improve collaboration with other USNH institutions?

This question asked interviewees to consider the details or areas that would need to be included in a strategic plan for administering online programs if such a plan were to be created for their institution. The main theme that emerged from this response spoke to the need for clarity in regard to role and how funding is allocated. Accordingly, the theme was labeled: "a market-driven guide for intra-system collaboration." 


\section{Theme 3:1 A Market-Driven Guide for Intra-System Collaboration}

This theme describes the expectations around potential collaboration of system institutions. More specifically, the theme refers to the roles and other details that would need to be clarified if system institutions were to seek out increased collaboration with other system institutions. One interviewee points to the need for such details to be specific and clear about what the positive outcomes would be, "It's difficult to allocate more funding for online programming without an institutional and/or system-wide strategic plan that provides specific goals and details around how new growth in this area will benefit an institution over time." Another interviewee suggested that such a plan should focus on improved quality, instructional approach and attention to price,

The market is increasingly competitive and becoming regionally competitive as well. Quality then wins out. Great is becoming accessible...Good won't be good enough. We don't have a systemwide programming plan in place for online--there should be an integrated plan. Each institution is tied to certain financial models that determine how they offer online programs. We need to figure out a business model that links program quality to price.

Similar to Zimpher's notion of systemness (2013), these responses point to alignment with improved efficiency and price.

Interview Question 4

At this point, UNH focuses only on graduate-level online programs. If UNH were to begin offering undergraduate online programs, what do you think the potential would be for enrollment growth and what obstacles would need to be overcome? How could collaboration with other USNH institutions help with this endeavor? 
This question was posed because of the following survey response that suggested there was some level of confusion about whether UNH was allowed to offer online degree programs:

There isn't a single coherent strategy for online learning. There are broad rules that define how we manage courses--governance via faculty oversight. We haven't focused on undergraduate online degree programs, but there has been a miscommunication that we won't allow that. I think the market has also been seeking out more hybrid than just online.

With that in mind, this question sought to understand whether interviewees from UNH felt that there were unrealized opportunities to pursue online undergraduate degrees and if so, could system-level collaboration help this effort. After coding and analyzing responses several themes emerged: belief in a statewide system and brand cachet.

\section{Theme 4.1 Belief in a Statewide System}

One interviewee questioned whether administrators at each system institution were able to identify productive ways to collaborate. However, this interviewee pointed to the deeper issue that influences administrators' willingness to collaborate with other system institutions: Do they believe in the statewide system?

We need to identify who the real competition is. There are some effective ways we can collaborate. We need to focus on growing revenue. The only way we can do this is by working together. We need to start with the question: do we believe in a statewide system? If Plymouth didn't exist, where would the north country be? Tapping into online revenue to augment residential outreach is important. We're in a new era. It's harder and harder to enter into these new markets, so we need to be more strategic about it. 
Another interviewee suggests that the biggest obstacle to offering more online undergraduate programs is the faculty senate, "UNH should be looking at this. The biggest obstacle is the faculty senate. We had over 1400 students taking undergraduate classes online--just UNH residential students. Social work could take $70 \%$ of their program online. We could fulfill this need almost all online. There has been no oversight of individual course development for undergraduate--no instructional design services or oversight."

\section{Theme 4.2 Brand Cachet}

This theme refers to the reputation or brand strength for each institution in the system. As the flagship institution in the system, UNH maintains the highest level of brand strength. This dynamically influences how each institution perceives their potential to reach new audiences, price programs and determine whether collaborations are beneficial. One interviewee summed up this theme by relating UNH's brand to its role in any system-level collaboration to develop new online programs, "Granite State doesn't have the same cachet as UNH, so they would need to put UNH in the lead and focus on back office service provision to other institutions within the system." In this response, the interviewee contrasts UNH's brand to GSC and suggests UNH should retain the lead role to better leverage UNH's stronger brand or reputation vision the market.

\section{Interview Question 5}

In many responses, Granite State College was mentioned as a potential resource or partner for other USNH institutions who desire to grow their online programs. How might one institution in the larger statewide system benefit other institutions based on that institution's lower cost structure and historical success in this area? 
This question sought to understand whether interviewees felt GSC could provide support for online programs to other USNH institution. The most comprehensive response for this question offers different steps to help support this level of collaboration. No theme was identified in this question.

First, identify which institutions have which programs (already have a lot of overlaps). Unless they are mapped to market segment, we should consider consolidating them to some degree. Step two: We should work towards a common LMS that would allow students and faculty to migrate more seamlessly across institutions. Step three: Instructional design and faculty development are two sides of same coin. Accessibility, incorporating assessments and then faculty dev to ensure faculty are delivering the best value to students in the learning process. $82 \%$ of GSC is online - they take good online engagement and feed it back to onsite. Extend this to expand residential access. UNH was losing summer students. We could keep them engaged while they are off campusespecially because many UNH students are from out of state. Cultivate utility of online learning. Map out the full spectrum of how online can complement student needs. Not just delivering content, cultivating a lifelong online learner. Build affinity while they are online, then this generation will spend the next 40 years working in many different roles - need to keep come back for continuing education (especially online). Not just thinking about alumni who will give dues.

Interview Question 6

Do you have any other comments or thoughts about how to administer online programs more effectively in a statewide system?

No additional themes emerged from answers provided in this question. 


\section{Overlap of Survey and Interview Themes}

When comparing themes that emerged in survey responses compared to interview responses, there were several areas where overlap was apparent. In these overlapping areas, prior research focusing on how online programs are administered also identified the same or similar factors. This section describes themes that were found in both surveys and interviews and provides some context regarding how each factor was described in prior research.

\section{Strategy}

In the survey responses, respondents discussed three different strategic approaches related to managing online programs: no strategy, an emerging strategy and a strategy that relies exclusively on face-to-face program strategy. In interview responses, one interviewee offered a detailed description for how USNH institutions can partner more successfully. In both survey and interview responses about strategy, study participants reference budget, roles and opportunities for collaboration. In the response below, an interviewee points to the need for improved quality assurance, collaboration among system institutions and a business model that helps connect quality to price.

The market is increasingly competitive and becoming regionally competitive as well. Quality then wins out. Great is becoming accessible... Good won't be good enough. We don't have a system wide programming plan in place for online--there should be an integrated plan. Each institution is tied to certain financial models that determine how they offer online programs. We need to figure out a business model that links program quality to price. 
In survey responses, one study participant mentioned that they are still defining their strategy, "As an institution, we are in the process of defining our online strategy," while another survey respondent stated that his "strategy is evolving but is coming with a lot of thought." In both cases, this discussion about strategy overlaps with the aforementioned interview response. Rovai and Downey (2010) discuss the connection between strategic planning and reaching a larger audience using online programs. According to Legon and Garrett, when an institution relies on a strategic plan that integrates the preferences of their audience, increased enrollment and revenue growth often follow (2017).

\section{Terminology}

Another theme that emerged in both surveys and interviews was the need for "a shared understanding of key terms." In survey responses, respondents pointed to difficulty defining "online program” or "quality." In several interview questions, respondents also stated that some terms related to online programming are difficult to define. In the following statement, the survey participant suggests there are challenges defining the term "marketing."

This makes sense that it's lower, but the term that's used matters. What kind of 'marketing' are we talking about? In many cases, this term has a negative connotation for faculty. This could be lower because it's sequential...other factors precede it. We definitely need quality and faculty support first.

In this response, the survey participant suggests there are terms, such as "marketing," that are difficult to define. Furthermore, the respondent suggests this particular term often has a negative connotation for faculty. When reviewing the recent 
literature on this topic, the most recent CHLOE report from 2017 stands out as a helpful resource when considering the potential source of terminological confusion among online program administrators (Legon \& Garrett, 2017). In this report, the authors state that many postsecondary institutions are in the process of moving their online programs from a peripheral to a mainstream function,

This focus reflects our shared belief that online education has been moving from an experimental and provisional status to a mainstream component at an increasing number of colleges and universities. This requires changes in leadership, management, finance, and strategic objectives (p.7,)

Additionally, in this same report, the authors suggest that online programs have been subjected to a more competitive market compared to five years ago. According to the report (Legon \& Garrett, 2017), half of the individuals surveyed by the CHLOE report "perceived today's online market to be more competitive than five years ago" (p.15). In a more competitive environment, it is no wonder that changes in leadership, management, finance and strategy are required. Along with these rapid changes has come more disagreement and confusion around what such terms mean. This differentiation of terminology is perhaps most pronounced by a trend where more institutions are relying on a dedicated chief online education officer to manage issues related to mission, resources, faculty needs, technology, curriculum, quality assurance, student demand and accreditation (Legon \& Garrett, 2017). Since the needs online students have in many of these domains are different than face-to-face students, terms that were used in the past or that characterize face-to-face programming do not always have the same meaning when discussing online programs. 


\section{Brand Cachet \& System Identity}

The topic of identity came up often in both survey and interview responses. In survey responses, student participants spoke about institutional identity in terms of institutional role and alignment of priorities with other system institutions. Gaskell and Hayton also state that institutions affiliated with statewide systems often assume a niche role, such as serving online students or offering degrees in unique content areas (Gaskell \& Hatyon, 2015). Since several survey participants mentioned Granite State College as an institution with unique capabilities to offer online programs. Due to these survey references, interview participants were asked whether they felt it would be advantageous for Granite State College to support other USNH institutions with online program services, such as marketing, instructional design or enrollment management. In most interview responses, survey and interview respondents acknowledged that such an idea could offer positive outcomes. However, respondents from UNH were less supportive of this idea when asked to comment on how such collaboration would occur. In one interview response, the study participant asserted, "Granite State doesn't have the same cachet as UNH, so they would need to put UNH in the lead and focus on back office service provision to other institutions within the system." In a survey response, one administrator suggested that UNH was the "big dog" among smaller institutions and that "the opportunity to collaborate may not be there."

While the issue of priority was never directly mentioned by survey participants, there were several survey responses that referenced the need for more financial support, marketing and support from leadership. When discussing whether there was an institutional strategy for online programming, the majority of respondents stated that 
those policies and procedures used for online programming were used for online programming. This perspective was summarized by one study participant who mentioned that online programming was nothing more than a different mode. In both survey and interview responses, it was evident that local operational priorities often took precedence over system-level goals since online program administrators were not tasked to prioritize system-related goals and in many cases, they were unable to identify appropriate next steps to facilitate collaboration. Subsuming online programs under face-to-face programs resembled the "prioritizing local priorities over system-level opportunities" theme that emerged in interview responses. This theme referred to each institution's need to prioritize the most urgent operational issues on a day-to-day basis, e.g. enrollment growth, compliance with accreditation, communication with governance bodies, over and above any potential benefits that might be realized through external partnerships.

\section{Table 14. Survey and Interview Theme Overlap}

\begin{tabular}{|l|l|l|}
\hline Overlapping Topic & Survey Responses & Interview Responses \\
\hline Strategy & $\begin{array}{l}\text { Managing online } \\
\text { programs like face-to-face } \\
\text { programs }\end{array}$ & $\begin{array}{l}\text { Local priorities and } \\
\text { identity supersede system } \\
\text { opportunities }\end{array}$ \\
\hline Terminology & Shared understanding of & Shared understanding of \\
key terms & key terms \\
\hline Brand cachet \& system & Brand cachet & Alignment with other \\
identity & & USNH institutions \\
\hline
\end{tabular}




\section{Chapter Summary}

Fourteen themes were identified in this study's survey responses and five themes were identified in the interview responses (see Tables 11 and 13 respectively). Themes from survey and the interview were identified independently although the interview questions were largely influenced by the themes that emerged from the survey responses. Central to this study were themes related to collaboration, relationships and the characteristics of the organizations and stakeholders who serve in and are served by these organizations. In most cases the local priorities of those administering online programs took precedence over system-level goals or priorities. In many cases, participants referenced "language" or "terminology" as being an essential part of the discussion since the study participants often had different notions of what a term like "marketing" or "quality" mean in the context of administering online programs. Participants' concern that collaboration or a lack of collaboration within the statewide system would cause "program cannibalization" was a recurring category found in both the survey and interview responses and in several cases, respondents suggested that online programs within the larger statewide system were "balkanized." Chapter 5 provides a discussion of the results, presentation of several theories, limitations and the value of the research. 


\section{CHAPTER FIVE: DISCUSSION}

In the following chapter, I will discuss the findings of this study. I will begin by reviewing the problem statement and the research questions that guided this study and then connect the 12 themes discussed in chapter four with the literature and conclude with additional areas of research as well as address the limitations of this study.

\section{Statement of the Problem}

Even though most online program administrators typically administer their online programs differently than face-to-face programs (Chaney, Chaney, \& Eddy, 2010;

Discenza, Howard, \& Schenk, 2002; Lowenthal \& White, 2014; Rovai, 2003; Rovai \& Downey, 2010) the majority of online programs are still governed by faculty and the terms of accreditation (Gaskell \& Hayton, 2015; Maguire, 2007). Regardless of which approach an institution prefers to use when administering their online programs, Berge (2007) suggests that strategic planning should occur early in the process to ensure the specific needs of online students are fully understood and prioritized.

Although previous studies describe how online programs should be conceptualized and administered (Rovai, 2003; Rovai \& Downey, 2010), there are very few previous studies that focus on how online programs should be administered on a larger scale (Essary, 2014) or in a statewide system (Maguire, 2007; Vines, 1998). As online program administrators in statewide systems become better equipped to collaborate with other institutions in their system, they can improve the competitiveness 
of their online program by leveraging increased scale and collaboration (King, 2013; Legon \& Garrett, 2017; Zimpher, 2013).

This study explored how institutions affiliated with a statewide university system administer their online programs. The following research questions guided this study:

\section{Research Questions}

- How are online programs administered by institutions affiliated with a public statewide system?

- Based on the perspective of institutional administrators, what are the advantages and disadvantages of administering online programs in a public statewide system?

- Do study participants prioritize some features or characteristics of their online program over others?

\section{Discussion of Results}

Since this study seeks to understand the influence statewide systems have on how online programs are administered, the complexity and multifaceted nature of these types of organizations adds to both the "thickness" or complexity of the data gathered.

Additionally, the process of categorizing data under the appropriate theme was at times more difficult since it is challenging to compare one statewide system to another. Consequently, this lessens the ability to generalize findings or compare them to other studies that seek to understand. Several study participants referenced the complexity of the organizations being discussed as well as the many different meanings ascribed to some of the key terms used in the study such as "quality." 
After evaluating survey and interview responses, an attempt to answer the first research question was made. Each identified theme offered insight into this question. This section of the study will highlight several of the more salient themes that help deepen understanding of how online programs are administered in public statewide systems.

\section{Research Question 1}

\section{How are online programs administered by institutions affiliated with a public} statewide system?

Since the term "local" or "central" wasn't descriptive enough for most of the survey participants, they in many cases questioned what appeared to them to be a false dichotomy and instead focused on which elements of online program management would be best managed locally or centrally. For example, in many responses, study participants stated that their day-to-day operations were managed locally with no connection to system-level governance. In cases where interviewees spoke about the potential of administering their online programs centrally, they still suggested that their institution maintain local control over primary functions such as marketing and course development.

In response to a more flexible and realistic organizational structure, one survey respondent suggested that an "and/both typology" was preferred and more realistic based on various factors related to politics, finances, roles and institutional identity. When survey participants were asked to offer their own opinion about whether they felt a local or centralized model would work better for their institution, many suggested that it was imperative to first seek out a common vocabulary for key terms such as "administration, marketing and even leadership.” Additionally, many survey and interview participants offered additional priorities that help determine what type of organizational structure or 
typology an institution should use. In most cases, information or opinions about the management of online programs were provided without connection to the larger system priorities.

- Shared tools;

- Gaining competitive advantage via strategic partnerships;

- Competent leadership;

- Curricular governance and;

- A both/and model for online program management.

In terms of shared tools, several study participants suggested that for improved collaboration to occur between system institutions, tools or platforms would need to be standardized to simplify data sharing and enrollment management. In several responses, participants noted that while Canvas was the LMS of choice for most institutions in the system, not all institutions had migrated to that platform. While partnerships at first seemed peripheral to the question of organizational structure, it became more evident that several student participants felt that the types of partnerships established by institutions influences their capacity, brand and to a large extent, their ability to enter into other meaningful and productive relationships with other institutions within their own system. In one response, a study participant referenced a partnership that one UNH organization had entered into with a third party. Questions regarding managing the UNH brand, curricular rigor and locus of control were discussed in light of how that partnership might influence that organizations willingness to partner with other UNH-based groups. In another response, a survey participant pointed out that one of the USNH institutions used "pre-canned" content that was taught by adjunct faculty. Based on several participant 
responses, this type of partnership reduced their willingness to partner with that institution unless the nature of the partnership involved back-office support.

Several other major factors that define how online programs are administered are funding and quality assurance. More than $70 \%$ of the study participants suggested that their online program lacked sufficient financial support. In terms of quality assurance, many study participants pointed to their institution's alignment with faculty governance as the primary means of ensuring curricular quality. In addition to curricular governance, study respondents also referenced policy, standard operating procedures and technical infrastructure as factors that influence quality assurance. One study participant summed up their institution's quality assurance in this way, "A curriculum built on clearly articulated learning outcomes, aligned with disciplinary and workforce expectations, delivered through well-constructed courses developed by talented instructional designers and facilitated by scholar-practitioners, primarily through asynchronous online courses (as well as some blended and hybrid versions), with appropriate mechanisms for assessment to ensure efficacy." Visible in this definition are positive outcomes, expectations, instruction, course design, format and learning management tools. Survey respondent \#1 from UNH mentions their group manages online programming using "operational and other documents guide our daily work."

\section{Research Question 2}

Based on the perspective of institutional administrators, what are the advantages and disadvantages of administering online programs in a public statewide system? 
The main theme that emerged in answers to this question was whether or not study participants actually believed in a statewide system. In other words, once study participants felt comfortable with the terminology used so that they knew what the term "system" referred to, they often pointed to a disconnect with the larger system or other system institutions in terms of how their own role or function overlapped with system priorities. In many cases, individuals mentioned that it was difficult to establish connection with their peers from other institutions and if they did, it was challenging to collaborate. When sharing her thoughts about this topic, one study participant stated, "We need to identify who the real competition is. There are some effective ways we can collaborate. Need to focus on growing revenue. The only way we can do this is by working together. We need to start with the question: do we believe in a statewide system? If Plymouth didn't exist, where would the north country be? Tapping into online revenue to augment residential outreach is important. We're in a new era. It's harder and harder to enter into these new markets, so we need to be more strategic about it." In this response and others about the larger system seem to be "What is the system?" and "Are members of the system willing to collaborate if the conditions were favorable?" To understand the former question, it is helpful to consider Zimpher's definition of "systemness" (2013; below) to see if there are features of a robust and synergistic system that could be appropriated in other statewide systems.

\section{Willingness to Collaborate with other System Institutions}

Almost every participant in the survey and interview referred to the challenges and opportunities of system-level collaboration. In several responses, respondents pointed to "program cannibalization, balkanization, and politics" as common obstacles to system- 
level collaboration. This sentiment was connected to all areas of potential collaboration; not just administering online programs. There were numerous categories, such as "system characteristics" and "relationships" that help describe the context of potential collaboration. Additional categories include: centralization, geography, finances, competition, mission, organizational complexity, synergy, scale, road map and policy. While collaboration between system institutions was rarely considered impossible, participants in this study also never discussed a rationale for potential partnership with other system institutions. In several cases, participants from one institution suggested their attempts to partner had not been welcomed by the other USNH institution. One respondent commented: "I am not optimistic for USNH collaboration around the administration of online degree programs. The main obstacle, in my opinion, is the current financial struggle felt by higher education in NH and more broadly. Every partnership would result in a division of an ever-shrinking pie."

\section{$\underline{\text { Systemness }}$}

"Systemness" is a term used by Nancy Zimpher, SUNY Chancellor Emeritus. "Systemness" refers to the extent to which an entity exhibits properties of organized action that defines its existence and impact on the surrounding environment (2013). In this study, one respondent spoke in great depth about the need for statewide systems like USNH to exhibit greater levels of collaboration. Another respondent discussed the benefits of a system or centralized services:

Strong strategic and operational leadership at the system or institution level with extensive knowledge and experience of online learning is required first before even embarking on a decision regarding organizational administration. My personal opinion is 
that a centralized approach is best to create a consistent experience for the student, the faculty, and the administration.

\section{$\underline{\text { Local Priorities }}$}

Ultimately, the majority of study participants stated that their local day-to-day priorities supersede all other considerations such as system collaboration. Based on responses provided in the survey and interviews, it appeared that this focus on immediate priorities over and above system or community needs is strengthened when an institutional strategy focused exclusively on online programs does not exist and the locus of authority for online program-related decisions is managed entirely by the faculty senate. Based on King's subsidiarity principle (2013), this form of local and autonomous management of an online program is advantageous, but when considering Zimpher's three benefits of systemness (2013), there are fewer opportunities for system institutions to collaborate around statewide initiatives or to reduce operational expenses by centralizing certain functions when local priorities always trump system-level opportunities to collaborate. These responses confirm the findings of other researchers who suggest that four-year colleges pursue online programs primarily for revenue generation (Berg, 2002; Legon \& Garrett, 2017; Rovai, 2009; Rovai \& Downey, 2010). Since revenue generation can be increased by lowering operational costs (Miller \& Schiffman, 2006; Roby, Ashe, Singh, \& Clark, 2013), this theme offers insight into the challenges and opportunities administrators face when seeking to manage their online programs effectively, but also in a manner that allows future growth and a reduction of operational expenses.

Since the main priority for online program administrators is typically enrollment 
growth or revenue, each institution in the system is focused exclusively on their local priorities. It was apparent from study responses that very little cross subsidization of programs or functions occurred across the system, except in cases such as the online master's degree program created by Granite State College for Plymouth State College. As noted in chapter four, most interviewees felt that local control was an already established feature of their program, which meant that most study participants had not yet explored or considered the benefits of a different model that might rely on increased centralization. As stated by a study participant from UNH "I think it's hard for people who are administering online programs to prioritize some of these other factors when the most pressing issues are securing faculty support and so on." Since there were few examples in the statewide system of productive collaboration, many study participants were either ambivalent about such opportunities or felt that pursuing intra-system partnerships might jeopardize their financial status or compromise their brand. Presidents were more hopeful about system partnerships and rarely mentioned potential obstacles, but the majority of UNH participants were concerned about Compromising or watering down their brand. Johnstone describes this concern in relation to the flagship campus--in this case, UNH--and suggests one of the main tensions statewide institutions experience is the "real or putative degree of difference in the prominence or esteem accorded to so-called flagship campuses” $(2013$, p. 6).

Although there was very little interest or enthusiasm to collaborate with other institutions within the system, one study participant described how institutions could successfully collaborate. One president in this study detailed the roles and financial arrangements that would need to be clarified if system institutions were to seek out 
increased collaboration with other system institutions. However, along with optimistic answers were some responses that were less hopeful about potential collaboration, "It's difficult to allocate more funding for online programming without an institutional and/or system-wide strategic plan that provides specific goals and details around how new growth in this area will benefit an institution over time." In this response, the study participant reinforces the idea that institutions will need to clearly understand how collaboration with other institutions will benefit their institution first.

\section{$\underline{\text { Research Question } 3}$}

Are some program characteristics perceived to be more important than others?

Survey question \#7 was designed to help understand whether administrators prioritized certain online program characteristics more important than others. Survey respondents ranked the factors in the sequence shown in Table 15.

\section{Table 15. Factor Priority}

\begin{tabular}{|l|l|l|}
\hline Factor & Ranking & Average Response Score \\
\hline Strategic planning & 1 & 8.2 \\
\hline Faculty support & 2 & 7.4 \\
\hline Quality assurance & 3 & 6.8 \\
\hline Online course design /pedagogy & 4 & 6.3 \\
\hline Student retention & & 5.9 \\
\hline Marketing & 5 & 5.8 \\
\hline
\end{tabular}




\begin{tabular}{|l|l|l|}
\hline Financial management & 7 & 5.1 \\
\hline Local control of operations & 8 & 4.4 \\
\hline
\end{tabular}

After evaluating the responses from this question and assessing the follow-up question included in the interviews, it was evident that most interviewees felt that while the survey-informed ranking seemed reasonable to them, they also questioned whether or not there was enough clarity in relation to the factors provided. As stated by one interviewee,

This makes sense that it's lower, but the term that's used matters. What kind of 'marketing' are we talking about? In many cases, this term has a negative connotation for faculty. This could be lower because it's sequential.... other factors precede it. We definitely need quality and faculty support first.

In interview responses, many respondents prioritized local operational goals over system-level goals. When discussing local operations, such as marketing, quality assurance, revenue generation and infrastructure, several interviewees suggested a strategic plan was a top priority since any future funding would depend on a system-wide strategic plan, "It's difficult to allocate more funding for online programming without an institutional and/or system-wide strategic plan that provides specific goals and details around how new growth in this area will benefit an institution over time."

Because many study participants found the factors used in this question were difficult to define and also felt there was a strong influence of "local priorities" over system- or even institution-level concerns, many participants who addressed the rationale 
of the ranking felt the responses provided were accurate, but largely irrelevant. In many ways, the belief that the majority of survey participants would naturally prioritize the most immediate factors such as faculty support, quality assurance, pedagogy and student retention was consistent with the fact that no strategic planning existing at the institutional or system level to help integrate online programming with the larger system mission and longer-term priorities, such as a system-wide focus on sharing curricula or integrating marketing campaigns across system institutions to reach a broader audience. In terms of those factors that ranked low, such as "marketing," most interviewees felt that the factor ranking reflected the issues that had immediate priority rather than longer-term importance. This was particularly evident with "marketing" since it has primacy over "retention" and other factors simply because it's impossible to retain students unless you first recruit them.

\section{Areas of Future Study}

Although this study examined both local and system-level operations related to the management of online programs, most study participants framed their survey or interview responses within the scope of their own unit and institution. While some respondents did discuss the statewide system in their responses, it was difficult to focus questions exclusively on the larger statewide system since many study participants lacked the vocabulary and motivation to consider the implications of collaboration at the system level. Subsequently, although it was apparent that most administrators would be willing to collaborate with other colleagues within the system, they were usually unsure about the system's purpose, what the benefit of collaboration would be and how they would

actually take any type of step towards such collaboration. In Maguire's study of distance 
education policy (2007), her main finding was that faculty needed to be more informed about and involved in the development of distance education policy. Similar to Maguire's study, this study suggests that a broad range of stakeholders should be involved in developing strategy. Future studies could draw on Rovai's distance education evaluation framework (2003) to help identify those online programs that are successful. After successful online programs are identified, the study could determine which stakeholders were involved in the creation of strategic planning and how such planning was undertaken. Because McBain's research on university mergers points to organizational culture being the primary obstacle to improved collaboration (2012), any future studies examining how stakeholders communicate or work towards consensus should also consider organizational culture. Brown reinforces this idea by stating that any innovation or change implemented in a higher education environment depends on cultural change first (2014). Chaney, Chaney and Eddy also suggest that new policies or strategies should be supported by every group of stakeholders in the university environment, e.g. students, faculty and administrators (2010).

Another topic that surfaced several times in this study was leadership. Although one study participant suggested online programming is nothing more than an additional mode, more research could be focused on the specific background and skills needed for those managing online programs in a large organization, especially if that leader is responsible for both operational priorities and strategic planning. The most senior administrator at UNH who was directly responsible for the day-to-day operations of online programs and a UNH Dean both pointed out that online programs are typically most successful when a senior leader who has expert-level knowledge of online programs 
has sufficient authority to administer both the daily operations and longer-term strategic goals related to online programs.

While online learning has been around for decades, there are still few expert practitioners and leaders in the field. Strong strategic and operational leadership at the system or institution level--with extensive knowledge and experience of online learning-is required first before even embarking on a decision regarding organizational administration. Following that, my personal opinion is that a centralized approach is best to create a consistent experience for the student, the faculty, and the administration. I am still undecided on if that centralization should be at the system level or at the institutional level.

These assertions align with earlier studies that identified leadership as an important factor when prioritizing factors that determine the success of online programs (Garrison \& Kanuka, 2008; Johnstone, 2005). Garrison and Kanuka (2008) state, "Successful leadership of complex organizations in times of change requires more than a charismatic leader and fundraiser" (p.21). At the very least, effective leaders of online programs must be fully engaged in the process of transformation from beginning to end, be prepared to be held accountable for the initiative outcomes and understand both the limitations and possibilities inherent in online programming. Future studies could explore the relationship between these leadership characteristics, the level of autonomy afforded a leader of an online program and the amount of financial support provided to achieve long-term goals. While the most recent CHLOE report (Legon \& Garrett, 2017) has documented a shift towards online programs being managed by executive-level leaders, it 
is less clear how their specific background or skill correlates with their future success managing online programs.

\section{Affordability}

One issue that only appeared twice in study participants' responses, the affordability of online learning loomed in the background as a major factor influencing discussions about student needs. In one response, a participant noted that "We need to make a 3-year investment at the system level to ensure we have the right resources in place along with a clearly articulated brand and cost or value proposition." Similarly, another responded mentioned that since online was first launched, the hoped for outcomes of this new mode--reduced cost, improved access and quality--were largely unachieved. While online programs have improved access for many students (Essary, 2014), the cost of most online programs has not been reduced below the cost of face-toface programs outside of programs like those found at Georgia Tech or Straighterline. Since students will incur severe levels of debt by the time they complete their degree, it was surprising to the researcher that this topic was not mentioned more frequently as respondents spoke about their local institution's goals in regard to online programs. In many ways, this factor reinforces Zimpher's notion of systemness (2013), where community priorities are more effectively pursued within the framework of a large, cohesive system. When online programs are well managed and leveraged to improve access and lower cost, it's often possible to improve their affordability (Meyer \& Wilson, 2010; Rovai \& Downey, 2010). Future studies could seek to identify programmatic and strategic decisions that lower the cost of online programming with the intent of 
understanding how managing these in a statewide system can more effectively lower overhead costs.

$\underline{\text { Implementation of Curricular Policy and Accreditation Requirements }}$

While each USNH institution relies on different curricular policies when developing their online programs, the issue of accreditation came up frequently. There were also numerous overlaps with "governance" since the faculty senate often determines which degrees can be offered online and under what conditions. The rigorous accreditation process adhered to by USNH institutions adds to the overall complexity of the system and to the length of the student experience, e.g. four year minimum to complete a degree. One survey respondent referenced the length of degree completion in the following remark, "Let's fit the problem we're trying to solve. Degrees are from another era — too long, too costly." Future studies could focus on the flexibility of accreditation in relation to curricular innovation. Using Zimpher's (2013) concept of "systemness," researchers could seek to understand how innovation can be more effectively diffused within a statewide system that embraces Zimpher's notion of "systemness."

\section{Student Perception of Quality}

The participants referenced the difficulty measuring quality. On one hand, students have their own perceptions of quality (Gómez-Rey, Barbera \& FernándezNavarro, 2016), which weren't captured in this study since administrators were questioned as opposed to students. In relation to administrator perspectives, managing or controlling quality is believed to be complicated since curricular quality is primarily 
linked to accreditation requirements and to the hiring and management of faculty who govern curricular decisions (Berge, 2007; Miller \& Schiffman, 2006).

Constraints to growth are complex: In some areas we are challenged by faculty constraints and accreditation requirements, which in turn maintains quality control. We don't have the luxury of being held up by politics anymore.

Although it would be difficult to ensure a common vocabulary was being used, students' perceptions of program quality could be compared to administrator perceptions of program quality. Drawing on Gómez-Rey, Barbera and Fernández-Navarro’s (2016) suggestion that student's value learning benefits or outcomes more than faculty, this future study could seek to identify these hoped-for benefits or outcomes and then compare those to instructor's hoped-for learning outcomes.

Institutional Adaptation to Student Preferences

Participants felt that their institution is capable of adapting to student preferences. When adaptation is intentional, it considers the challenges many students confront at contemporary universities: poor completion rates, high costs, anachronistic or overly traditional processes. One study participant pointed out "The market is increasingly competitive and becoming regionally competitive as well. Quality then wins out. Great is becoming accessible...Good won't be good enough. We don't have a system wide programming plan in place for online--there should be an integrated plan. Each institution is tied to certain financial models that determine how they offer online programs. We need to figure out a business model that links program quality to price." Future studies could examine the effectiveness of change management within a larger statewide system that collaborates regularly and one that does not. 
Decisions that Codify How Work is Completed and by Whom

While the term "policy" usually captures the idea of which tasks are completed by whom, in universities, there are many decisions or processes that are managed by an individual who does not necessarily rely on a policy. King, Nugent, Eich, Mlinek and Russell (2000) define online program policy as "a written course of action adopted to facilitate program development and delivery in distance education” (p.3). When policies are formalized, enforced and governed, they can then more easily be shared between institutions that desire greater collaboration. However, Legon and Garrett (2017) remind us that "four-year public institutions have the widest internal variation or inconsistency in policy" (p.5) while King suggests: "The best level of governance for decisions to be made is where there is the most direct information about the body or bodies affected, with sufficient awareness of policies" (p.145).

One study participant pointed out the need for decisions to be made locally for fear of slowing down the program management process. Clearly defining which areas of administration might be targets for collaboration is important. Centralizing any administrative functions at the system level must never slow down a process, even though it may save money. Building on this observation, a future study could seek to identify the which functions can be centralized without jeopardizing the primary benefit of local control--efficiency.

\section{Social Responsibility}

Social responsibility rarely emerged as a topic since local needs trumped community or societal needs. Zimpher (2013) suggests that systems are able to more effectively meet the needs of the surrounding community. Future studies could research 
the relationship between a public university's commitment to access and its responsibility to serve the public. Since online programs typically improve an institution's access, future research could explore the nature of this relationship in public statewide systems like California State University since many of their institutions are impacted and lack the capacity to serve constituents.

\section{Limitations}

Every study has limitations. Limitations are potential weaknesses in a study that cannot be controlled by the researcher (Leedy \& Ormrod, 2014). The limitations in this study are as follows:

\section{Local Versus Central}

In most cases, study participants were able to provide insight into activity that occurs within their immediate unit, department or college, but it was at times challenging for some participants to provide additional insight into university-level or system-level dynamics. Even when study participants were able to draw on local and institutional knowledge, it was rare that respondents were able to offer insight into system-level priorities. Additionally, in most cases, participants lacked a shared vocabulary and motivation to explore several of the primary research questions when they were asked to comment on system-level dynamics. Although it would have been helpful to interview individuals outside of USNH who have experience managing online programs across system institutions, the scope of research for this study did not include stakeholders outside of USNH. 


\section{The Number of Study Participants}

This study engaged a total of 18 individuals. While the interview phase of the study allowed the researcher to probe more deeply into specific questions that had emerged after the survey questions were analyzed, the number of interviewees was six. Since USNH is a smaller system compared to many other systems in the United States, there were fewer individuals within the system who have some form of responsibility over online programming compared to administrators in larger systems with more online programs. Consequently, saturation of potential study participants was reached more quickly even though it took almost five months to engage all of the study participants. Additionally, one of the universities studied, Plymouth State University, did not have any online undergraduate or graduate programs. While the president of PSU participated in the survey, the scope of this study was smaller due to only three of the four system institutions having online programming.

Although the system's smaller size along with the researcher's affiliation with UNH allowed increased access to top-level administrators, it was still very difficult to obtain access to several higher-level administrators who were not employed at the researcher's university, UNH. In several cases, reaching a participant required 4-5 months of follow up. Lastly, although they were invited, the president of UNH and the Chancellors of USNH chose not to participate in this study.

\section{Repeatability}

Gaining access to the type of data that was gathered for this study was very difficult and may not be possible if the researcher does not work at the system being studied. In several cases, study participants were hesitant to share information about their 
internal operations or enrollment data. Because of such challenges, some data collection required more than three months of back-and-forth communication to assure study participants that their responses would be anonymous or to remind them to complete the survey. In many cases, study participants were willing to help the researcher as a professional courtesy because the researcher already had a good working relationship with that individual. Conversely, it was also possible that since the researcher worked at UNH, study participants who did not work at UNH may have felt the researcher was biased towards UNH and seeking to use the results of this study to advance a UNH agenda. Lastly, since USNH is not a large system, it was easier to recruit high-level administrators such as presidents, provosts and deans, although the president of UNH and Chancellor or USNH were invited to participate in this study but chose not to. Executivelevel participants might not be willing to participate in this kind of study in larger systems where it's often more difficult to gain access to executive administrators. Because of these complicating factors, it would be difficult to repeat this study; especially in a larger system or if the researcher were not an employee of the system being studied. Generalizability and Transferability

Although the results case studies are not easily transferred to other contexts (Yin, 2009), Guba (1981) suggests that there are various steps researchers can take to increase the transferability of study findings. In this study, sampling was purposive or based on a desire to represent as many different perspectives as possible. As recommended by Guba (1981), some study participants were asked to recommend other participants who they thought might have other perspectives. Next, as much as possible, this study relied on "thick data" (Gertz, 1973) that could more easily be compared or transferred to other 
contexts. In this study, New Hampshire has much in common with nearby states that share cultural, geographic and demographic characteristics similarities, such as Vermont, Maine, Massachusetts and other New England states. Consequently, it's more likely that conclusions reached in this study transfer more readily to nearby states. In relation to larger state systems, such as New York or California, the increased scale of postsecondary systems in these other states further complicates any attempt to generalize findings across systems of different size.

In addition to gathering "thick data," Guba (1981) recommends researchers develop a "thick" description of the data that details the context of the study. To work towards this outcome, Guba suggests researchers include a full description of all contextual factors affecting the inquiry. In this study, the constant comparison method helped the researcher pursue a line of inquiry over a prolonged period of time using a series of questions that were adjusted during the interview phase of the study. Additionally, this study includes numerous figures and information about instruments used in this study in the appendix. Lastly, a grounded theory approach provided the researcher with a more flexible framework to adapt questions, sampling and coding so that categories that appeared more frequently in the survey responses could be explored in more detail during the survey phase.

\section{Summary and Conclusion}

This qualitative case study explored perceptions of key administrators at institutions within the University System of New Hampshire to better understand how online programs are administered at their respective institution and within the system as a 
whole. Additionally, these administrators were asked whether they believe there are opportunities to collaborate with other system institutions and if so, how such opportunities could be pursued more effectively. After data were analyzed in light of the research questions, 20 themes emerged from the questions asked in the survey and interview. Themes identified in this study overlapped with earlier studies focused on online program by Rovai (2003) and Rovai and Downey (2010). King's subsidiarity principle (2013) was also apparent in survey and interview responses although most study participants did not believe that local control was an easy term to define or prioritize since they often recommended centralizing some operations while keeping others locally managed. There were three major findings in this study:

1. Study participants had a difficult time finding a common vocabulary when talking about online programs and the potential benefits of system-level collaboration;

2. Administrators always prioritized their local program tasks before any consideration about collaboration could occur; and

3. Although there was not a strategic plan in place to help system institutions collaborate, several participants offered suggestions for how such collaboration could occur.

\section{Finding 1. Common Vocabulary and Confusion about the System}

The first major finding was that the majority of study respondents lacked a common vocabulary to speak about online program management. Outside of the presidents who participated in this study, the majority of study participants did not prioritize system needs or articulate ideas to collaborate across institutions. When study 
respondents did talk about system-level opportunities for collaboration, they pointed to the need for a strategy that provided detail regarding institutional roles, finances, tools and a rationale for partnership.

\section{Finding 2. Local Priorities First}

The second major finding in this study is that in almost every response, study participants valued local operational priorities over system or community priorities. This was most pronounced for those participants who were most directly responsible for their institution's online programs since they had in many cases taken some preliminary steps to collaborate, but unable to determine how best to proceed. Although it is understandable that local priorities would trump the needs of the system, the majority of study participants were unaware of any system-level or societal needs (e.g. reducing student indebtedness or improving access for rural populations). Because of this disconnect between system-level goals and local operations, very few responses pointed to the broader needs of the audience such as reducing student debt or improving access for nontraditional students who would benefit from a fully online undergraduate degree. Since there was no strategic planning for online programming at any of the system institutions or at the system itself, the majority of decisions regarding online programming were operational in nature, prioritized local tasks or initiatives over community-level goals, such as lowering costs or improving access for students. This disconnect was also evident at UNH where online undergraduate classes help improve access for currently enrolled residential students who replace in-person classes with online classes, but aren't helpful for potential non-residential students who would like to 
complete an entire undergraduate degree online since UNH does not have fully online undergraduate degree programs.

While there were many responses that pointed to the notion of curricular quality, the majority of these responses inferred that quality assurance was most effective when governed by faculty. While such a perspective is supported by prior research (Laws, Howell, \& Lindsay, 2009), there was very little mention of how student preferences for specific high-demand programs or fully online programs influence the program development process. While this dynamic simplifies quality assurance and helps each institution adhere to terms of accreditation, it frequently limits the strategic potential of online programming since online programs are not differentiated in any meaningful way with face-to-face programs. This was apparent in responses about strategy where respondents pointed to face-to-face policy when managing online programs or referred to their institution's mission or the faculty senate as reasons their institution did not yet have any strategic planning related to online programming. This finding took on extra weight since almost all study participants felt that their institution would benefit from a strategic plan for online learning that helped justify additional funding and direction for their online programs. Very few respondents made the connection between lowering the operational costs of their online programs by scaling operations, centralizing certain functions and relying on other system institution's strengths to lower costs for students. While it's certain that most study participants understood and appreciated this idea, it was too removed from their day-to-day responsibilities. Therefore, comments about the potential benefits of intra-system collaboration were minimal and lacked optimism. This disconnect resembles Maguire's study (2007) where faculty didn't feel like they had been 
engaged in the process of policy development, which left them focused primarily on their most immediate responsibilities.

Several study participants mentioned the need to reach students during off cycle periods and also mentioned the ability to do so more effectively using online programs. However, similar to the first finding, many study participants struggled to define terms such as "online program" or "quality" in light of a shared vocabulary or a set of common conventions; instead referring at times to online learning as a "modality" or an "extension of the institution's mission." Individuals who were most directly responsible for the dayto-day management of online programs at their institution recognized the need for a dedicated strategy to help integrate their operations more effectively with their institution, but also pointed to the need for an executive-level leader who is focused exclusively on defining online strategy expansion.

\section{Finding 3. Principles for Intra-System Collaboration}

Although the majority of study participants acknowledged that a strategic plan for online programs would help them improve collaboration among other system institutions, several participants offered suggestions about how such collaboration should occur after there was agreement about roles, finance and timeline. One interviewee pointed to the need for such details to be specific and clear about what the positive outcomes would be, "It's difficult to allocate more funding for online programming without an institutional and/or system-wide strategic plan that provides specific goals and details around how new growth in this area will benefit an institution over time." Another interviewee suggests that such a plan should focus on improved quality, instructional approach and attention to price, 
The market is increasingly competitive and becoming regionally competitive as well. Quality then wins out. Great is becoming accessible...Good won't be good enough. We don't have a system wide programming plan in place for online--there should be an integrated plan. Each institution is tied to certain financial models that determine how they offer online programs. We need to figure out a business model that links program quality to price.

The most common obstacle to intra-system collaboration was "politics." After surveying the distance education literature for references to the exercise of political power, Maguire states,

Although the adult education literature and the public administration policy literature are both rich with political and power perspectives, the distance education participation literature does not contain such perspectives (p.40). This lack of prior research in this area presents opportunities for future researchers to explore how political power is consolidated and exercised in the context of online programs.

Survey participants referred to a misunderstanding of system strengths, district among system members and a lack of support or direction to pursue such partnerships. When asked whether one university within the system could leverage its strength in administering online programming, many respondents felt that this type of collaboration would be productive, but they could not picture how they would be able to overcome the political obstacles. Regardless of this barrier, one study participant offered a set of recommendations for such collaboration, 
First, identify which institutions have which programs (we already have a lot of overlaps). Unless they are mapped to market segments, we should consider consolidating them to some degree. Step two: we should work towards a common LMS that would allow students and faculty to migrate more seamlessly across institutions. Step three: instructional design and faculty development are two sides of same coin. Eighty-two percent of GSC is online. Extend this to expand residential access. UNH was losing summer students. We could keep these students engaged while they are off campus--especially because many UNH students are from out of state. We need to cultivate the utility of online learning. We should then map out the full spectrum of how online can complement student needs. We need to make sure we're not just delivering content, but that we're cultivating a lifelong online learner. We need to build affinity while they are online, then this generation will spend the next 40 years working in many different roles. They will keep coming back for continuing education (especially online).

\section{Chapter Summary}

Prior research has suggested that no two statewide systems are alike, which makes them difficult to compare. Consequently, comparing online programs at different statewide institutions can be challenging, since it is difficult to find a common language to compare program characteristics across institutions. This challenge is exacerbated by variations in institutional geography, history, audience, staffing, infrastructure and budget. Although it is difficult to compare system institutions, the administrators at each institution in this study were able to describe the characteristics of their own online 
program in great detail. When these administrators were asked whether they would consider collaborating with other system institutions, the majority of study participants were willing to collaborate with other system institutions if there were guidelines in place to assure their institution's unique strengths could be leveraged and the outcome of the collaboration wouldn't endanger their finances or reputation. Zimpher's notion of “systemness" (2013) and King’s subsidiarity principle (2013) provide a framework to help administrators of online programs in statewide systems structure partnerships that leverage increased scale to reach more students and improve outcomes for existing students. Since increased scale is a primary characteristic of several successful online programs, such as Arizona State University or Southern New Hampshire University, it's important for postsecondary institutions to pursue strategic partnerships with other institutions, especially when those institutions are affiliated with each other through a statewide system. 


\section{REFERENCES}

Aldiabat, K. M., \& Navenec, L. (2018). Data saturation: The mysterious step in grounded theory method. The Qualitative Report, 23(1), 245-261.

Allen, I. E., \& Seaman, J. (2015). Grade level: Tracking online learning in the United States. Wellesley MA: Babson Survey Research Group. Retrieved from http://onlinelearningconsortium.org/read/survey-reports-2014/

Berg, G. A. (2002). Why distance learning? Higher education administrative practices. Westport, CT: Praeger.

Berge, Z. L. (2007). Barriers and the organization's capabilities for distance education. Distance Learning, 4(4), 1-15.

Bermann, G. A. (1994). Taking subsidiarity seriously: Federalism in the European community and the United States. Columbia Law Review, 94(2), 331-456.

Boston, W. E., Ice, P., \& Gibson, A. M. (2011). Comprehensive assessment of student retention in online learning environments. Online Journal of Distance Learning Administration, 14(1). Retrieved from https://www.westga.edu/ distance/ojdla/spring141/boston_ice_gibson141.html

Brady, L. (2001). Fault lines in the terrain of distance education. Computers and Composition, 18(4), 347-358.

Brown, S. (2014). You can't always get what you want: change management in higher education. Campus-Wide Information Systems, 31(4), 208-216.

Cahalan, M., \& Perna, L. (2015). Indicators of higher education equity in the United States: 45 year trend report. Pell Institute for the Study of Opportunity in Higher Education. 
Carlson, S., \& Carnevale, S. (2001, December 14). Debating the demise of NYU online. The Chronicle of Higher Education, A31.

Chaney, D., Chaney, E., \& Eddy, J. (2010). The context of distance learning programs in higher education: Five enabling assumptions. Online Journal of Distance Learning Administration, 13(4). Retrieved from https://www.westga.edu/ distance/ojdla/winter134/chaney134.html

Colorado State University Global Campus. (n.d.). In Wikipedia. Retrieved from https://en.wikipedia.org/wiki/CSU\%E2\%80\%93Global_Campus

Cook, D. A., \& Steinert, Y. (2013). Online learning for faculty development: A review of the literature. Medical Teacher, 35(11), 930-937.

Creswell, J. W. (2013). Qualitative inquiry and research design: Choosing among five traditions. (3rd ed.). Thousand Oaks, CA: Sage.

Creswell, J. W., Roskens, R. W., \& Henry, T. C. (1985). A typology of multicampus systems. The Journal of Higher Education, 56(1), 26-37.

Deepwell, F. (2007). Embedding quality in e-learning implementation through evaluation. Educational Technology \& Society, 10(2), 34-43.

Discenza, R., Howard, C., \& Schenk, K. (2002). The design and management of effective distance learning programs. Hershey PA: Idea Group.

Ernst \& Young (2012). University of the future. A thousand year old industry on the cusp of profound change. Ernst \& Young. Retrieved from http://www.ey.com/Publication/vwLUAssets/University_of_the_future/ \$FILE/University_of_the_future_2012.pdf

Essary, M. L. (2014). Key external factors influencing successful distance education programs. Academy of Educational Leadership Journal, 18(3), 121-136.

Finlay, L. (2002). Negotiating the swamp: The opportunity and challenge of reflexivity in research practice. Qualitative Research, 2(2), 209-230. 
Fraenkel, J. R., Wallen, N. E., \& Hyun, H. H. (1993). How to design and evaluate research in education (Vol. 7). New York, NY: McGraw-Hill.

Garrison, D. R., \& Kanuka, H. (2008). Changing distance education and changing organizational issues. In W. J. Bramble \& S. K. Panda (Eds.), Economics of distance and online learning: Theory, practice and research, (pp.13-25). New York, NY: Routledge.

Gaskell, C., \& Hayton, E. (2015). Distance administration: Multiple perspectives on multi-site institutions. Perspectives: Policy and Practice in Higher Education, 19(2), 43-48.

Geertz, C. (1973). Thick description. The interpretation of cultures, 3-30.

Geiger, R. (2015). Impact of the financial crisis on higher education in the United States. International Higher Education, 59. Retrieved from https://ejournals.bc.edu/ojs/index.php/ihe/article/view/8486/7620

Gerth, D. R. (2010). The people's university: A history of the California State University. Berkeley, CA: Berkeley Public Policy Press.

Ginder, S. A., Kelly-Reid, J. E., \& Mann, F. B. (2016). Postsecondary Institutions and Cost of Attendance in 2015-16; Degrees and Other Awards Conferred, 2014-15; and 12-Month Enrollment, 2014-15. First Look (Preliminary Data). NCES 2016112. National Center for Education Statistics. Retrieved from http://nces.ed.gov/pubsearch

Glaser, B. G. (1978). Advances in the methodology of grounded theory: Theoretical sensitivity. Mill Valley, CA: Sociology Press.

Glaser, B. G. (1998). Doing grounded theory: Issues and discussions. Mill Valley, CA: Sociology Press.

Glaser, B. (2017). Discovery of grounded theory: Strategies for qualitative research. New York, NY: Routledge. 
Glaser, B. G., \& Strauss, A. L. (1967). The discovery of Grounded Theory: Strategies for qualitative research. New York, NY: Aldine De Gruyter.

Gómez-Rey, P., Barbera, E., \& Fernández-Navarro, F. (2016). Measuring teachers and learners' perceptions of the quality of their online learning experience. Distance Education, 37(2), 146-163.

Grbich, C. (2007). Qualitative data analysis: An introduction. Thousand Oaks, CA: Sage.

Guba, E. G. (1981). Criteria for assessing the trustworthiness of naturalistic inquiries. Ectj, 29(2), 75.

Halcomb, E. J., \& Davidson, P. M. (2006). Is verbatim transcription of interview data always necessary?. Applied nursing research, 19(1), 38-42.

Hanna, D. (2013). Emerging organizational models in higher education. In M. G. Moore \& W. G. Anderson (Eds.), Handbook of distance education (pp. 684-695). Mahwah, NJ: Lawrence Erlbaum Associates.

Inglis, A. (2013). The changing costs of delivery of distance education programs. In M. G. Moore \& W. G. Anderson (Eds.), Handbook of distance education (pp. 507520). Mahwah, NJ: Lawrence Erlbaum Associates.

Johnstone, D. B. (2005). Role, scope, mission, and purposes of multi-campus system. Retrieved from http://gseweb.gse.buffalo.edu/fas/Johnston/systems.htm

Johnstone, D. B. (2013). Higher education autonomy and the appointment of authority among state governments, public multicampus systems, and the member colleges and universities. In J. E. Lane \& D. B. Johnstone (Eds.), Higher education systems 3.0: Harnessing systemness, delivering performance (pp. 75-99). Albany, NY: State University of New York Press.

Kenward, J. (2008). "Is there a best way to structure the administration?" Perspectives: Policy and Practice in Higher Education, 12(4), 103-109. doi:10.1080/13603100802376584 
King, J. C. (2013). On the apportionment of administrative governance functions within multi-campus universities and university systems. Retrieved from https://cshe.berkeley.edu/publications/apportionment-administrative-Governancefunctions-within-multi-campus-universities-and

King, J. W., Nugent, G. C., Eich, J. J., Mlinek, D. L., \& Russell, E. B. (2000). A policy framework for distance education: A case study and model. DESONEWS, 10(10). Retrieved on January, 2018 from http://www.ed.psu.edu/acsde/deos/deosnews/deosnews10_10.asp.

Kingdon, J. W. (2011). Agendas, alternatives, and public policies. Boston, MA: Longman.

Krenelka, L. M. (2009). A review of the short life of the US open university. New Directions for Higher Education, 2009(146), 65-72.

Lane, J. E., \& Johnstone, D. B. (2013). Higher education systems 3.0: Harnessing systemness, delivering performance. Albany, NY: State University of New York Press.

Laws, R. D., Howell, S. L., \& Lindsay, N. K. (2008). Ten scalability factors in distance education. In L. Tomei \& IGI Global (Eds.), Online and distance learning: Concepts, methodologies, tools, and applications (pp. 300-308). Hershey, PA: IGI Global.

Legon, R., \& Garrett, R. (2017). The changing landscape of online education (CHLOE): Quality Matters and Eduventures survey of chief online officers, 2017. Retrieved from https://www.qualitymatters.org/node/1040

Legon, R., \& Garrett, R. (2018). The changing landscape of online education 2 (CHLOE2): A deeper dive 2018. Retrieved from https://www.qualitymatters.org/qa-resources/resource-center/articlesresources/CHLOE-2-report-2018

Lee, E. C., \& Bowen, F. M. (1971). The multicampus university. New York, NY: McGraw-Hill. 
Leedy, P. D., \& Ormrod, J. E. (2014). Qualitative research. Practical research: Planning and design, 141-172.

Levy, S., \& Beaulieu, R. (2003). Online distance learning among the California community colleges: Looking at the planning and implementation. The American Journal of Distance Education, 17(4), 207-220.

Lincoln, Y. S., \& Guba, E. G. (1985). Naturalistic inquiry. Beverly Hills, CA: Sage.

Lorenzo, G., \& Moore, J. (2002). Five pillars of quality online education. The Sloan consortium report to the nation, 15-09.

Lowenthal, P. R., \& White, J. W. (2014). Enterprise model. In P. Rogers, G. Berg, J. Boettcher, C. Howard, L. Justice, \& K. Schenk (Eds.), Encyclopedia of distance and online learning (pp. 932-936.). Hershey, PA: Information Science Reference.

Maguire, L. L. (2007). Developing distance education policy within a state system of higher education: the faculty perspective. Unpublished doctoral dissertation, The Pennsylvania State University, State College, Pennsylvania.

Marcus, J. (2017, June 29). Universities and college students struggle to stem big drops in enrollment. The Hechinger Report. Retrieved from http://hechingerreport.org/universities-colleges-struggle-stem-big-dropsenrollment/

McBain, L. (2009). College and University Mergers: Recent Trends. Policy Matters: A Higher Education Policy Brief. American Association of State Colleges and Universities. Retrieved 2/7/2018 from http://www.aascu.org/policy/publications/policymatters/2012/collegemergersupda te.pdf

Merriam, S. B., Johnson-Bailey, J., Lee, M. Y., Kee, Y., Ntseane, G., \& Muhamad, M. (2001). Power and positionality: Negotiating insider/outsider status within and across cultures. International Journal of Lifelong Education, 20(5), 405-416. 
Meyer, K. A., \& Wilson, J. L. (2010). The 'virtual face' of planning: How to use higher education web sites to assess competitive advantage. Planning for Higher Education, 38(2), 11-21.

Miller, G. E., \& Schiffman, S. (2006). ALN business models and the transformation of higher education. The Journal of Asynchronous Learning Networks, 10(2), 15-21. Mills, A. J., Durepos, G., \& Wiebe, E. (Eds.). (2010). Encyclopedia of case study research: L-Z; index (Vol. 1). Sage.

Mills, A., Durepos, G., \& Wiebe, G. (2010). Encyclopedia of case study research. Thousand Oaks, CA: Sage.

Moloney, J. F., \& Oakley, B. (2010). Scaling online education: Increasing access to higher education. Journal of Asynchronous Learning Network, 14,(1), 55-70. Moore, M. G., \& Kearsley, G. (2012). Distance education: A systems view of online learning. Belmont: Wadsworth, Cengage Learning.

Moore, M. G., \& Kearsley, G. (2012). Distance Education: A Systems View of Online Learning. Belmont: Wadsworth, Cengage Learning.

Morse, J. M., Barrett, M., Mayan, M., Olson, K., \& Spiers, J. (2002). Verification strategies for establishing reliability and validity in qualitative research. International Journal of Qualitative Methods, 1(2), 13-22.

National Association of System Heads (n.d.). About. Retrieved from http://nashonline.org/about/

National Student Clearinghouse Research Center (2014). Report: Current term enrollment Report - Spring 2014. Retrieved from: https://nscresearchcenter.org/currenttermenrollmentestimate-spring2014/

Poulin, R., \& Straut, T. (2015). Busting the myth: Distance education enrollments. WICHE Cooperative for Educational Technologies. Retrieved from https://wcet.wiche.edu/sites/default/files/WCETDistanceEducationEnrollmentRep ort2016.pdf 
Roby, T., Ashe, S., Singh, N., \& Clark, C. (2013). Shaping the online experience: How administrators can influence student and instructor perceptions through policy and practice. Internet and Higher Education, 17(1), 29-37.

Rossman, G. B., \& Rallis, S. F. (2003). Learning in the field: An introduction to qualitative research. Thousand Oaks, CA: Sage.

Rovai, A. P. (2003). A practical framework for evaluating online distance education programs. Internet and Higher Education, 6(2), 109-124.

Rovai, A. P. (2009). The internet and higher education: Achieving global reach. Oxford, UK: Chandos.

Rovai, A. P., \& Downey, J. R. (2010). Why some distance education programs fail while others succeed in a global environment. Internet and Higher Education, 13(3), 141-147.

Rumble, G. (1999). Cost analysis of distance learning. Performance Improvement Quarterly, 12(2), 122-137.

Rumble, G. (2001). Re-inventing distance education, 1971-2001. International Journal of Lifelong Education, 20(1-2), 31-43.

Rumble, G. (2012). The costs and economics of open and distance learning. New York, NY: Routledge.

Saldaña, J. (2015). The coding manual for qualitative researchers. Thousand Oaks, CA: Sage.

Shelton, K., \& Saltsman, G. (2005). An administrator's guide to online education. Greenwich, CT: IAP-Information Age.

Stake, R. E. (1994). Case studies. In N. K. Denzin \& Y. S. Lincoln (Eds.) Handbook of Qualitative Research (pp. 236-247). Thousand Oaks, CA: Sage.

Stake, R. E. (2006). Multiple case study analysis. New York, NY: Guilford Press. 
Stake, R. E. (2010). Qualitative research: Studying how things work. New York, NY: Guilford Press.

Strauss, A., \& Corbin, J. M. (1990). Basics of qualitative research: Grounded theory procedures and techniques. Thousand Oaks, CA: Sage.

Stufflebeam, D. L. (1971). The use of experimental design in educational evaluation. Journal of Educational Measurement, 8(4), 267-274.

SUNY (n.d.). What is open SUNY? Retrieved from http://sln.suny.edu/about/what-isopen-suny/

Tinto, V. (1987). Leaving college: Rethinking the causes and cures of student attrition. Chicago, IL: University of Chicago Press.

University of New Hampshire. (n.d.). In Wikipedia. Retrieved January 20, 2018, from https://en.wikipedia.org/wiki/University_of_New_Hampshire

Vines, D. (1998). Large-scale distance learning initiatives. Campus-Wide Information Systems, 15(4), 137-141.

Wladis, C., Conway, K., \& Hachey, A. C. (2017). Using course-level factors as predictors of online course outcomes: a multi-level analysis at a US urban community college. Studies in Higher Education, 42(1), 184-200.

Yin, R. K. (1981). The case study as a serious research strategy. Beverly Hills, CA: Sage.

Yin, R. K. (2003). Case study research: Design and methods. Thousand Oaks, CA: Sage.

Yin, R. K. (2009). Case study research: Design and methods (4th ed.). Thousand Oaks, CA: Sage.

Zimpher, N. L. (2013). Systemness: Unpacking the value of higher education systems. In J.E. Lane \& D. B. Johnstone (Eds.), Higher education systems 3.0: Harnessing systemness, delivering performance (pp. 27-44). Albany, NY: State University of New York Press. 
APPENDIX A 
Greetings,

Good morning. I emailed an online survey to each of you several times over the last few weeks via Qualtrics. Unfortunately, for many of you, the Qualtrics-generated email was flagged as spam and never made it to your inbox. To avoid that problem, I'm sending this latest survey request using my Outlook account, which shouldn't trigger the spam filter. The link for the survey can be found below.

Why are you receiving this request? I am in the process of completing a doctoral dissertation at Boise State University in Educational Technology. My dissertation paper focuses on how online programs are administered in statewide systems-like USNH. In short, I'm asking approximately 20 administrators at USNH institutions to complete this short online survey and then participate in a short in-person interview. Most of the survey questions are modified questions taken from Rovai and Downey's (2010) earlier work on the administration of online learning and were reviewed by my research committee and the IRB at Boise State and UNH. The survey should take about 10-15 minutes to complete.

What is this survey about? The purpose of this research is to contribute to the existing body of research that focuses on how statewide systems administer programs - in this case, online programs. The results of this survey will be sorted and analyzed to help identify trends in this area. It would be wonderful if you could complete the survey by 
April 20. Please call or email if you'd like more information about this project. I deeply appreciate your help with this request.

\section{Survey Link}

https://unh.az1.qualtrics.com/jfe/form/SV_6RUkIecSqCnlsYB

The verbiage below is also included in the online survey:

You are being asked to complete this survey because of your involvement with online programs at your institution. Please contact Dr. Patrick Lowenthal (208-426-2426 patricklowenthal@boisestate.edu) if you have questions or concerns about the study. If you have questions about your rights as a research participant, contact the Boise State University Institutional Review Board (IRB), which is concerned with the protection of volunteers in research projects, between $8 A M-5 P M$, Monday through Friday, by calling 208-426-5401 or writing: Institutional Review Board, Office of Research Compliance, Boise State University, 1910 University Dr., Boise, ID 83725-1138.

Thanks, Chris 


\section{Chris LaBelle}

Director, UNH Professional Development \& Training

o: $603-862-1252$

f: $603-862-1585$

e: christopher.labelle@unh.edu

w: http://[training.unh.edu]training.unh.edu |Like us on Facebook!

Durham / 59 College Road, Durham, NH 03824

Manchester / 88 Commercial Street, Manchester, NH 03101

Portsmouth / 119 International Drive, Portsmouth, NH 03801 
APPENDIX B 


\section{(1.) University of New Hampshire}

INSTITUTIONAL REVIEW BOARD FOR THE PROTECTION OF HUMAN SUBJECTS IN RESEARCH

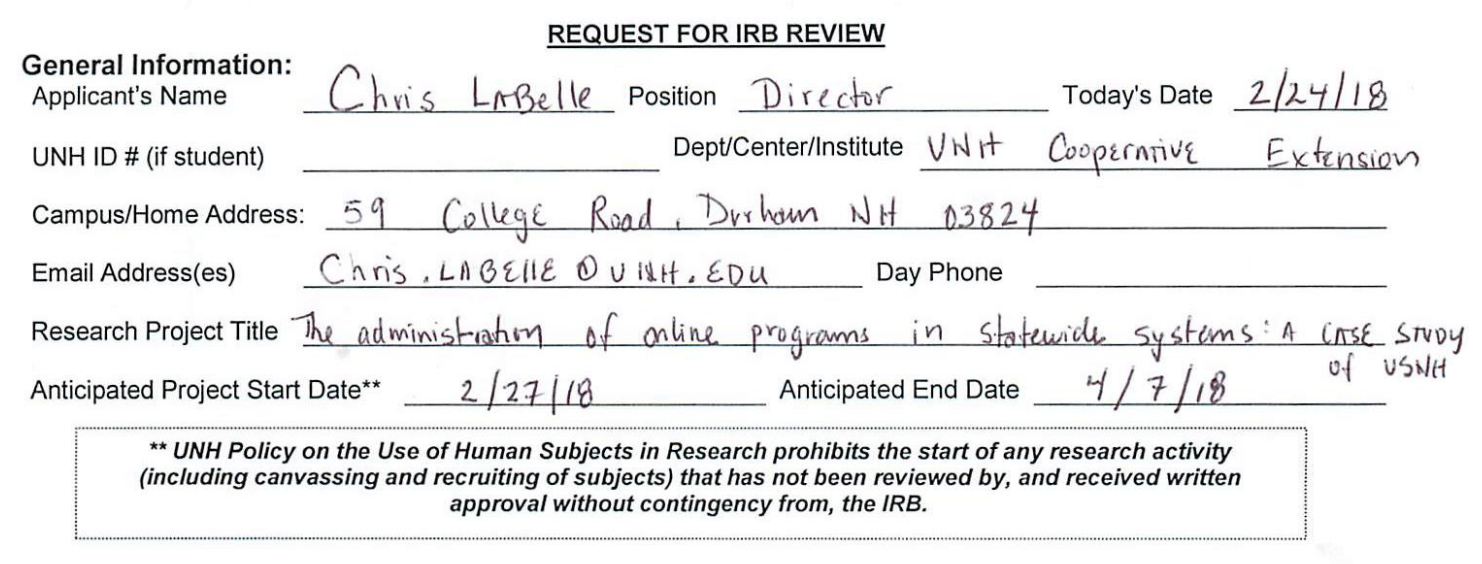

Project Status Information (please check one):
New Project
X
Modification to Existing Project
If Yes, provide IRB \#

Project Funding Information (for sponsored projects only include internal \& external funding): Has a proposal for funding been submitted to a sponsor? If a proposal has been submitted, has

Sponsor $\quad N / A+\begin{aligned} & \text { Pl on proposal } \\ & \text { if not IRB applicant }\end{aligned}$

Is notification of IRB approval required by the sponsor? Yes _ No If yes, notification deadline

For externally-funded projects only: By initialing this statement, the applicant certifies that (s)he: Has read the applicable UNH policy on financial conflict of interest in research (http://www.usnh.edu/olpm/UNHNIII. Res/E.htm or http://www. usnh.edu/olpm/UNH/VIII. Res/T.htm) and has made all required financial disclosures; has made every effort to ensure that all individuals responsible for the design, conduct, or reporting of the research have submitted the required disclosures; has completed any required training; and prior to the expenditure of award funds will have reached an agreement with UNH that provides for conditions or restrictions necessary to manage, reduce, or eliminate any financial conflicts of interest under UNH policy.

Review by Non-UNH IRB(s) (if applicable):

If this project has been submitted to a review board at another institution, provide the review date and that board's documentation. Please attach relevant correspondence.

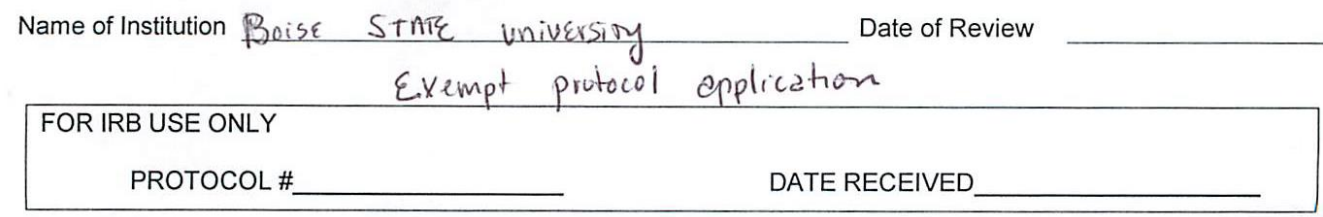


APPENDIX C 


\section{$\boldsymbol{E}$}

BOISE STATE UNIVERSITY

RESEARCH AND ECONOMIC DEVELOPMENT

Date: March 20, 2018

To: Chris LaBelle

cc: Patrick R. Lowenthal

From: Office of Research Compliance (ORC)

Subject: SB-IRB Notification of Exemption - 104-SB18-053

THE ADMINISTRATION OF ONLINE PROGRAMS IN STATEWIDE SYSTEMS: A CASE STUDY OF THE UNIVERSITY SYSTEM OF NEW HAMPSHIRE

The Boise State University ORC has reviewed your protocol application and has determined that your research is exempt from further IRB review and supervision under 45 CFR 46.101(b).

Protocol Number: 104-SB18-053

Approved: $3 / 20 / 2018$

Application Received: 2/24/2018

Review: Exempt

Category: 2

This exemption covers any research and data collected under your protocol as of the date of approval indicated above, unless terminated in writing by you, the Principal Investigator, or the Boise State University IRB. All amendments or changes (including personnel changes) to your approved protocol must be brought to the attention of the Office of Research Compliance for review and approval before they occur, as these modifications may change your exempt status. Complete and submit a Modification Form indicating any changes to your project.

Annual renewals are not required for exempt protocols. When the research project is completed, please notify our office by submitting a Final Report. The exempt status expires when the research project is completed (closed) or when the review category changes as described above.

All forms are available on the ORC website at http://goo.gl/D2FYTV

Please direct any questions or concerns to ORC at 426-5401 or humansubjects@boisestate.edu.

Thank you and good luck with your research.

Office of Research Compliance

1910 University Drive Boise, Idaho $83725 \cdot 1139$

Phone (208) 426.5401 orc@boisestate.edu

This lenter is an dectronic communication from Boise State Unherrity 